Supporting Information for:

\title{
Bottlebrush Polymer Excipients Enhance Drug Solubility: Influence of End-Group Hydrophilicity and Hydrophobicity
}

\author{
Monica L. Ohnsorg ${ }^{1}$, Paige C. Prendergast ${ }^{1}$, Lindsay L. Robinson ${ }^{1}$, Matthew R. Bockman ${ }^{1}$, \\ Frank S. Bates ${ }^{2 *}$, and Theresa M. Reineke ${ }^{1 *}$ \\ ${ }^{1}$ Department of Chemistry and ${ }^{2}$ Department of Chemical Engineering and Material Science, University of \\ Minnesota, Minneapolis MN 55455
}

Corresponding Emails: bates001@umn.edu, treineke@umn.edu 


\section{Supporting Information Table of Contents:}

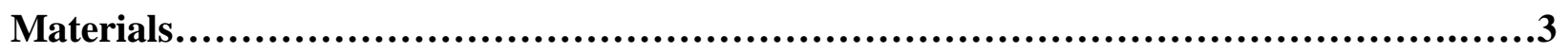

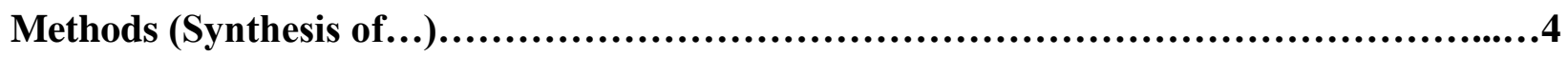

Exo-Imide Norbornene Alcohol................................................ 4

2-(propylthiocarbonothioylthio)-2 methyl propionic acid..............................6

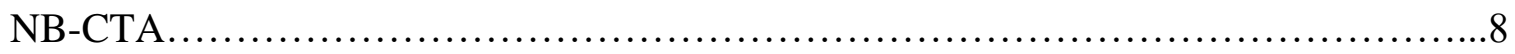

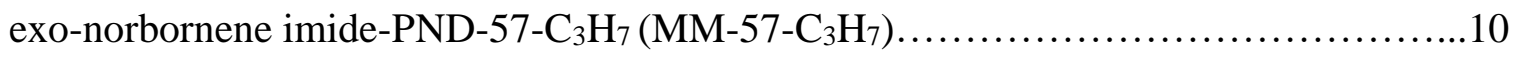

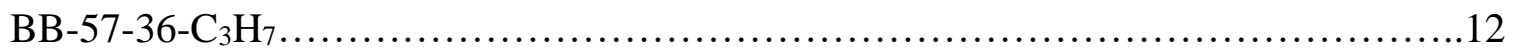

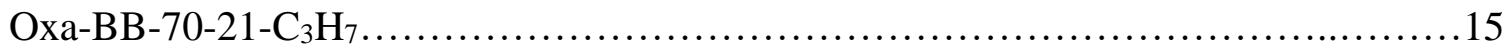

Poly(ethylene glycol) hydroxy ether acrylate ...................................18

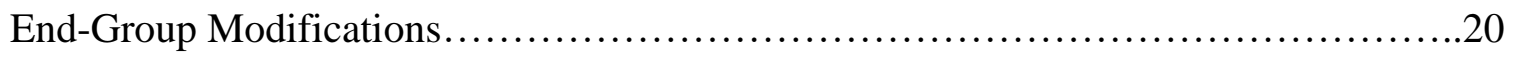

Photoinitiated Trithiocarbonate Cleavage ................................20

Thio-Michael Addition End-Group Modification...............................22

Linear Statistical poly(NIPAm-co-DMA) Control Polymers...........................30

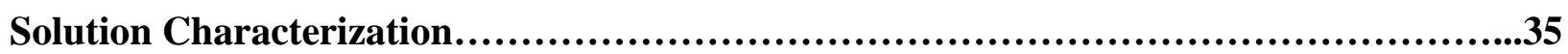

Cloud Point Measurements........................................................... 35

Dynamic Light Scattering ....................................................... 38

Extra Discussion - End-Groups Dictate Solution Properties........................41

Multiangle Dynamic Light Scattering .............................................44

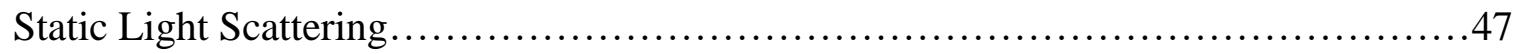

Extra Discussion - Shape Factor and Density Calculations.........................48

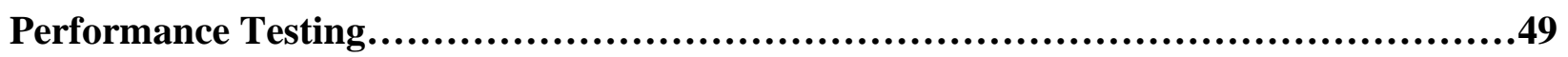

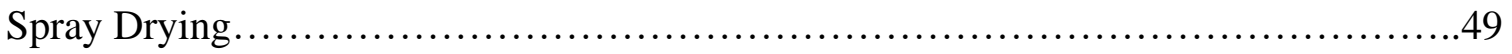

Wide-Angle X-Ray Scattering................................................... 49

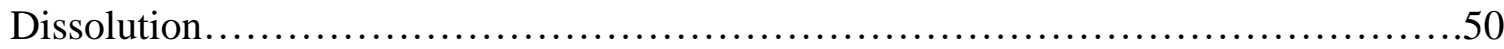

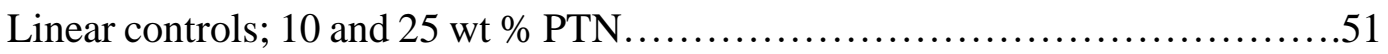

MM-57-X; 10 wt \% PTN........................................................53

BB-57-36-X; 10 wt \% PTN ..................................................54

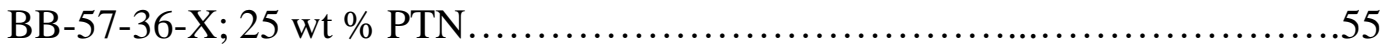

Extra Discussion - Macromonomer and Room Temperature Dissolution Performance..56 Dynamic Light Scattering During Dissolution......................................61

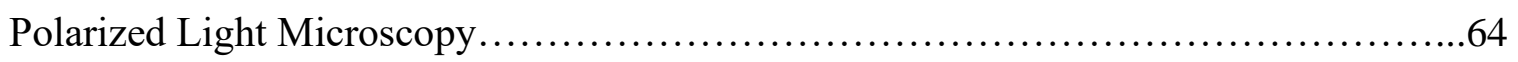




\section{Materials.}

The following reagents were used as received from Aldrich, unless otherwise noted: ethanolamine (98\%), toluene, acetone, potassium phosphate tribasic (98\%), propane thiol (97\%), carbon disulfide $\left(\mathrm{CS}_{2}, 99 \%\right)$, 2-bromo-2-methylpropionic acid (98\%), hexanes, ethyl acetate, dichloromethane, $N$-isopropylacrylamide (NIPAm, $97 \%$ ), $N, N$-dimethylacrylamide (DMA, contains 500 ppm MEHQ as inhibitor, $99 \%$ ) 2,2'-azobis(2-methylpropionitrile) (AIBN, $98 \%$ ), 1 , 4-dioxane, methanol, Dichloro[1,3-bis(2,4,6-trimethylphenyl)-2imidazolidinylidene](benzylidene)bis(3-bromopyridine)ruthenium(II) (Grubbs Catalyst M300, G3), 2-(Dodecylthiocarbonothioylthio)-2-methylpropionic acid (98 \%), 4-Cyano-4[(dodecylsulfanylthiocarbonyl)sulfanyl]pentanoic acid (97 \%), 2-Cyano-2-propyl dodecyl trithiocarbonate (97\%), poly(ethylene oxide) (PEG, average $\left.\mathrm{M}_{\mathrm{n}}=400 \mathrm{Da}\right)$, triethylamine $(\geq 99$ $\%$ ), tetrahydrofuran (THF, anhydrous, contains $250 \mathrm{ppm}$ BHT as inhibitor, $\geq 99.9 \%$ ), acryloyl chloride (contains <210 ppm MEHQ as stabilizer, $97 \%$ ), 1-ethylpiperidine hypophosphite (EPHP, $95 \%$ ), Tris(2-carboxyethyl)phosphine hydrochloride (TCEP, powder), n-propylamine ( $\geq 99 \%$ ), 2-hydroxyethyl acrylate (HEA, contains 200-650 ppm MEHQ as inhibitor, $96 \%$ ), poly(ethylene glycol) methyl ether acrylate (methyl-PEGA, average $M_{n}=480$, contains 100 ppm BHT as inhibitor), tert-butyl acrylate (contains 10-20 ppm MEHQ as inhibitor, $98 \%$ ), trifluoroacetic acid (TFA, $99 \%)$, and phenytoin (99\%).

$N, N$-dimethylacrylamide was passed through a small basic alumina column to remove inhibitor prior to use.

Cis-5-norbornene-exo-2,3-dicarboxylic anhydride (> $98 \%$ ) was purchased from AOKChem.

SiliaMetS-DMT was purchased from SiliCycle.

Diisopropylcarbodiimide (DIC, $97 \%$ ) was purchased from Matrix Scientific. 
Methods.

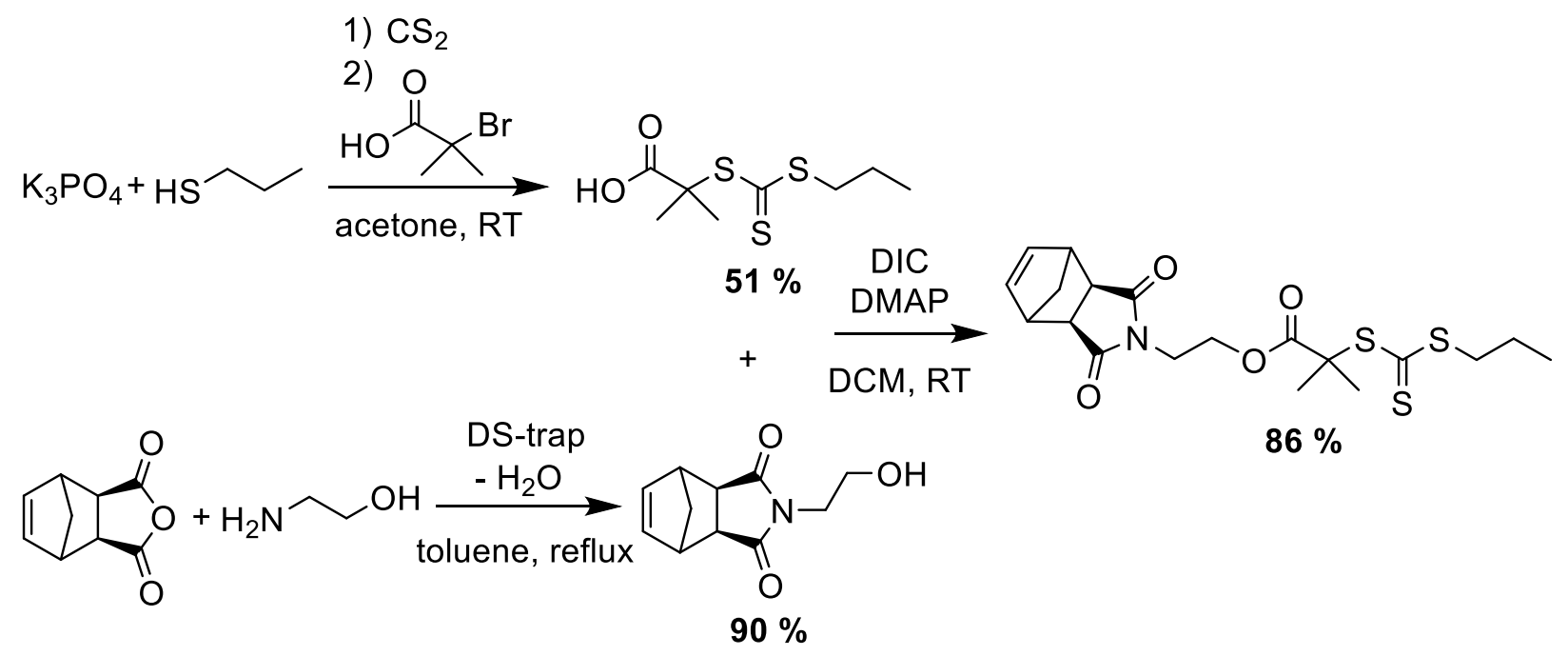

Scheme S1. Synthesis of (2-(1,3-dioxo-1,3,3a,4,7,7a-hexahydro-2H-4,7-methanoisoindol-2yl)ethyl2-methyl-2-(((propylthio)carbonothioyl)thio)propanoate.

Exo-Imide norbornene alcohol (yield: $90 \%$ )

Exo-carbic anhydride $(9.85 \mathrm{~g}, 60.0 \mathrm{mmol})$ was charged to a $500 \mathrm{~mL}$ round bottom flask with 300 $\mathrm{mL}$ of toluene. While stirring vigorously, ethanolamine $(3.80 \mathrm{~mL}, 63.0 \mathrm{mmol})$ was added dropwise to the reaction mixture. After 25 hours at reflux conditions with a Dean-Stark trap, the reaction mixture was removed from heat. The toluene was removed under rotary evaporation and an offwhite crystalline solid was collected as pure product (11.15 g, $90 \%$ yield). ${ }^{1} \mathrm{H}$ NMR (500 MHz, $\left.\mathrm{CDCl}_{3}\right) \delta 6.30(\mathrm{~s}, 1 \mathrm{H}), 3.79(\mathrm{t}, J=4.6 \mathrm{~Hz}, 2 \mathrm{H}), 3.71(\mathrm{t}, J=5.0 \mathrm{~Hz}, 2 \mathrm{H}), 3.29(\mathrm{~s}, 2 \mathrm{H}), 2.72(\mathrm{~s}, 2 \mathrm{H})$, $2.09(\mathrm{~s}, 1 \mathrm{H}), 1.53(\mathrm{~d}, J=9.8 \mathrm{~Hz}, 1 \mathrm{H}), 1.35(\mathrm{~d}, J=10.2 \mathrm{~Hz}, 1 \mathrm{H}) .{ }^{13} \mathrm{C} \mathrm{NMR}\left(500 \mathrm{MHz}, \mathrm{CDCl}_{3}\right) \delta$ $178.8,137.9,60.7,47.9,45.3,42.8,41.4$ 


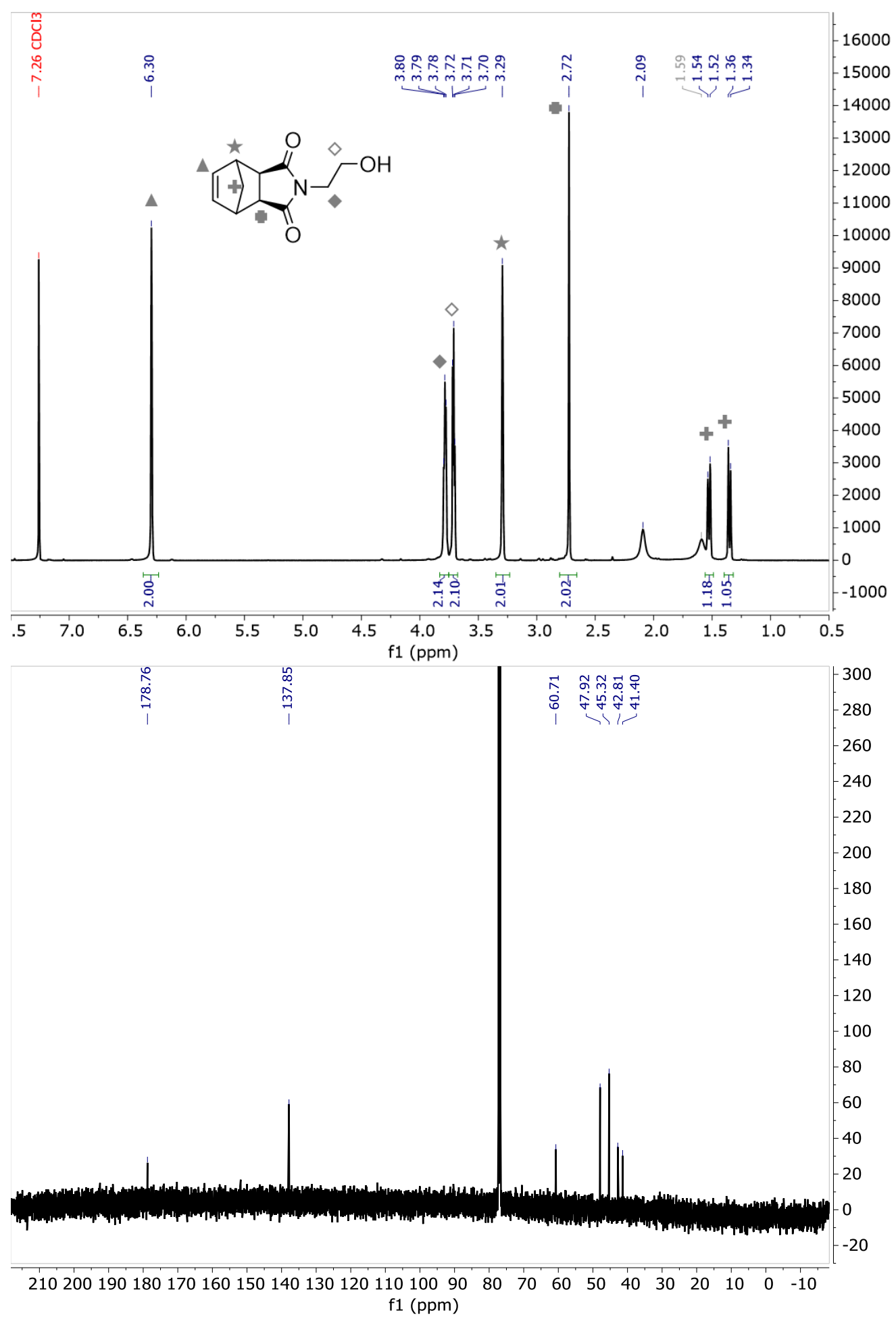

Figure S1. ${ }^{1} \mathrm{H}$ and ${ }^{13} \mathrm{C}$ NMR in $\mathrm{CDCl}_{3}$ of exo-norbornene imide alcohol 


\section{2-(propylthiocarbonothioylthio)-2 methyl propionic acid (yield: $51 \%$ )}

Potassium phosphate tribasic $(13.99 \mathrm{~g}, 65.9 \mathrm{mmol})$ was dissolved in a $500 \mathrm{~mL}$ round bottom flask

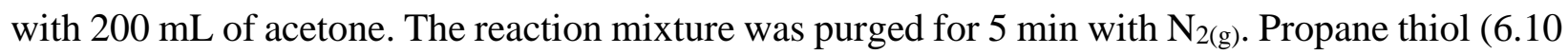
$\mathrm{mL}, 65.9 \mathrm{mmol}$ ) was added dropwise to the reaction mixture while stirring. After 10 minutes, carbon disulfide $(10.7 \mathrm{~mL}, 177.9 \mathrm{mmol})$ was added dropwise to the reaction mixture and stirred for 20 minutes. To add the 2-bromo-2-methylpropionic acid $(12.10 \mathrm{~g}, 72.5 \mathrm{mmol})$ the reaction flask was opened to atmosphere. The reaction flask was then re-sealed and stirred for 24 hours at room temperature. After 24 hours, the reaction was orange in color with solid precipitate. The salt precipitate was removed via vacuum filtration and rinsed with acetone. The filtrate was concentrated using rotary evaporation to a dark orange oil. The oil was diluted with $100 \mathrm{~mL}$ of DCM and rinsed with $300 \mathrm{~mL}$ of $1 \mathrm{~N} \mathrm{HCl}$. The aqueous layer was extracted 3 times with $100 \mathrm{~mL}$ of DCM which was washed with $100 \mathrm{~mL}$ of ultra-pure water two times. The organic layer was dried over magnesium sulfate and concentrated under rotary evaporation. Product was isolated on a silica gel column, eluting with 4:1 hexanes-ethyl acetate, to give $7.94 \mathrm{~g}$ of pure product as a yellow solid (51\% yield). ${ }^{1} \mathrm{H}$ NMR (500 MHz, $\left.\mathrm{CDCl}_{3}\right) \delta 3.28(\mathrm{t}, J=7.3 \mathrm{~Hz}, 2 \mathrm{H}), 1.73(\mathrm{~s}, 8 \mathrm{H})$, $1.01(\mathrm{t}, J=7.4 \mathrm{~Hz}, 3 \mathrm{H}) .{ }^{13} \mathrm{C} \mathrm{NMR}\left(500 \mathrm{MHz}, \mathrm{CDCl}_{3}\right) \delta 178.2,60.5,55.6,38.9,25.2,24.2,21.4$, 13.5 . 

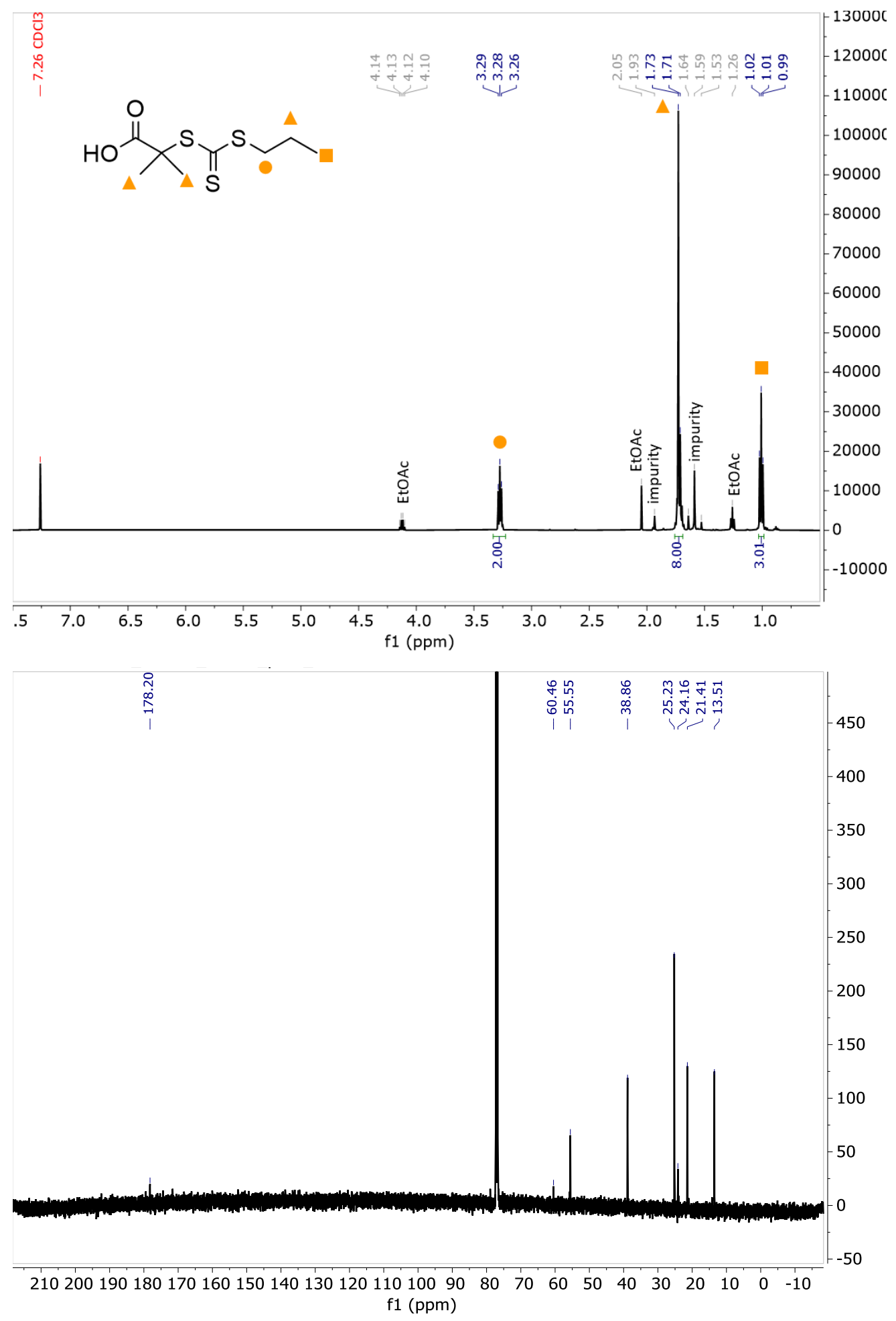

Figure S2. ${ }^{1} \mathrm{H}$ and ${ }^{13} \mathrm{C} \mathrm{NMR}$ in $\mathrm{CDCl}_{3}$ of 2-(propylthiocarbonothioylthio)-2 methyl propionic acid 
(2-(1,3-dioxo-1,3,3a,4,7,7a-hexahydro-2H-4,7-methanoisoindol-2-yl)ethyl2-methyl-2-

(((propylthio)carbonothioyl)thio)propanoate (NB-CTA) (yield:86\%)

2-(propylthiocarbonothioylthio)-2 methyl propionic acid $(7.49 \mathrm{~g}, \quad 33.33 \mathrm{mmol}), \quad 4-$ dimethylaminopyridine $(0.339 \mathrm{~g}, 2.77 \mathrm{mmol})$ and exo-imide norbornene alcohol $(5.80 \mathrm{~g}, 27.75$ mmol) was charged to a 1 liter round bottom with $300 \mathrm{~mL}$ of dichloromethane. The reaction mixture was purged with $\mathrm{N}_{2}$ (g) for 30 minutes prior to adding diisopropylcarbodiimide $(5.60 \mathrm{~mL}$, $36.08 \mathrm{mmol}$ ) dropwise to the reaction mixture. The reaction was stirred at room temperature under a static $\mathrm{N}_{2}$ atmosphere overnight. The reaction mixture was filtered to remove the urea precipitate. The crude product was purified on a neutral alumina column eluting with 5:1 hexanes:ethyl acetate to isolate the coupled product ( $10.4 \mathrm{~g}, 86 \%$ yield) which was dried under vacuum to yield a yellow solid. ${ }^{1} \mathrm{H}$ NMR (500 MHz, $\left.\mathrm{CDCl}_{3}\right) \delta 6.28(\mathrm{~s}, 2 \mathrm{H}), 4.26(\mathrm{t}, J=5.3 \mathrm{~Hz}, 2 \mathrm{H}), 3.77(\mathrm{t}, J=5.2 \mathrm{~Hz}, 2 \mathrm{H})$, 3.27 (s, 3H), 3.23 (t, $J=7.4 \mathrm{~Hz}, 2 \mathrm{H}), 2.69$ (s, 2H), $1.73-1.63(\mathrm{~m}, 8 \mathrm{H}), 1.52(\mathrm{~d}, J=10.0 \mathrm{~Hz}, 1 \mathrm{H})$, $1.30(\mathrm{~d}, J=9.8 \mathrm{~Hz}, 1 \mathrm{H}), 0.99(\mathrm{t}, J=7.4 \mathrm{~Hz}, 3 \mathrm{H}) .{ }^{13} \mathrm{C} \mathrm{NMR}\left(500 \mathrm{MHz}, \mathrm{CDCl}_{3}\right) \delta 177.7,137.8$, $62.3,61.1,55.6,47.9,45.3,42.9,41.1,38.8,37.4,25.1,24.6,21.4,13.5$. 

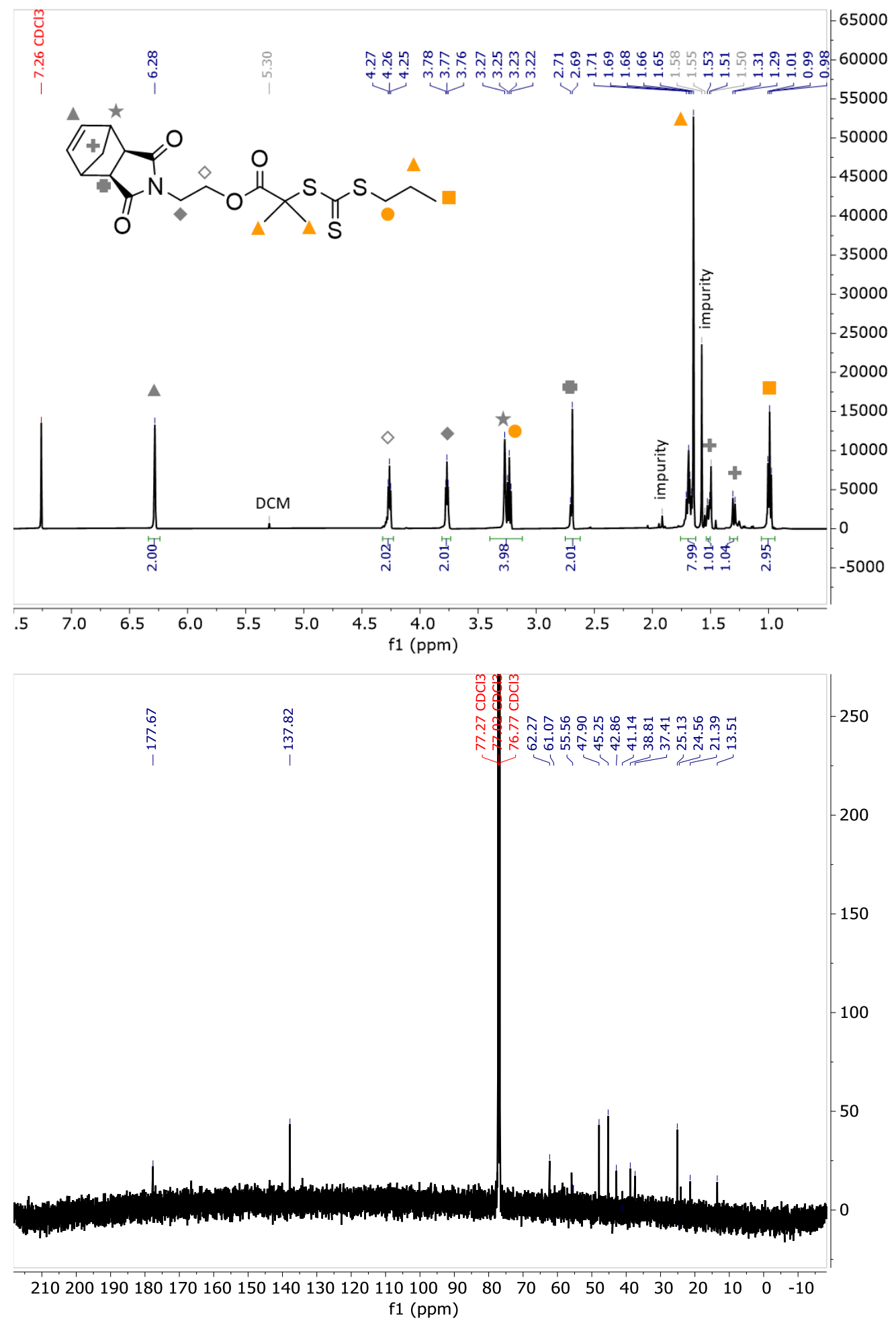

Figure S3. ${ }^{1} \mathrm{H}$ and ${ }^{13} \mathrm{C}$ NMR in $\mathrm{CDCl}_{3}$ of NB-CTA 

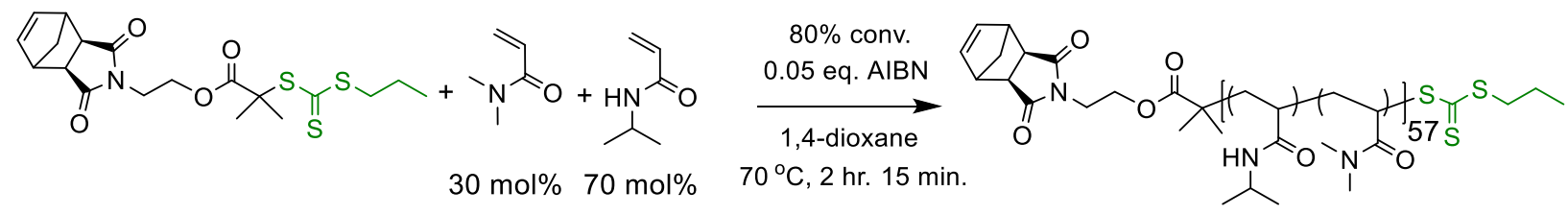

Scheme S2. Synthesis of macromonomers via RAFT polymerization

Synthesis of exo-norbornene imide-PND-57- $\mathrm{C}_{3} \mathrm{H}_{7}\left(M M-57-\mathrm{C}_{3} \mathrm{H}_{7}\right)$

A representative polymerization procedure is as follows: NB-CTA $(1.60 \mathrm{~g}, 3.74 \mathrm{mmol}), \mathrm{N}$ isopropylacrylamide (15.84 g, $140.0 \mathrm{mmol}), N, N$-dimethylacrylamide $(6.31 \mathrm{~mL}, 60.0 \mathrm{mmol})$, and AIBN (30.7 mg, $0.187 \mathrm{mmol}$ ) were dissolved in $200 \mathrm{~mL}$ of 1, 4-dioxane. The reaction mixture was purged with $\mathrm{N}_{2}$ gas for 90 minutes before stirring for 2 hours and 15 minutes at $70{ }^{\circ} \mathrm{C}$ (approx. $80 \%$ conv., Figure S4). The reaction was quenched in liquid nitrogen and opened to air. Polymer was purified by dialysis ( $1 \mathrm{kDa}$ RC dialysis tubing) in methanol and characterized via ${ }^{1} \mathrm{H}$ NMR in $\mathrm{CDCl}_{3}$ and SEC-MALS (DMF with $0.05 \mathrm{M} \mathrm{LiBr}$ ).
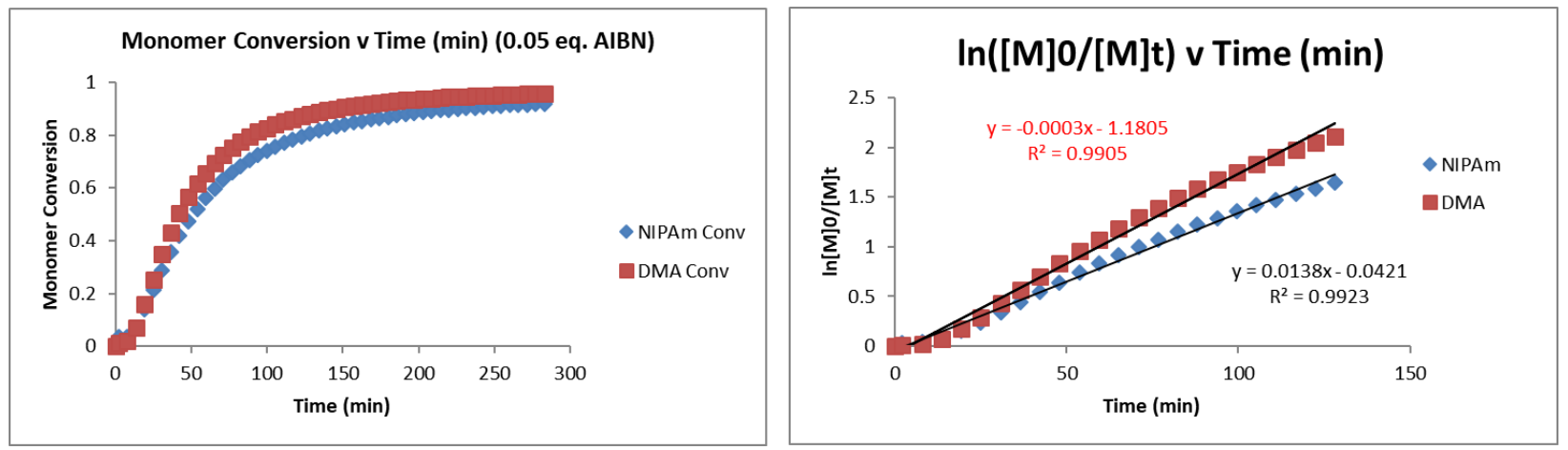

Figure S4. Copolymerization kinetics for the macromonomer monitored by ${ }^{1} \mathrm{H}$ NMR run in 1,4dioxane-d8 with 0.05 eq of AIBN using the NB-CTA as an internal standard to calculate NIPAm and DMA conversion. 


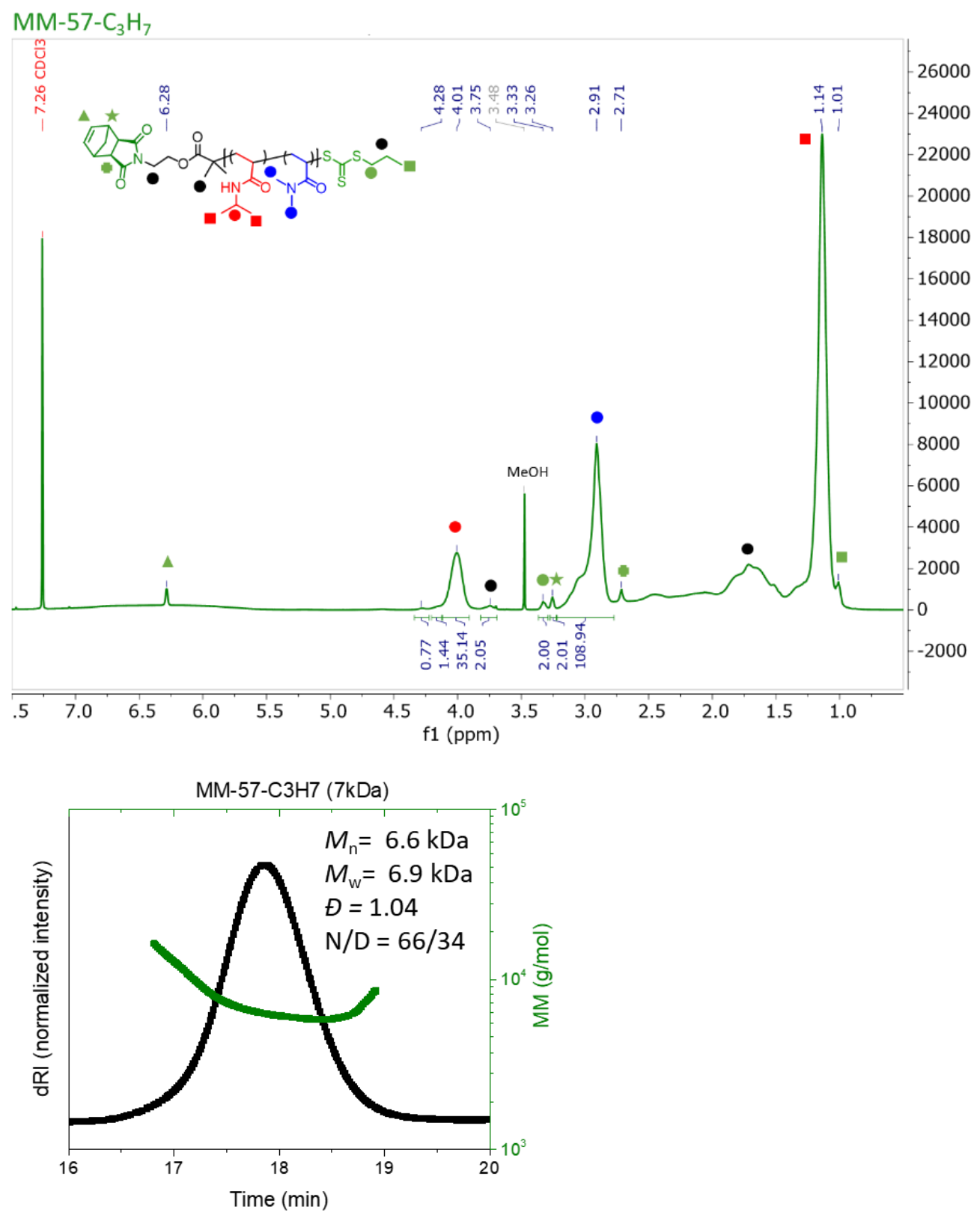

Figure S5. ${ }^{1} \mathrm{H}$ NMR and SEC of MM-57- $\mathrm{C}_{3} \mathrm{H}_{7}$ 


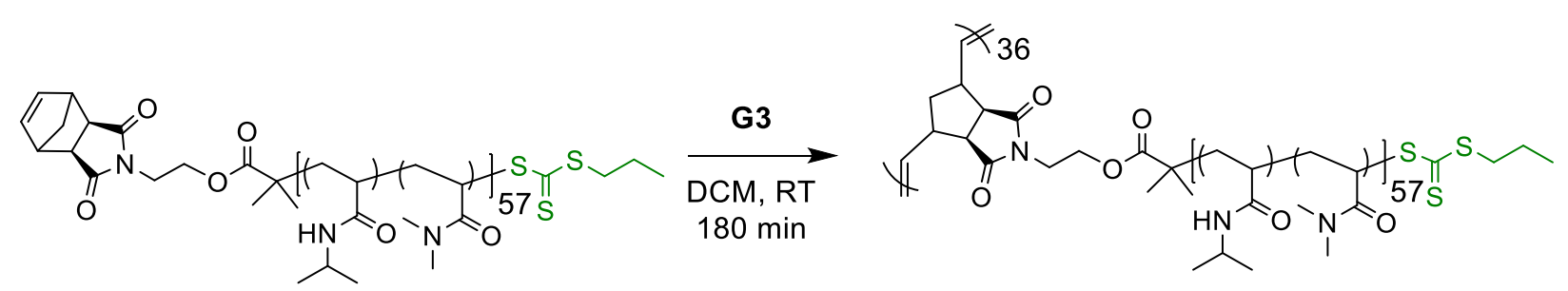

Scheme S3. Synthesis of the bottlebrush copolymer scaffold via ROMP

Synthesis of $B B-57-36-C_{3} H_{7}$ :

MM- $57-\mathrm{C}_{3} \mathrm{H}_{7}(9.95 \mathrm{~g}, 1.5 \mathrm{mmol})$ was dissolved in anhydrous DCM (30 mL, $\left.0.05 \mathrm{M}\right)$ under $\mathrm{N}_{2(\mathrm{~g})}$ atmosphere in a glove box. A stock solution $(60 \mathrm{mg} / \mathrm{mL})$ of $\mathrm{G} 3$ in anhydrous DCM was prepared, and $890 \mu \mathrm{L}$ of the stock was added to the vigorously stirring macromonomer solution. An immediate color change was observed of the catalyst from green to brown. The reaction was stirred at room temperature for 3 hours and quenched with ethyl vinyl ether and exposed to air. The diluted reaction mixture was stirred with SiliaMetS-DMT to remove the Ru catalyst and filtered to remove the silica particles. The bottlebrush was further purified by dialysis (12-14 $\mathrm{kDa}$ RC dialysis tubing) in methanol. The bottlebrush polymer was characterized using ${ }^{1} \mathrm{H}$ NMR in $\mathrm{CDCl}_{3}$ and by SECMALS (DMF with $0.05 \mathrm{M} \mathrm{LiBr)}$. 

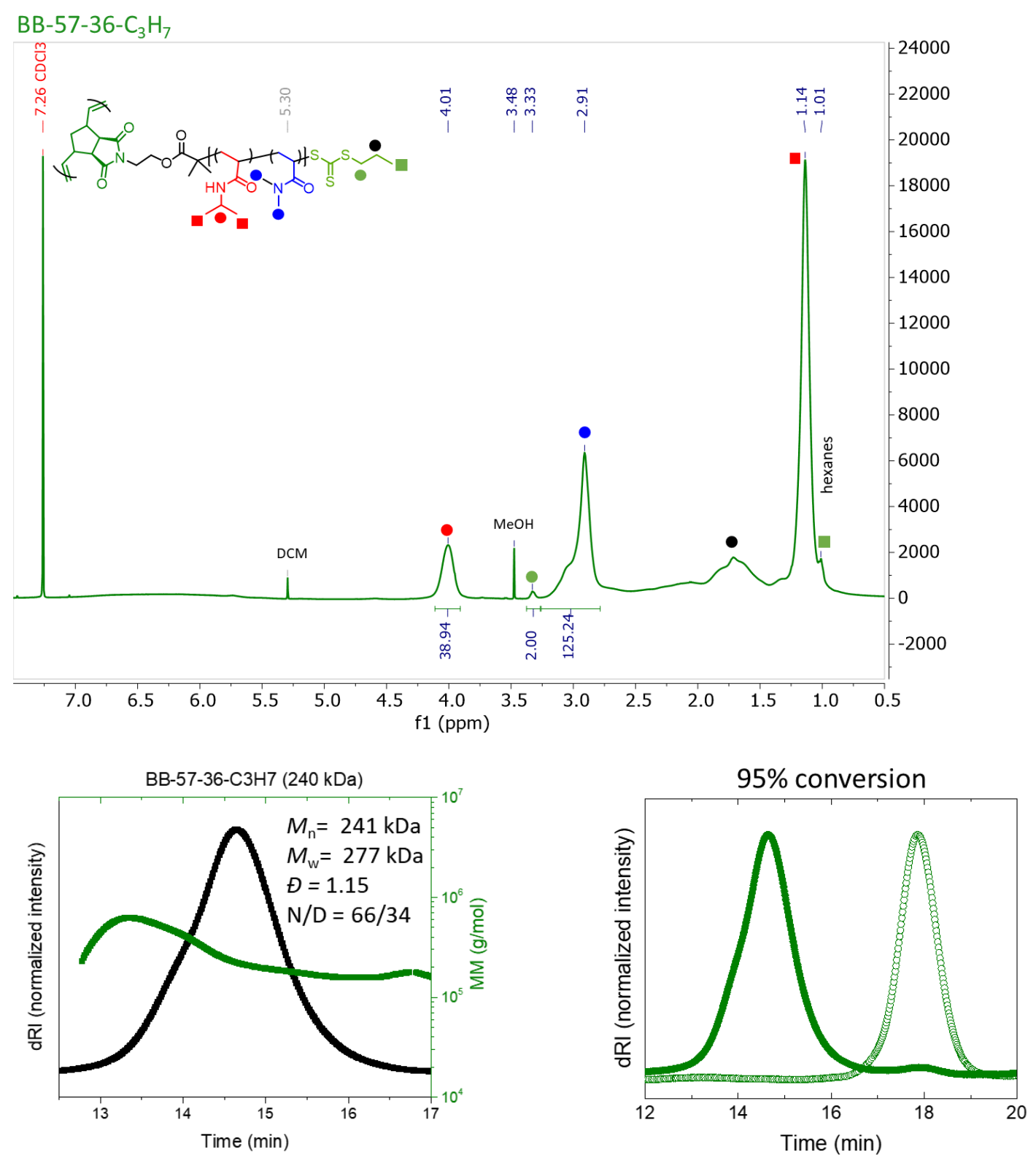

Figure S6. ${ }^{1} \mathrm{H}$ NMR and SEC of BB-57-36- $\mathrm{C}_{3} \mathrm{H}_{7}$ 

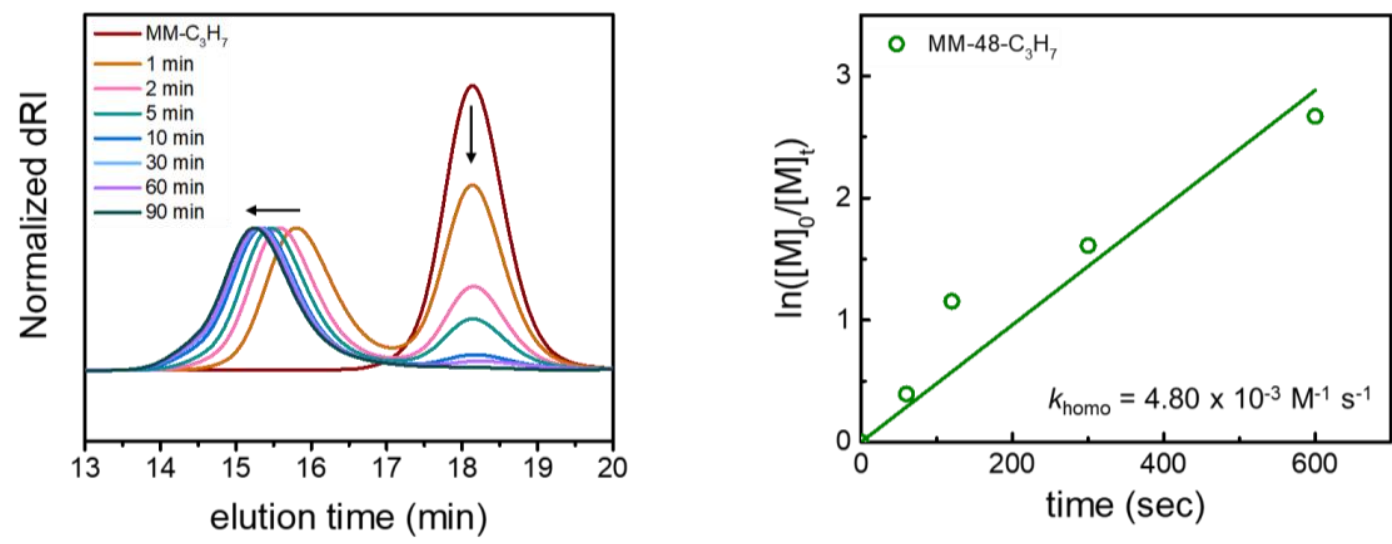

Figure S7. Kinetics study of the ROMP of MM- $\mathrm{C}_{3} \mathrm{H}_{7}$. (left) Normalized differential refractive index (dRI) traces from SEC. (right) Plot of $\ln \left([\mathrm{M}]_{0} /[\mathrm{M}]_{\mathrm{t}}\right.$ ) versus time. The conversion was estimated by calculating the area under the curve corresponding to the MM or BB in the SEC trace at $1,2,5$, and 10 min. khomo was found to be similar to polystyrene $\mathrm{MM}$ of similar $\mathrm{MW}^{1}$

\section{ROMP of end-group modified MMs:}

ROMP tests with the end-group modified macromonomers resulted in varied results over the polymerization success. Therefore, the method of post-polymerization post-ROMP was adopted to streamline the synthesis and enable comparison of each end-group modified bottlebrush copolymer excipient independent of architectural uniformity. ROMP was successful with MM-H and MM-PEG-CH 3 (see below in Figures S8), but MM-OH was not successfully polymerized by ring-opening metathesis with a Grubb's $2^{\text {nd }}$ or $3^{\text {rd }}$ Generation catalyst. This is what solidified the decision to do post-polymerization modification on the bottlebrush polymer templates ensuring architecture uniformity between end-group modified samples.
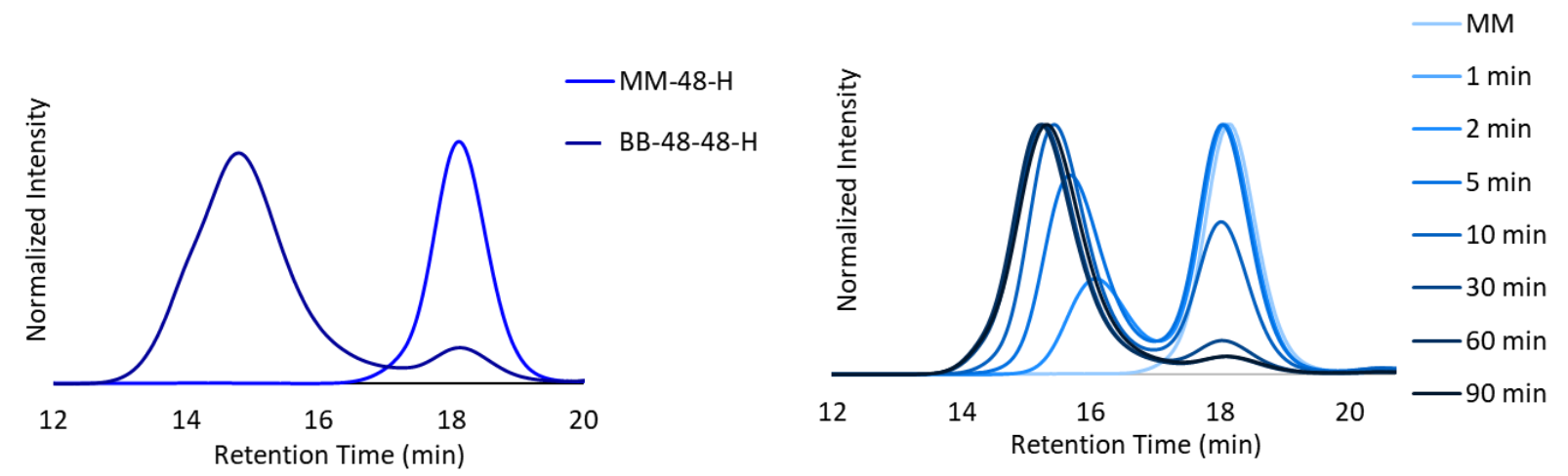

Figure S8. SEC traces of successful ROMP studies with MM-48-H (left) and MM-48-PEG-CH (right). 
Synthesis of oxa-BB-70-20- $\mathrm{C}_{3} \mathrm{H}_{7}$ :

Previous PNIPAm bottlebrush papers used an oxo-norbornene ROMP active CTA. Our synthesis following literature procedures are outlined below. ${ }^{2}$ The oxa-norbornene functionalized macromonomer did not polymerize to high enough conversion for us to consider it a viable relatively homogeneous architecture to study rigorously as the poly(norbonene) backbone analogues in the main text of this manuscript.

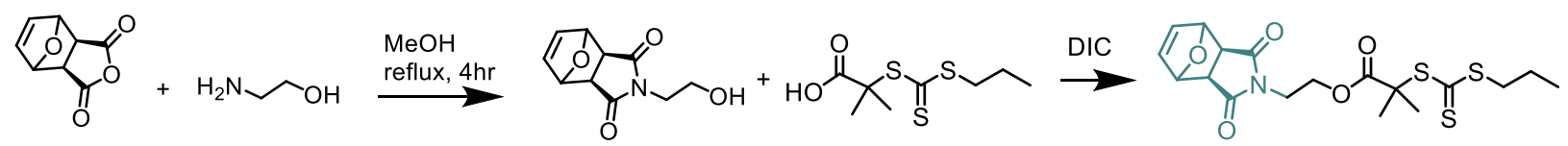

Scheme S4. Synthesis of the oxa-norbornene ROMP-active chain transfer agent.
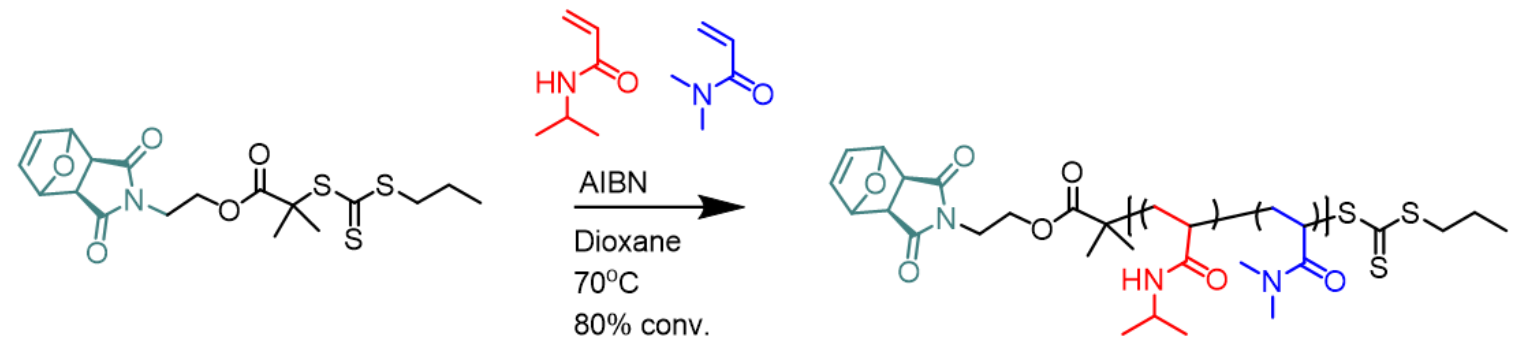

Scheme S5. Synthesis of the oxa-norbornene functionalized macromonomer. 


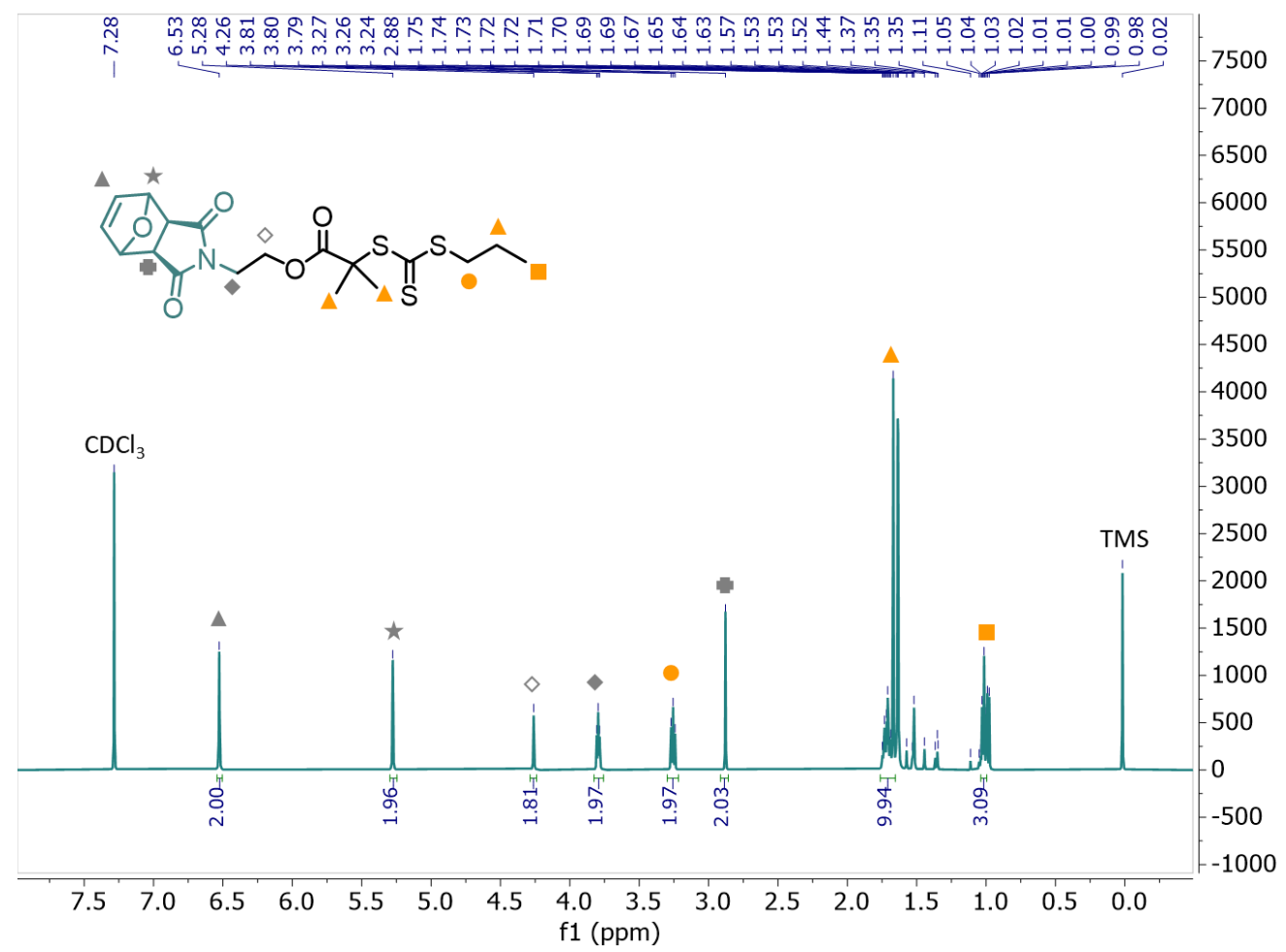

Figure S9. ${ }^{1} \mathrm{H} \mathrm{NMR}$ in $\mathrm{CDCl}_{3}$ of oxa-NB-CTA

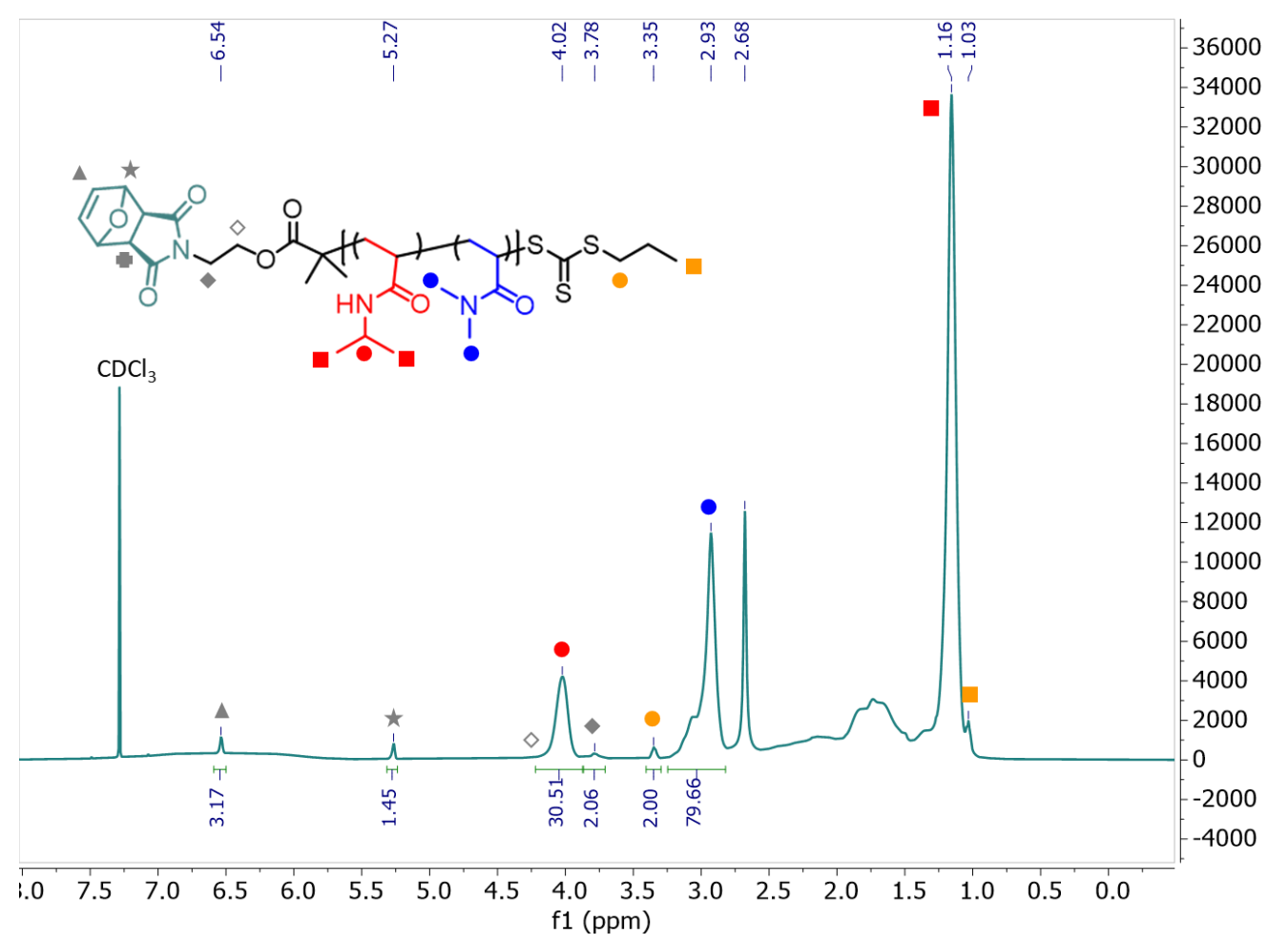

Figure S10. ${ }^{1} \mathrm{H}$ NMR in $\mathrm{CDCl}_{3}$ of oxa-MM-70- $\mathrm{C}_{3} \mathrm{H}_{7}$ 


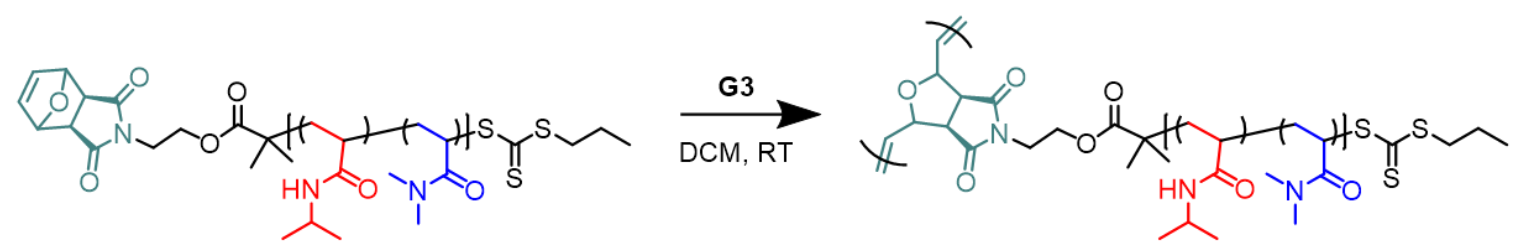

Scheme S6. Synthesis of the oxa-norbornene bottlebrush.

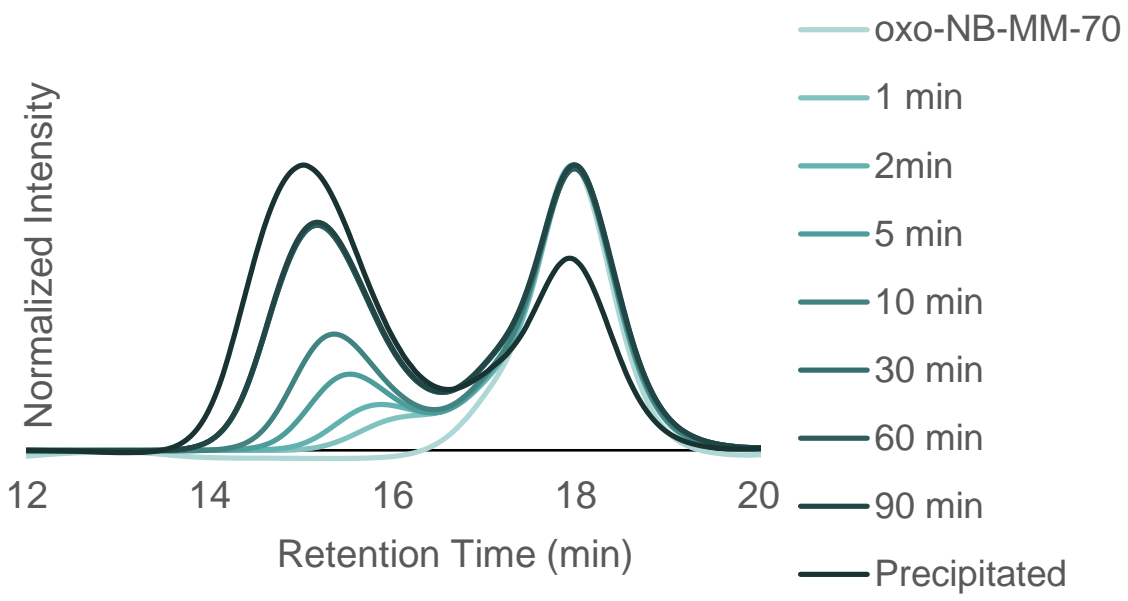

Figure S11. Normalized dRI SEC traces of the ROMP of oxa-MM-70- $\mathrm{C}_{3} \mathrm{H}_{7}(\mathrm{Mn}=7.1 \mathrm{kDa}, \mathrm{Ð}=$ 1.12) into oxa-BB-70-20- $\mathrm{C}_{3} \mathrm{H}_{7}(\mathrm{Mn}=140 \mathrm{kDa}, \mathrm{D}=1.17)$. The polymerization did not $>60 \%$ conversion within $90 \mathrm{~min}$. Samples with residual MM present were not suitable for our studies. 
TEA (1.19 eq.)<smiles>O=C(Cl)C=C[C@H]([Hg])OCCC(O)O</smiles>

THF, $\mathrm{N}_{2}$

$\mathrm{RT}(2 \mathrm{hr}$.)

$45^{\circ} \mathrm{C}(3 \mathrm{hr}$.

Scheme S7. Synthesis of poly(ethylene glycol) hydroxy ether acrylate

Synthesis of poly(ethylene glycol) hydroxy ether acrylate (PEGA) (yield: $31 \%$ )

A two neck round bottomed flask $(250 \mathrm{~mL})$ equipped with an addition funnel was charged with a solution of poly(ethylene oxide) $400 \mathrm{Da}(2.25 \mathrm{~mL}, 7.50 \mathrm{mmol}, 1.0$ equiv) and triethylamine (1.36 $\mathrm{mL}, 9.75 \mathrm{mmol}, 1.3$ equiv) in THF $(75 \mathrm{~mL})$. The reaction was then cooled to $0{ }^{\circ} \mathrm{C}$. To this solution was then added a solution of acryloyl chloride $(0.58 \mathrm{~mL}, 7.37 \mathrm{mmol}, 0.95$ equiv) in THF (10 mL) dropwise via the addition funnel over the course of $5 \mathrm{~h}$. After $5 \mathrm{~h}$, during which TLC showed complete consumption of starting material, the reaction was warmed to $23{ }^{\circ} \mathrm{C}$, filtered over Celite, and the filtrate was concentrated in vacuo. Purification by flash chromatography on silica gel (1$\left.3 \% \mathrm{MeOH} / \mathrm{CH}_{2} \mathrm{Cl}_{2}\right)$ afforded the title compound $(1.12 \mathrm{~g}, 31 \%)$ as an off-yellow oil: $R_{\mathrm{f}}=0.24$ $\left(2.5 \% \mathrm{MeOH} / \mathrm{CH}_{2} \mathrm{Cl}_{2}\right) ;{ }^{1} \mathrm{H} \mathrm{NMR}\left(400 \mathrm{MHz}, \mathrm{CDCl}_{3}\right) \delta 6.42(\mathrm{~d}, J=18.7 \mathrm{~Hz}, 1 \mathrm{H}), 6.15(\mathrm{dd}, J=$ 17.3, 10.4 Hz, 1H), 5.83 (d, $J=11.8 \mathrm{~Hz}, 1 \mathrm{H}), 4.31$ (t, $J=5.0 \mathrm{~Hz}, 2 \mathrm{H}), 3.75-3.59$ (m, 34H), 2.41 (s, $1 \mathrm{H}) ;{ }^{13} \mathrm{C} \mathrm{NMR}\left(400 \mathrm{MHz}, \mathrm{CDCl}_{3}\right) \delta 166.2,131.0,128.3,72.5,70.6,70.4,69.1,63.7,61.8$. 


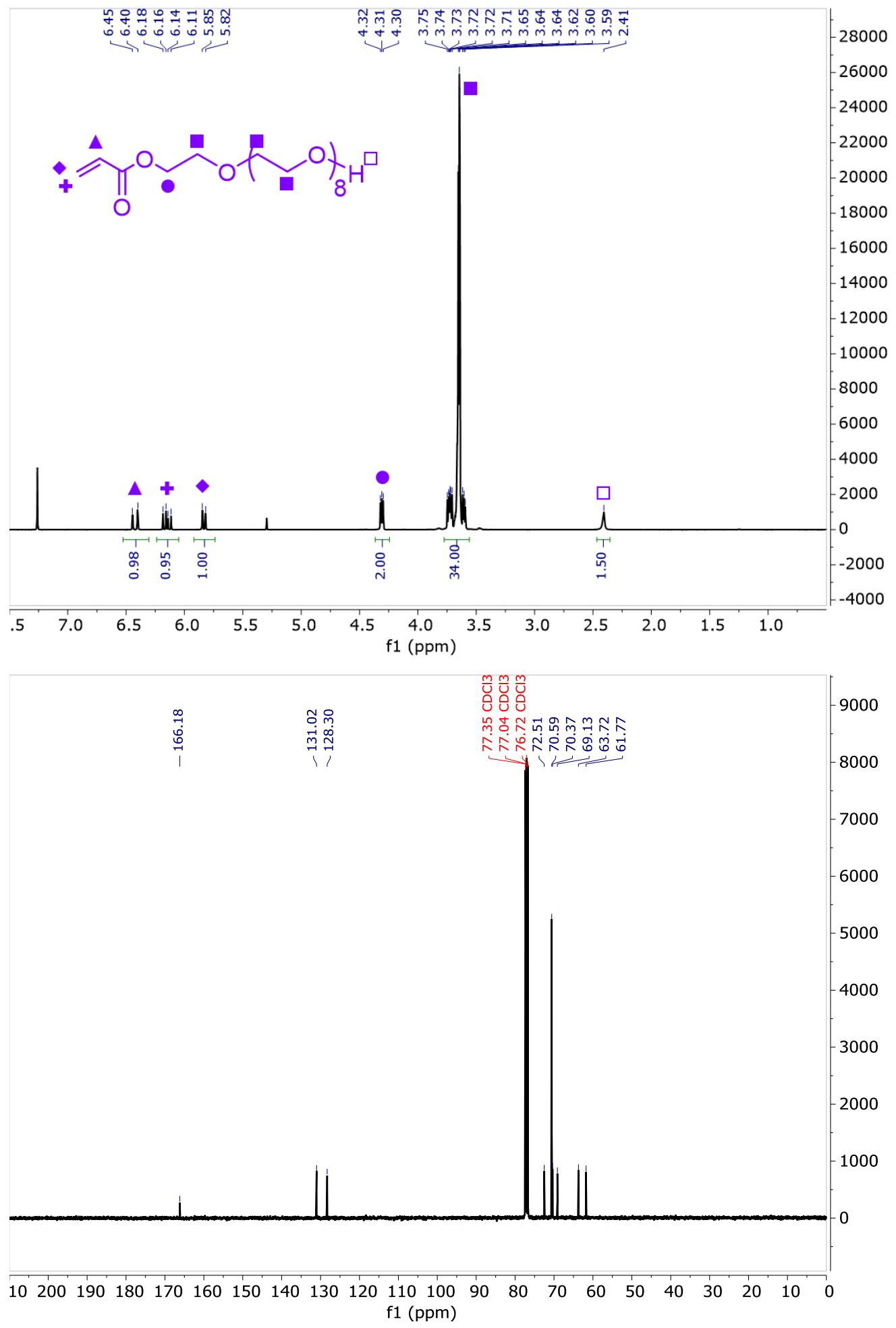

Figure S12. ${ }^{1} \mathrm{H} \mathrm{NMR}$ and ${ }^{13} \mathrm{C}$ NMR of hydroxy-PEGA in $\mathrm{CDCl}_{3}$ 


\section{End-Group Modification Procedures:}

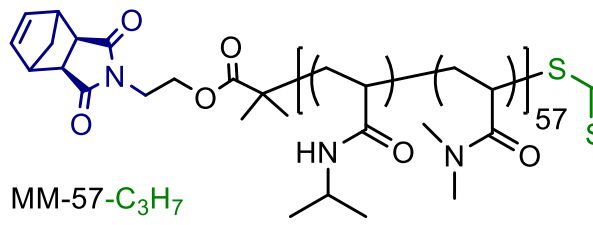

(exo-norbornene imide-PND-57- $\mathrm{C}_{3} \mathrm{H}_{7}$ )
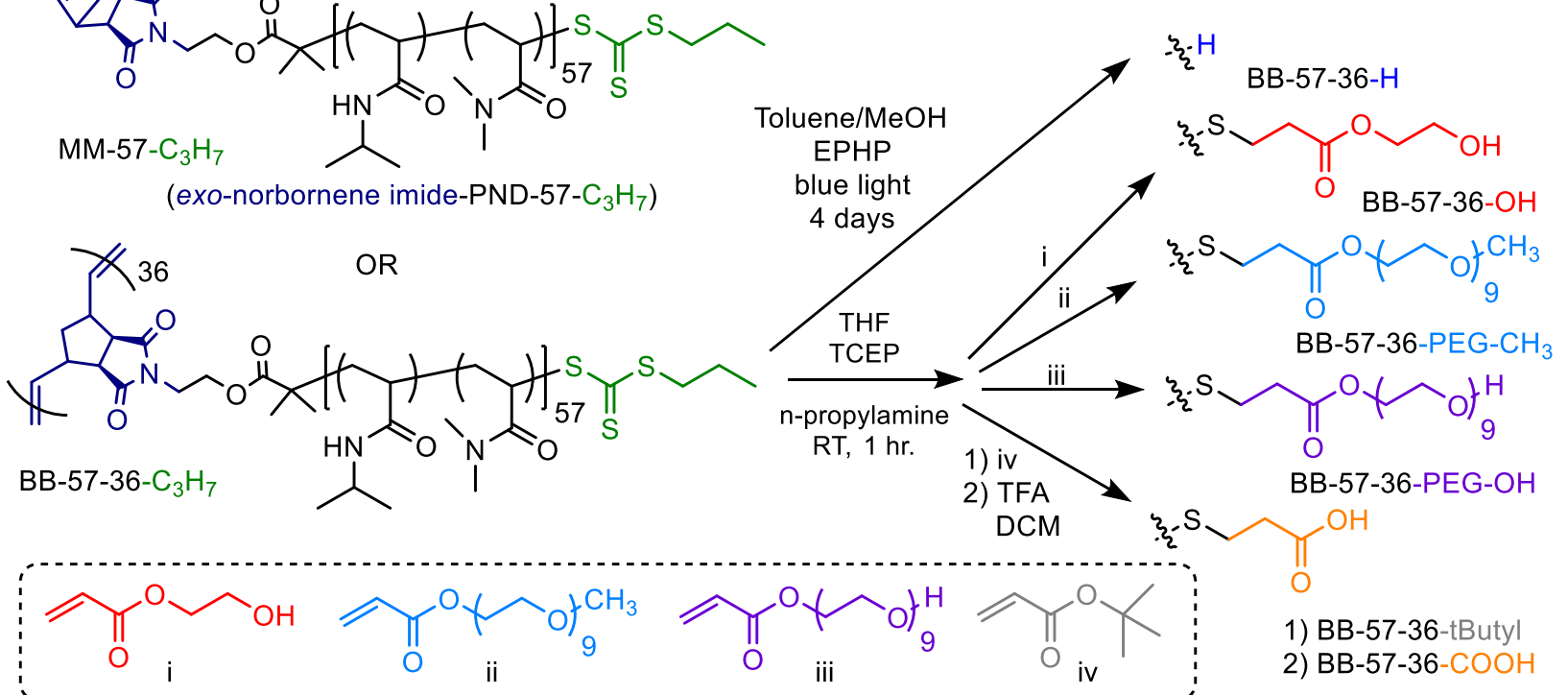

Scheme S8. Post polymerization end-group modification of both the macromonomers and bottlebrushes through photointitiated end-group cleavage with UV light $(450-470 \mathrm{~nm})$ or aminolysis followed by Michael addition of: (i) hydroxyethyl acrylate, (ii) poly(ethylene glycol) methyl ether acrylate, (iii) poly(ethylene glycol) hydroxy ether acylate, or (iv) tert-butyl acrylate.

Photoinitiated Trithiocarbonate Cleavage: MM-57- $\mathrm{C}_{3} \mathrm{H}_{7}$ or BB-57-36- $\mathrm{C}_{3} \mathrm{H}_{7}$ was dissolved in a mixture of toluene and methanol (70:30) and EPHP (30 eq. to each Z-group). After the reaction mixture was purged with $\mathrm{N}_{2(\mathrm{~g})}$ for 30 minutes, the reaction mixture was stirred at room temperature while irradiating with blue light $(450-470 \mathrm{~nm})$ for 4 days or until the reaction mixture was colorless. The colorless reaction mixture was purified by dialysis in methanol. 


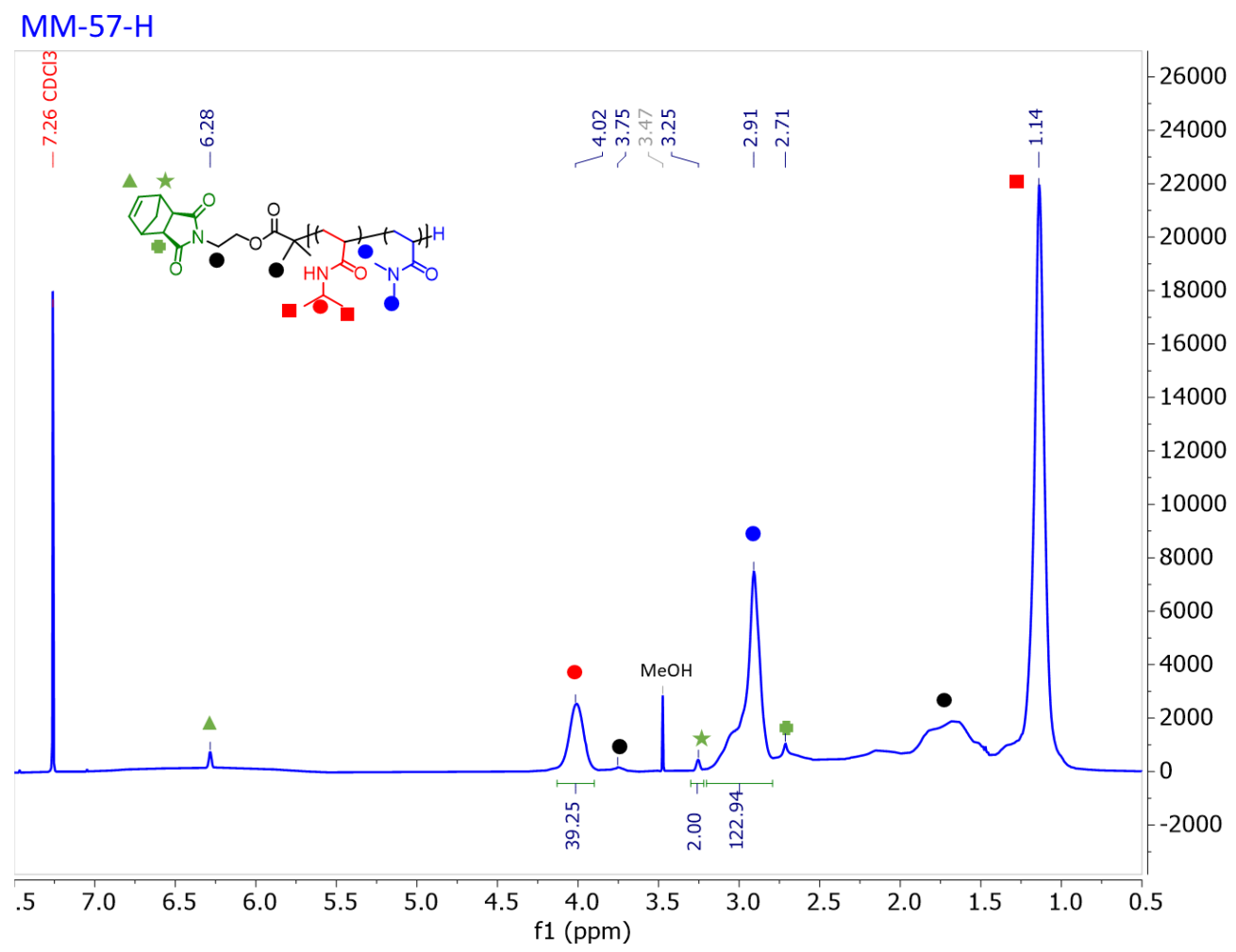

Figure S13. ${ }^{1} \mathrm{H} \mathrm{NMR}$ in $\mathrm{CDCl}_{3}$ of $\mathrm{MM}-57-\mathrm{H}$

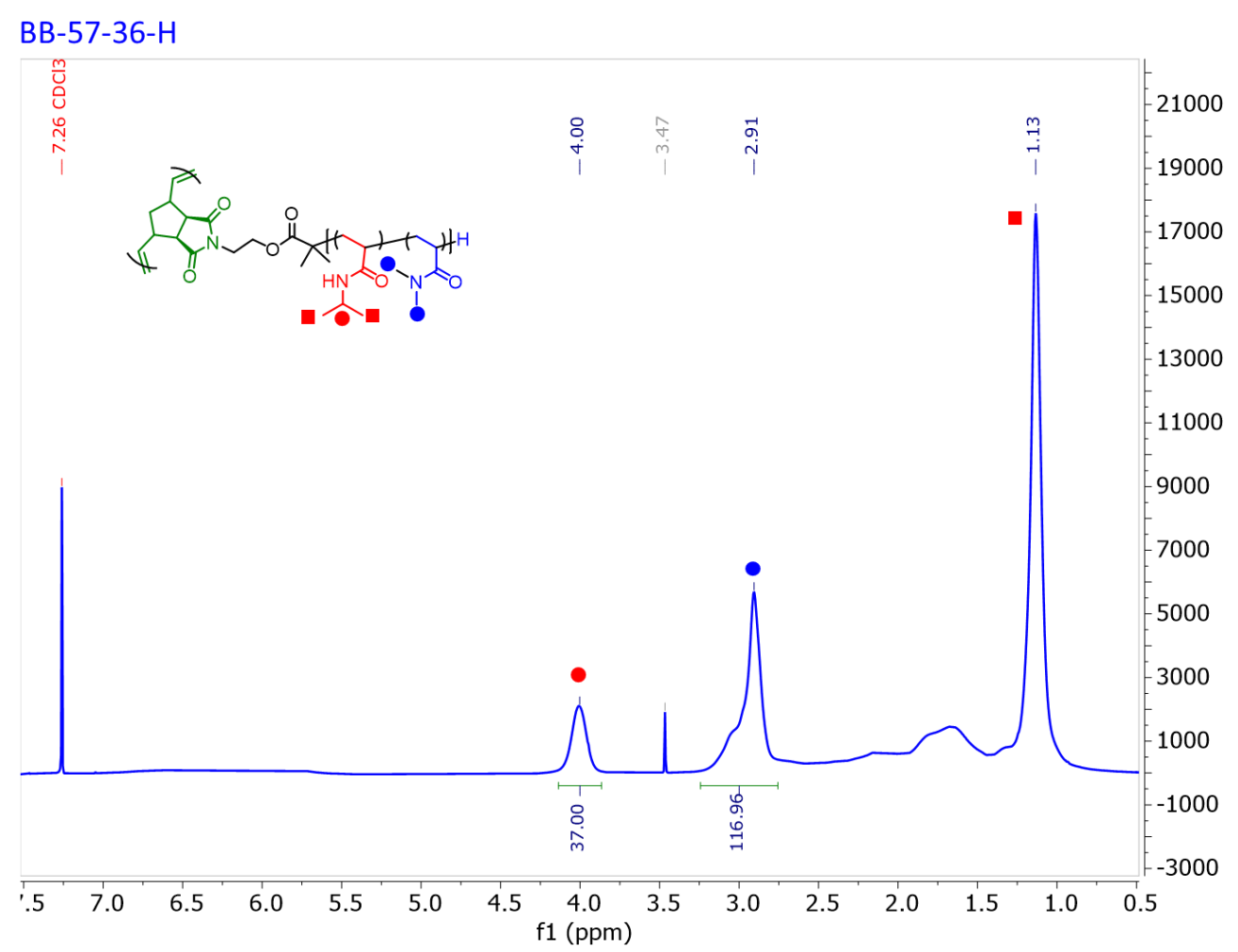

Figure S14. ${ }^{1} \mathrm{H}$ NMR in $\mathrm{CDCl}_{3}$ of $\mathrm{BB}-57-36-\mathrm{H}$ 
Thia-Michael Addition End-Group Modification: MM-57- $\mathrm{C}_{3} \mathrm{H}_{7}$ or BB-57-36- $\mathrm{C}_{3} \mathrm{H}_{7}$ was dissolved in THF $(0.10 \mathrm{M})$ with TCEP (1 eq. to each Z-group). The solution was degassed with $\mathrm{N}_{2(\mathrm{~g})}$ for 15 minutes before n-propylamine (50 eq. to each Z-group) was added dropwise to the solution. The solution was stirred at room temperature for 2 hours. After only 20 minutes, the reaction mixture was colorless. After 2 hours, acrylate [hydroxy-ethyl acrylate (50 eq. to each Z-group), poly(ethylene glycol) methyl ether acrylate (25 eq. to each Z-group), poly(ethylene glycol) methyl ether acrylate (25 eq. to each Z-group), tert-butyl acrylate (25 eq. to each Z-group)] was added dropwise to the reaction mixture and the reaction was stirred at room temperature overnight (14 hours). The reaction mixture was purified by dialysis in methanol. The tert-butyl group was removed by stirring MM-57-tButyl or BB-57-36-tButyl in DCM (0.01 M) with TFA (200 eq. for the MM end group cleavage and 15 eq. per Z-group for the BB) for 5 hours. The DCM and TFA was removed by rotary evaporation with a base trap and further purified by dialysis in methanol. 


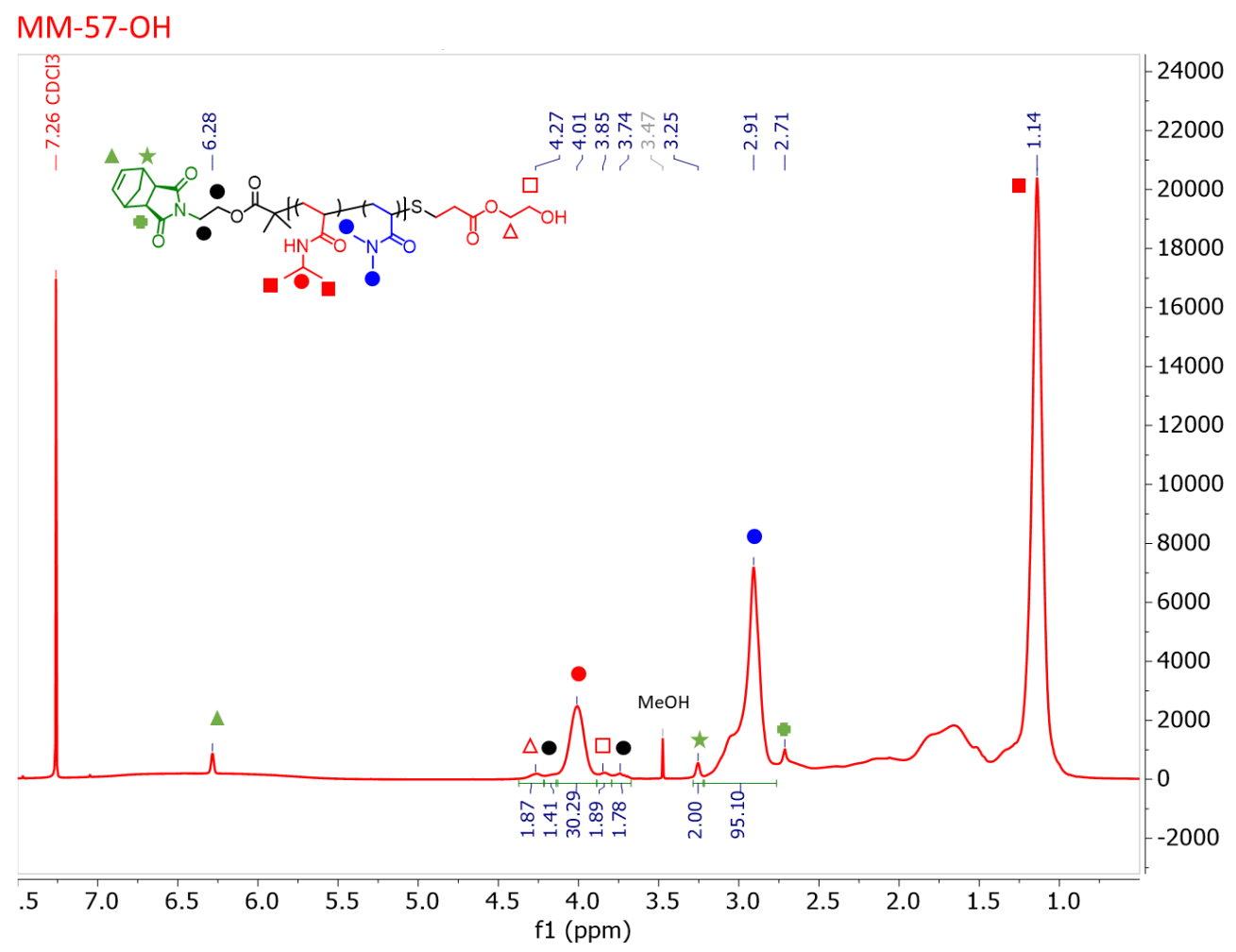

Figure S15. ${ }^{1} \mathrm{H}$ NMR in $\mathrm{CDCl}_{3}$ of $\mathrm{MM}-57-\mathrm{OH}$

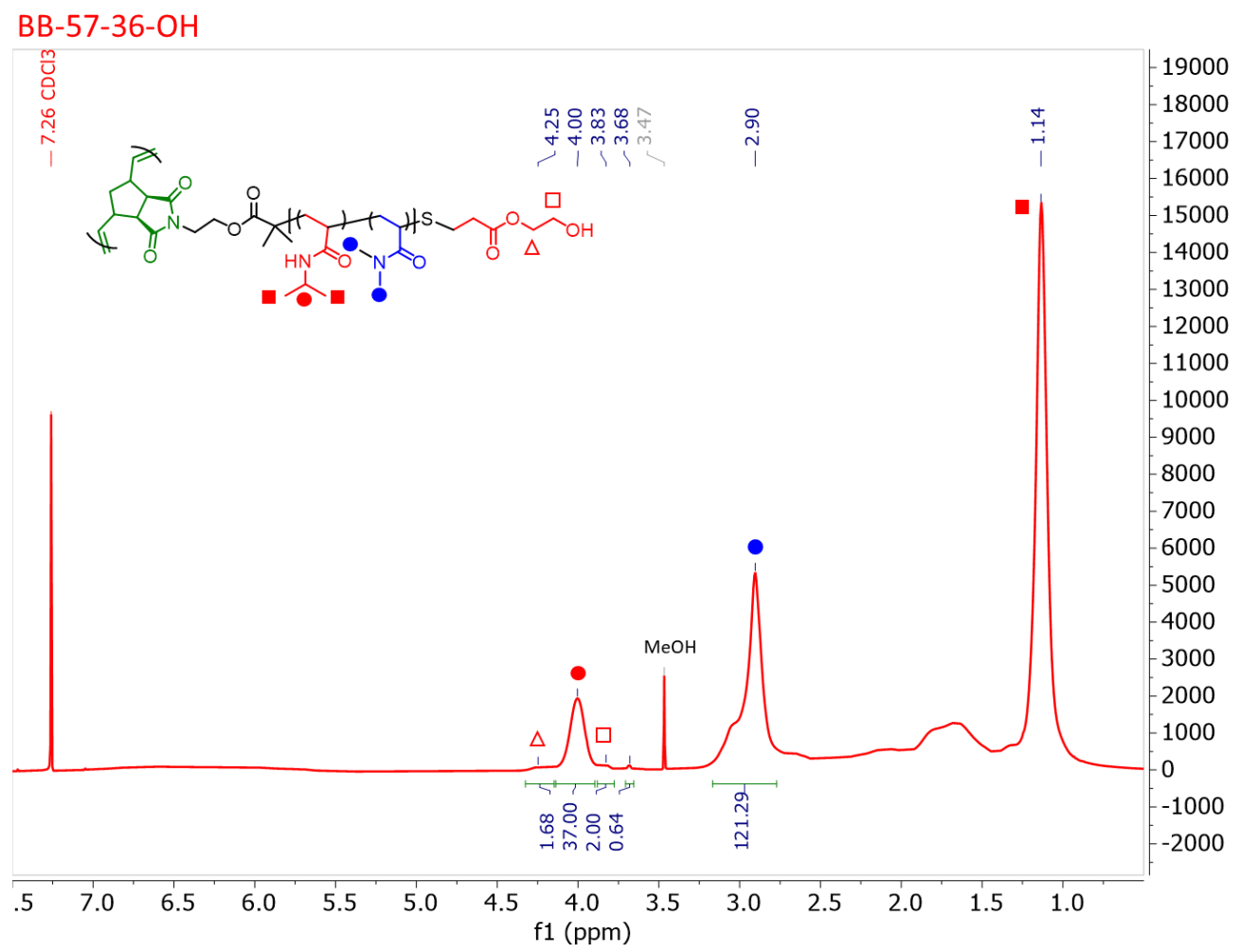

Figure S16. ${ }^{1} \mathrm{H}$ NMR in $\mathrm{CDCl}_{3}$ of $\mathrm{BB}-57-36-\mathrm{OH}$ 


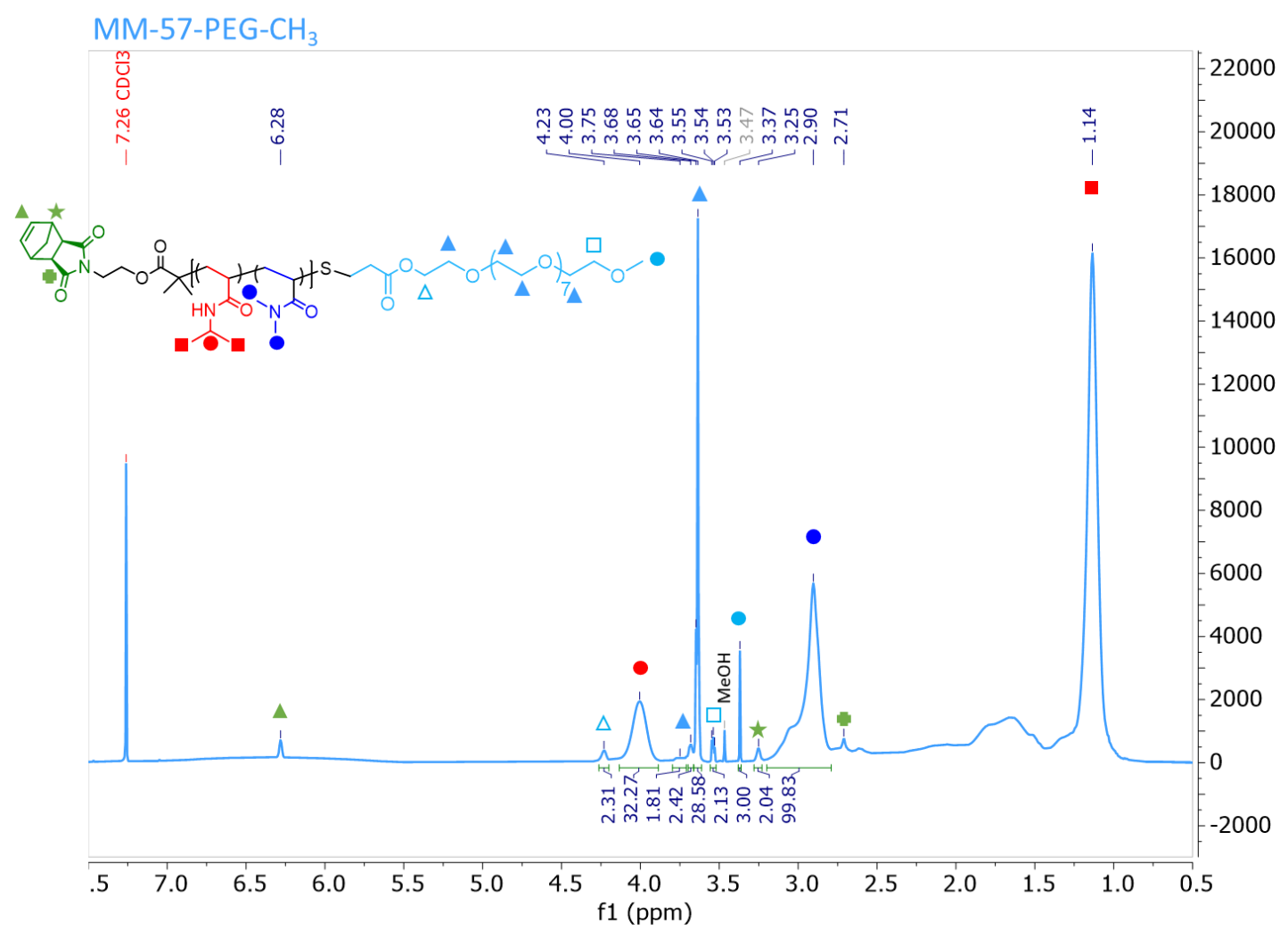

Figure S17. ${ }^{1} \mathrm{H}$ NMR in $\mathrm{CDCl}_{3}$ of MM-57-PEG-CH

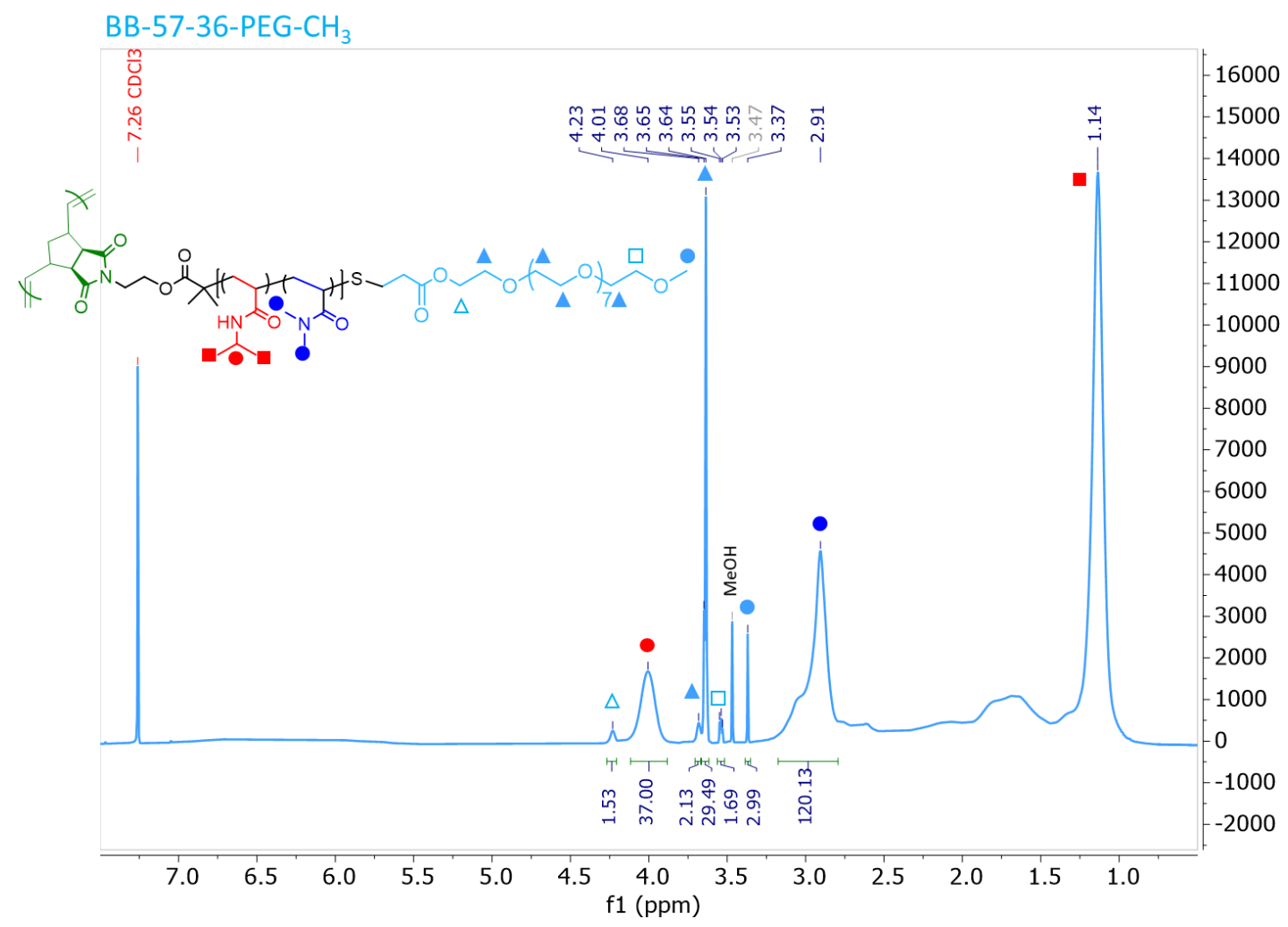

Figure S18. ${ }^{1} \mathrm{H}$ NMR in $\mathrm{CDCl}_{3}$ of $\mathrm{BB}-57-36-\mathrm{PEG}^{-\mathrm{CH}_{3}}$ 


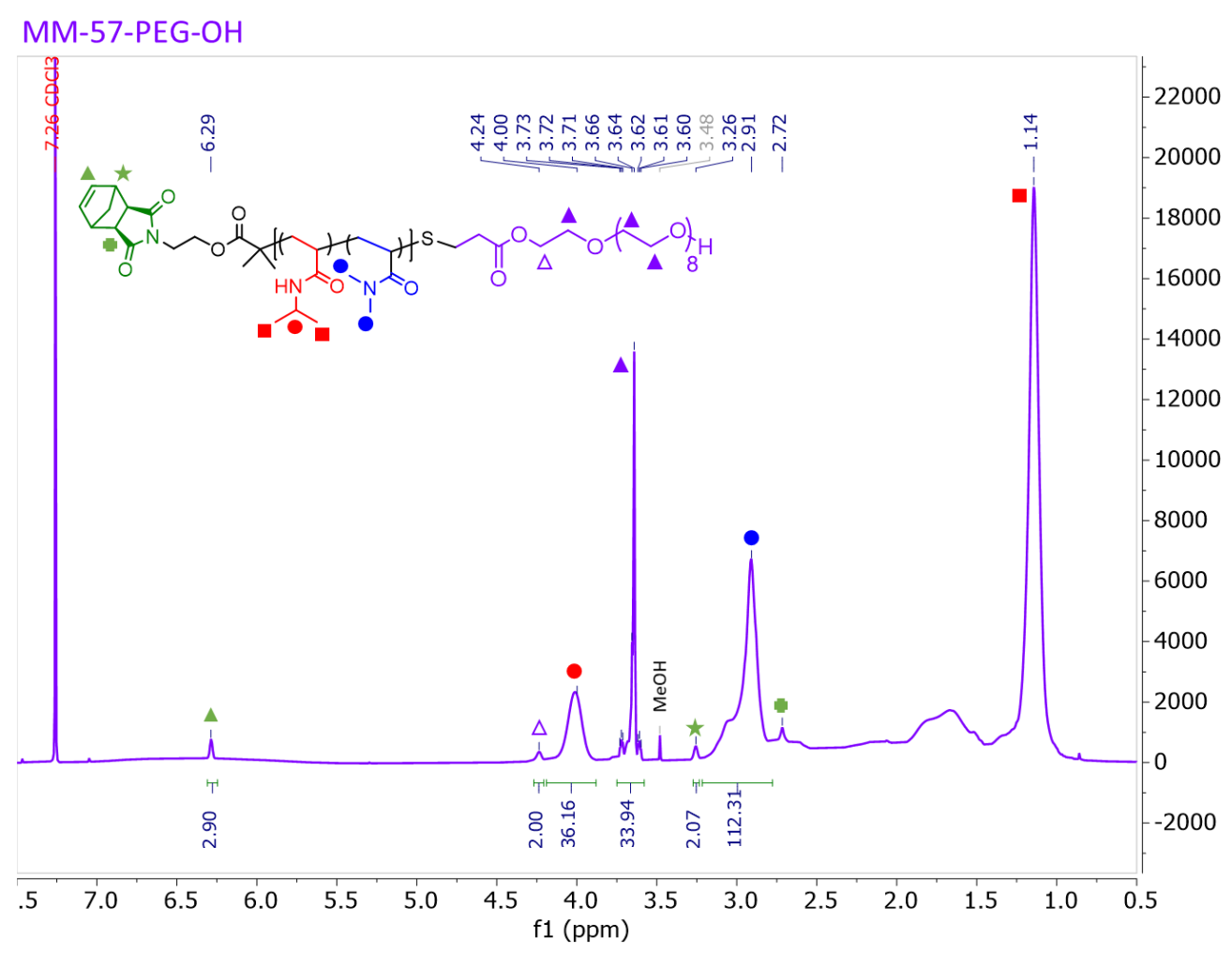

Figure S19. ${ }^{1} \mathrm{H} \mathrm{NMR}$ in $\mathrm{CDCl}_{3}$ of $\mathrm{MM}-57-\mathrm{PEG}-\mathrm{OH}$

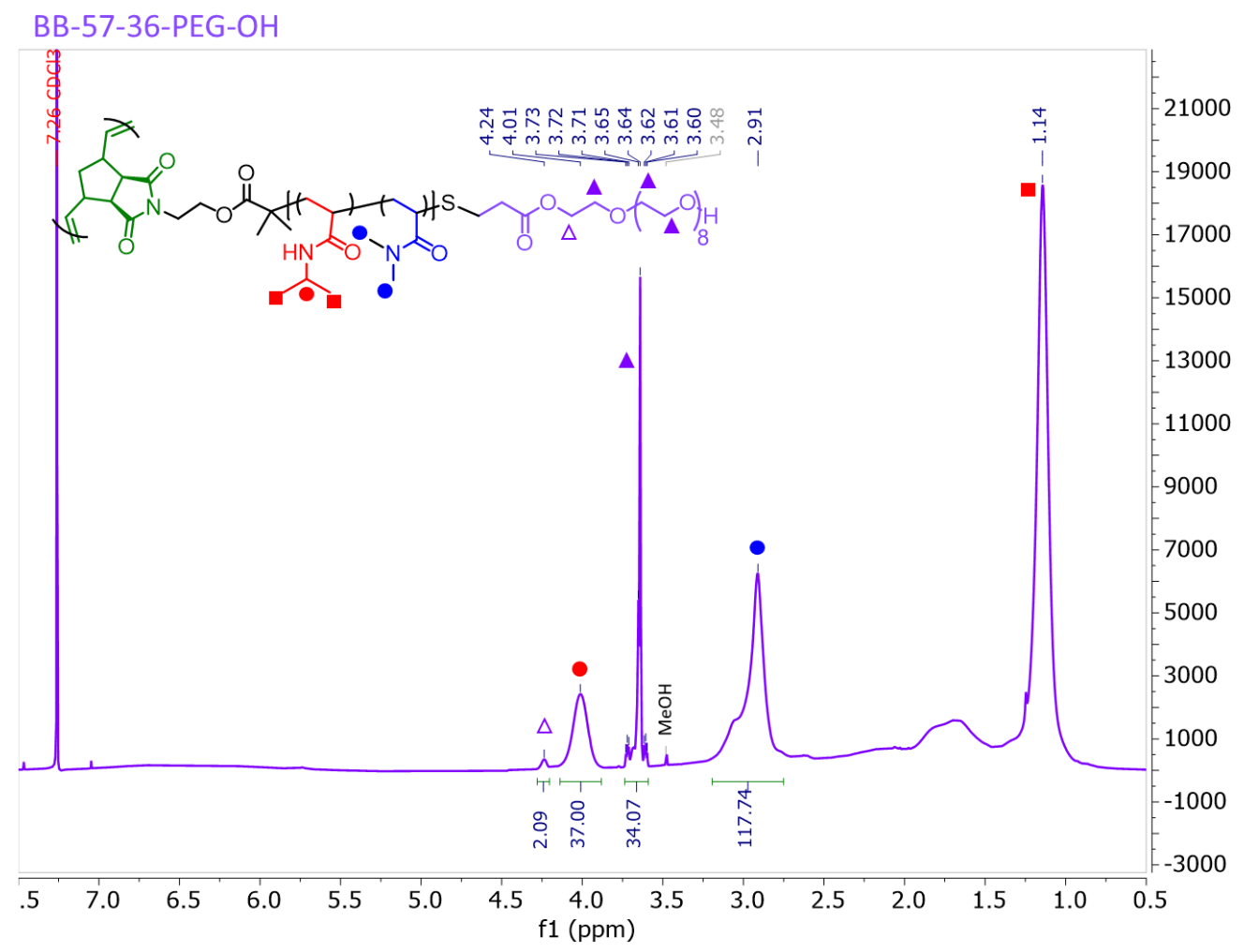

Figure S20. ${ }^{1} \mathrm{H}$ NMR in $\mathrm{CDCl}_{3}$ of $\mathrm{BB}-57-36-\mathrm{PEG}-\mathrm{OH}$ 


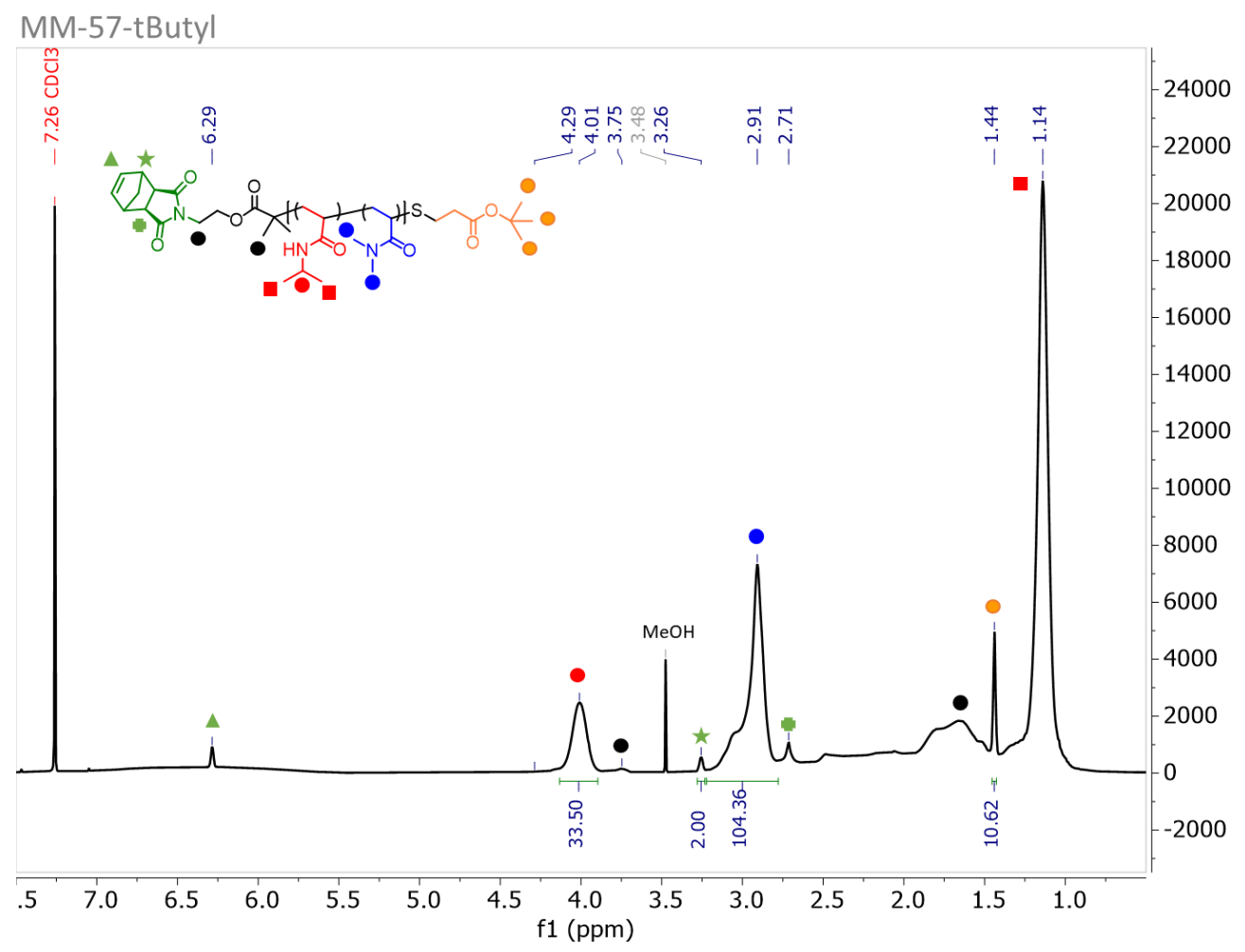

Figure S21. ${ }^{1} \mathrm{H}$ NMR in $\mathrm{CDCl}_{3}$ of MM-57-tButyl

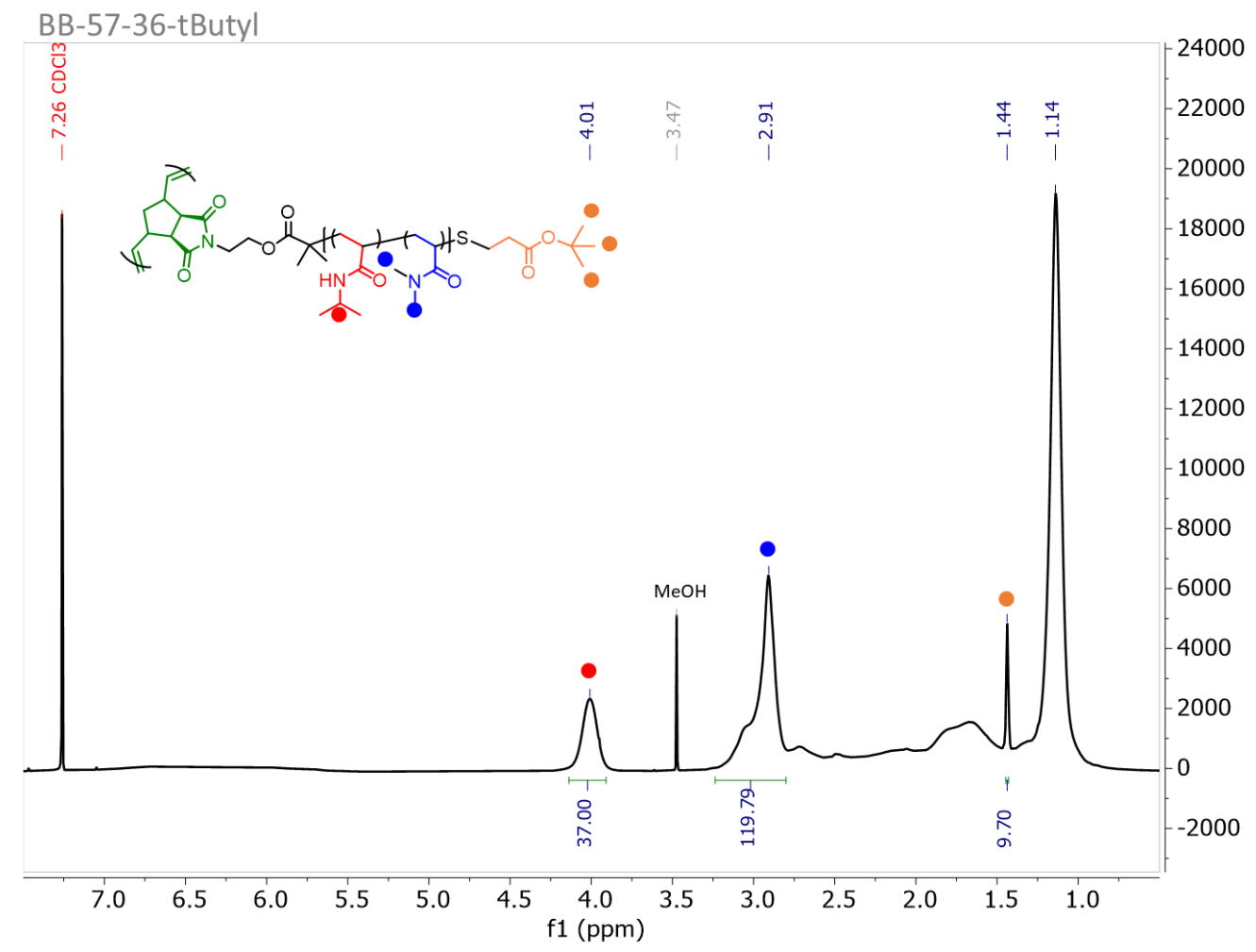

Figure S22. ${ }^{1} \mathrm{H}$ NMR in $\mathrm{CDCl}_{3}$ of BB-57-36-tButyl 


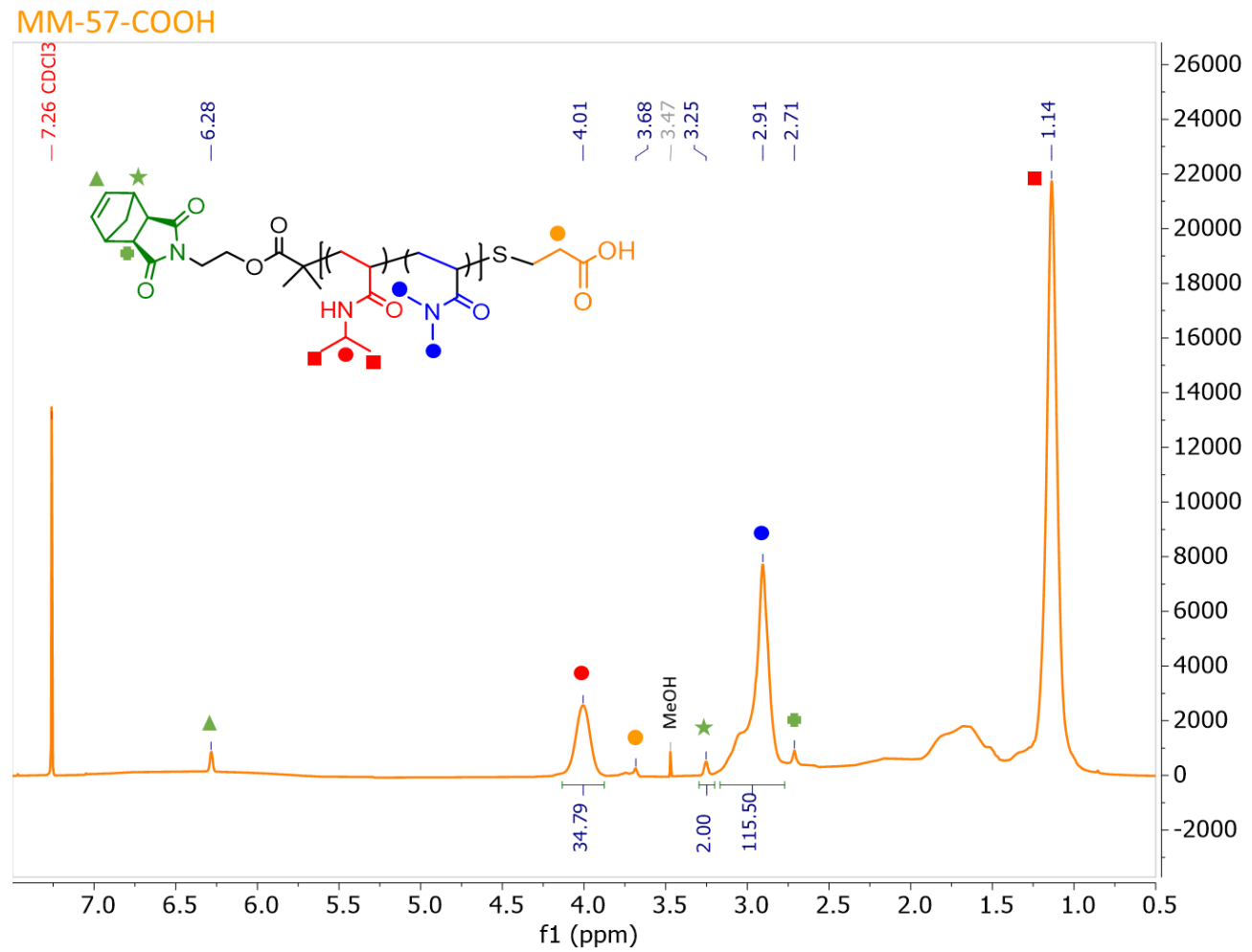

Figure S23. ${ }^{1} \mathrm{H}$ NMR in $\mathrm{CDCl}_{3}$ of $\mathrm{MM}-57-\mathrm{COOH}$

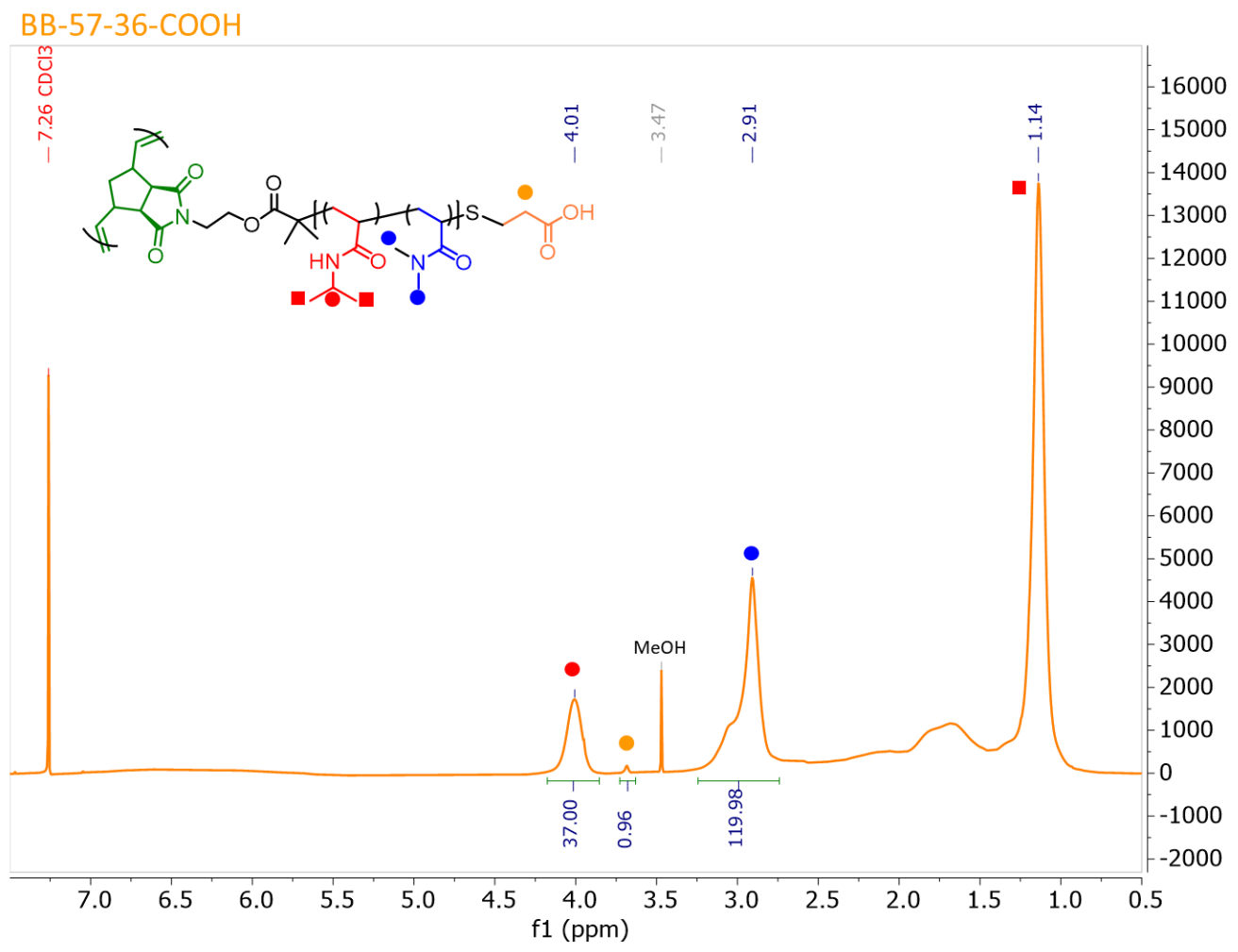

Figure S24. ${ }^{1} \mathrm{H}$ NMR in $\mathrm{CDCl}_{3}$ of $\mathrm{BB}-57-36-\mathrm{COOH}$ 

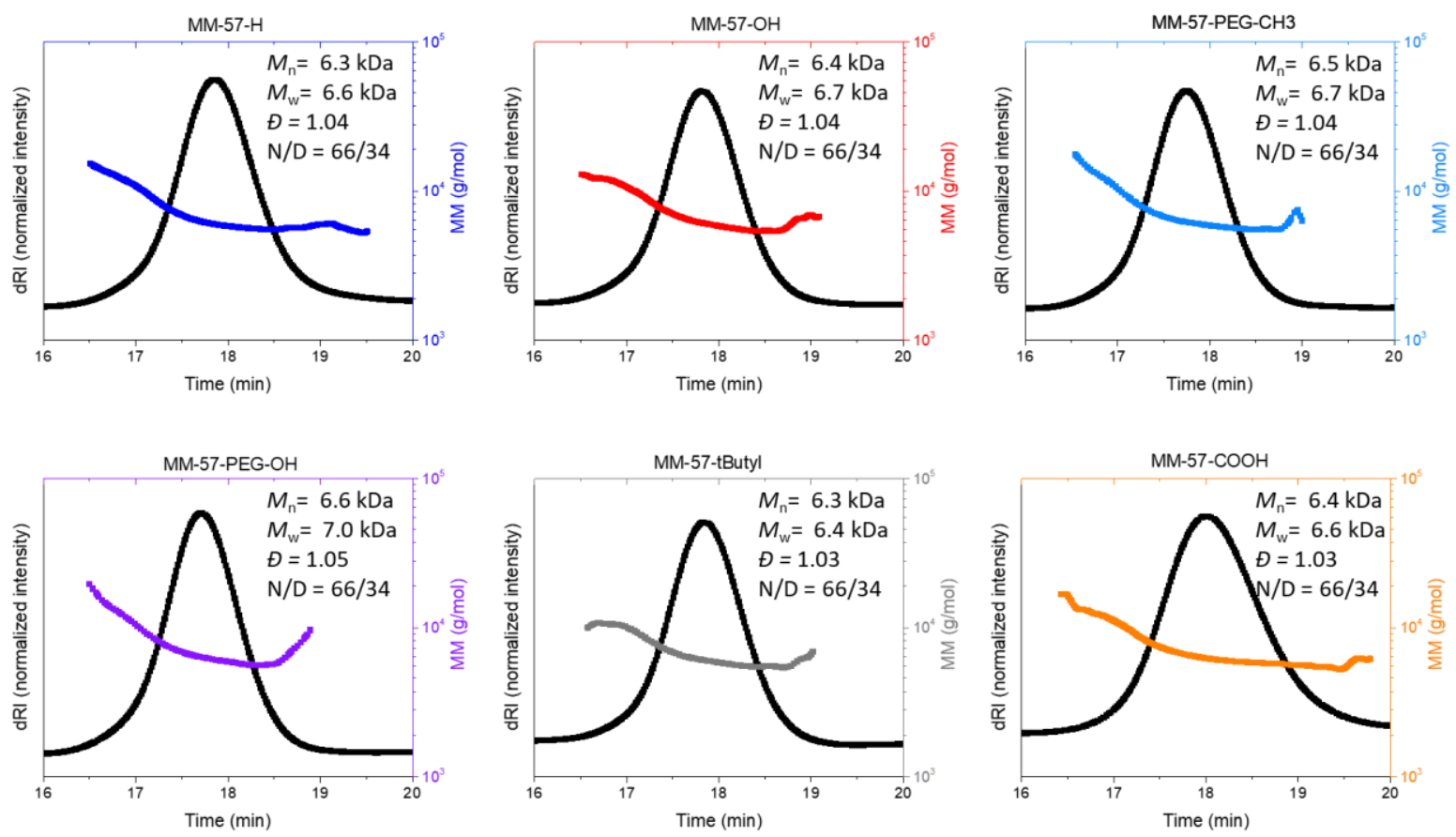

Figure S25. SEC-MALS in DMF with 0.05M of all end-group modified MM-57-Z.
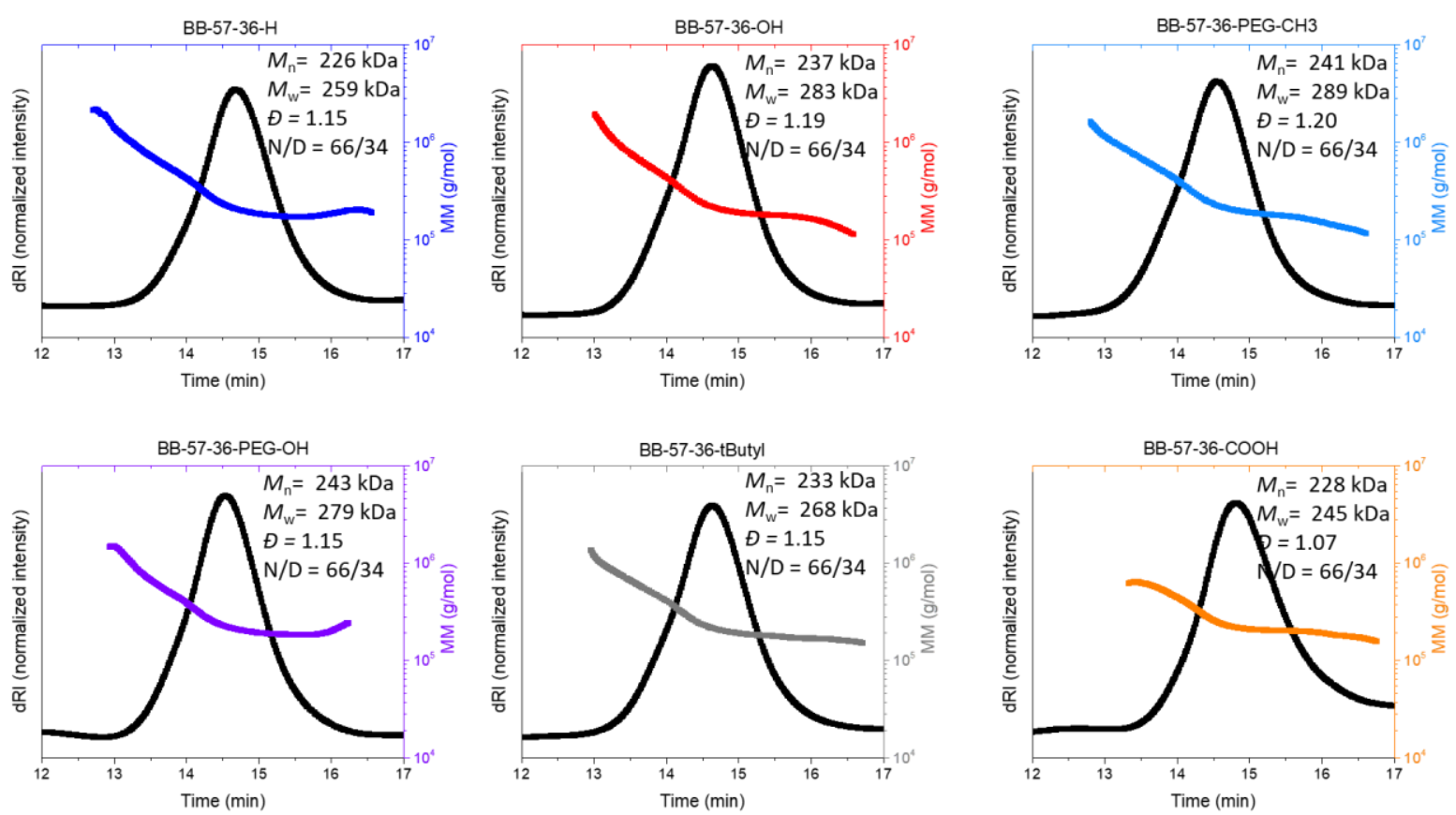

Figure S26. SEC-MALS in DMF with 0.05M of all end-group modified BB-57-36-Z. 

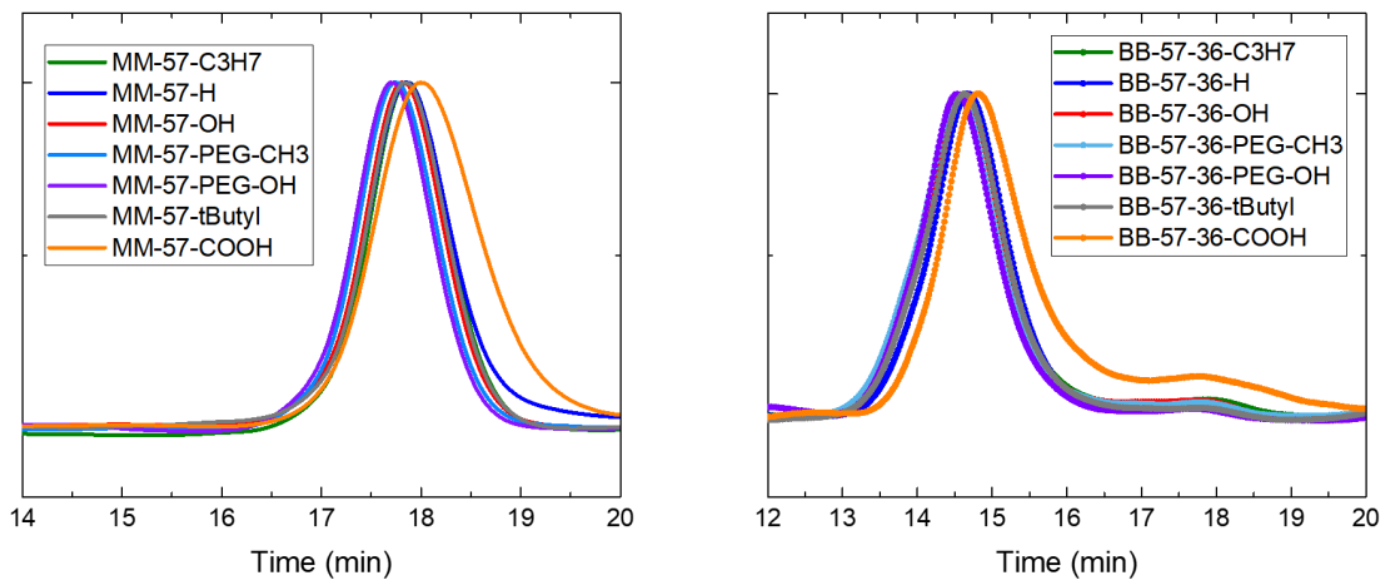

Figure S27. Overlaid RI traces of the MM (left) and BB (right) samples after end-group modification measured by SEC-MALS in DMF with $0.05 \mathrm{M} \mathrm{LiBr}$.

The RI trace for BB-57-36-COOH was shifted to higher retention times (Figure S27); however, this was confirmed to be an artifact due to column dragging through static light scattering (SLS) weight-average molecular weight measurements (Table 1 and Figure S45). 

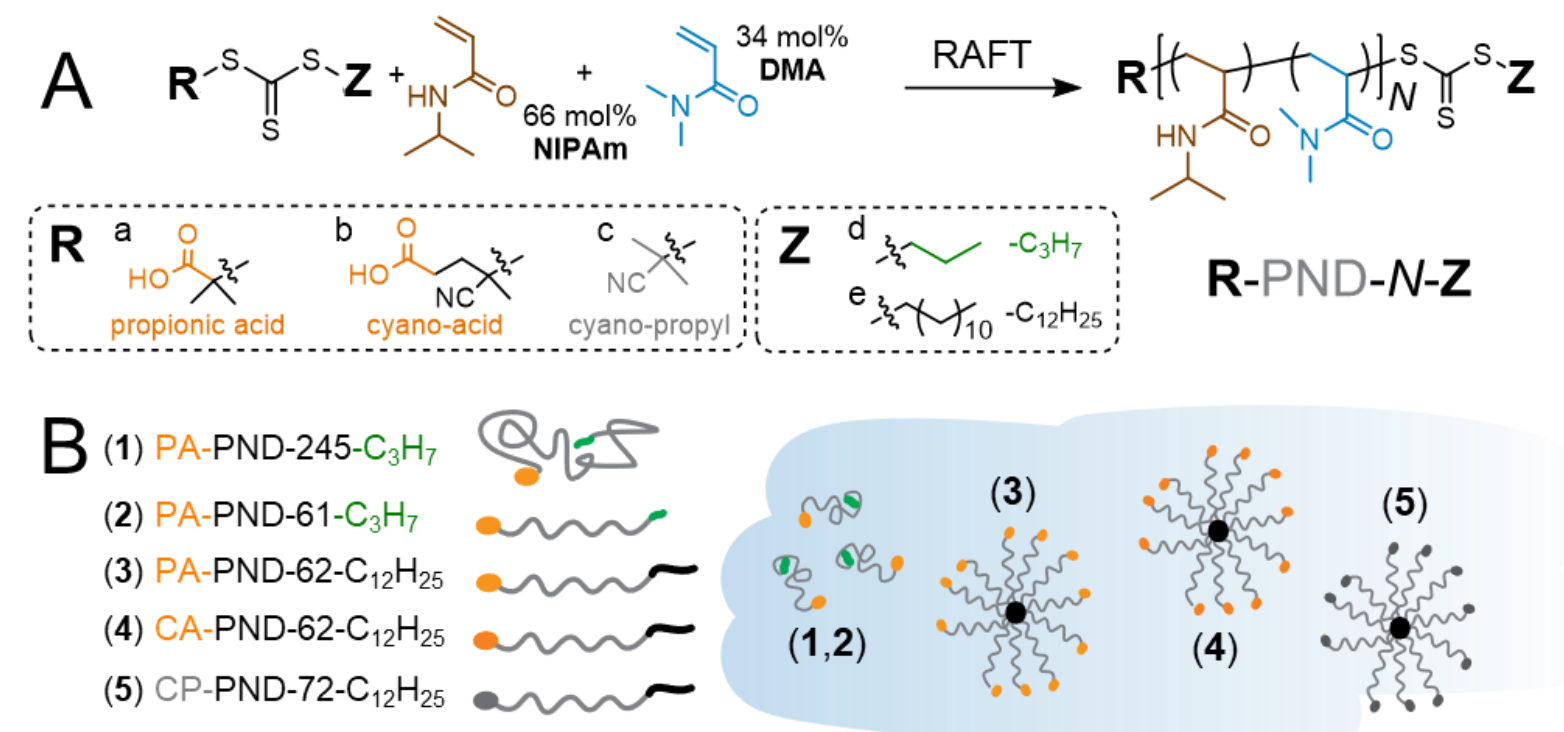

Scheme S9. Synthetic scheme of poly(NIPAm-stat-DMA) (PND) linear copolymer controls. (A) A general RAFT polymerization scheme for linear controls 1-5 with the following chain transfer agents: (1,2) 2-(propylthiocarbonothioylthio)-2 methyl propionic acid, (3) 2(Dodecylthiocarbonothioylthio)-2-methylpropionic acid, (4) 4-Cyano-4[(dodecylsulfanylthiocarbonyl)sulfanyl]pentanoic acid, and (5) 2-Cyano-2-propyl dodecyl trithiocarbonate. The R- and Z-groups of the trithiocarbonate CTA and molecular weight were changed to create the five controls: (a) propionic acid (PA, orange), (b) cyano-acid (CA, orange), (c) cyano-acid (CA, grey), (d) propyl hydrocarbon chain $\left(-\mathrm{C}_{3} \mathrm{H}_{7}\right.$, green), and (e) dodecyl hydrocarbon chain $\left(-\mathrm{C}_{12} \mathrm{H}_{25}\right.$, black). (B) Cartoon representations of the linear polymer controls and their solution structures in aqueous media - grey lines represent the copolymer: (1) PA-PND-245$\mathrm{C}_{3} \mathrm{H}_{7}$ and (2) PA-PND-61- $\mathrm{C}_{3} \mathrm{H}_{7}$ exist as free chains, (3) PA-PND-62- $\mathrm{C}_{12} \mathrm{H}_{25}$ forms micelles, (4) CA-PND-62- $\mathrm{C}_{12} \mathrm{H}_{25}$ forms micelles, and (5) CP-PND-62- $\mathrm{C}_{12} \mathrm{H}_{25}$ forms micelles. 
Linear Statistical poly(NIPAm-co-DMA) Control Polymers:

Five linear statistical copolymer controls were synthesized via RAFT polymerization with four different chain transfer agents. General polymerization procedure: DMA was filtered through basic alumina. NIPAm (140 mmol, 15.83g) and the respective chain transfer agent $(3.74 \mathrm{mmol}, 1.61 \mathrm{~g})$ was dissolved in 1,4-dioxane (200 mL, 1.0 M). DMA (60 mol, $6.314 \mathrm{~mL})$ was added along with AIBN (0.187 mmol, $30.7 \mathrm{mg})$. The solution was degassed with $\mathrm{N}_{2(\mathrm{~g})}$ for 30 minutes and stirred overnight at $70{ }^{\circ} \mathrm{C}$. The reaction was quenched in liquid nitrogen and opened to air. The polymer was either purified by precipitation in 60/40 Hexanes/Ethyl Ether three times to remove all monomer (1 and 2) or dialysis in methanol with a $1 \mathrm{kDa}(\mathbf{3 - 5})$ and dried in a vacuum oven. The polymers were characterized by ${ }^{1} \mathrm{H}$ NMR in $\mathrm{CDCl}_{3}$ and SEC-MALS in DMF with 0.05M LiBr. (procedures adapted from: Ting, J. M et al. ACS Cent. Sci. 2016, 2 (10), 748-755) ${ }^{3}$

Table S1. Summary of linear statistical copolymers 1-5 physical characterization

\begin{tabular}{|c|c|c|c|c|c|c|c|}
\hline \# & Control & $\begin{array}{c}\text { Composition } \\
\text { (N/D) }\end{array}$ & $\begin{array}{c}M_{\mathrm{n} . \mathrm{SEC}} \\
(\mathbf{k D a})\end{array}$ & $\begin{array}{c}M_{\mathrm{w}, \mathrm{SEC}} \\
(\mathbf{k D a})\end{array}$ & $\begin{array}{c}M_{\mathrm{n}, \mathrm{NMR}} \\
(\mathrm{kDDa})\end{array}$ & Đ & $T_{\text {cp }}\left({ }^{\circ} \mathrm{C}\right)$ \\
\hline 1 & Propionic acid-PND-245- $\mathrm{C}_{3} \mathrm{H}_{7}$ & $65 / 35$ & 27 & 30 & $31 *$ & 1.11 & 39 \\
\hline 2 & Propionic acid-PND-61- $\mathrm{C}_{3} \mathrm{H}_{7}$ & $66 / 34$ & 7.0 & 6.8 & $7.3 *$ & 1.03 & 44 \\
\hline 3 & Propionic acid-PND-62- $\mathrm{C}_{12} \mathrm{H}_{25}$ & $66 / 34$ & 7.0 & 7.2 & $7.1 * *$ & 1.02 & 50 \\
\hline 4 & Cyano-acid-PND-62- $\mathrm{C}_{12} \mathrm{H}_{25}$ & $66 / 34$ & 7.0 & 7.2 & $7.0 * *$ & 1.02 & 52 \\
\hline 5 & Cyano-propyl-PND-72- $\mathrm{C}_{12} \mathrm{H}_{25}$ & $64 / 36$ & 8.1 & 8.3 & $9.0 * *$ & 1.02 & 38 \\
\hline
\end{tabular}

*end-group analysis calibrated to $\mathrm{CH}_{2}$ at $3.35 \mathrm{ppm}$

**end-group analysis calibrated to $\mathrm{CH}_{3}$ at $0.87 \mathrm{ppm}$ 


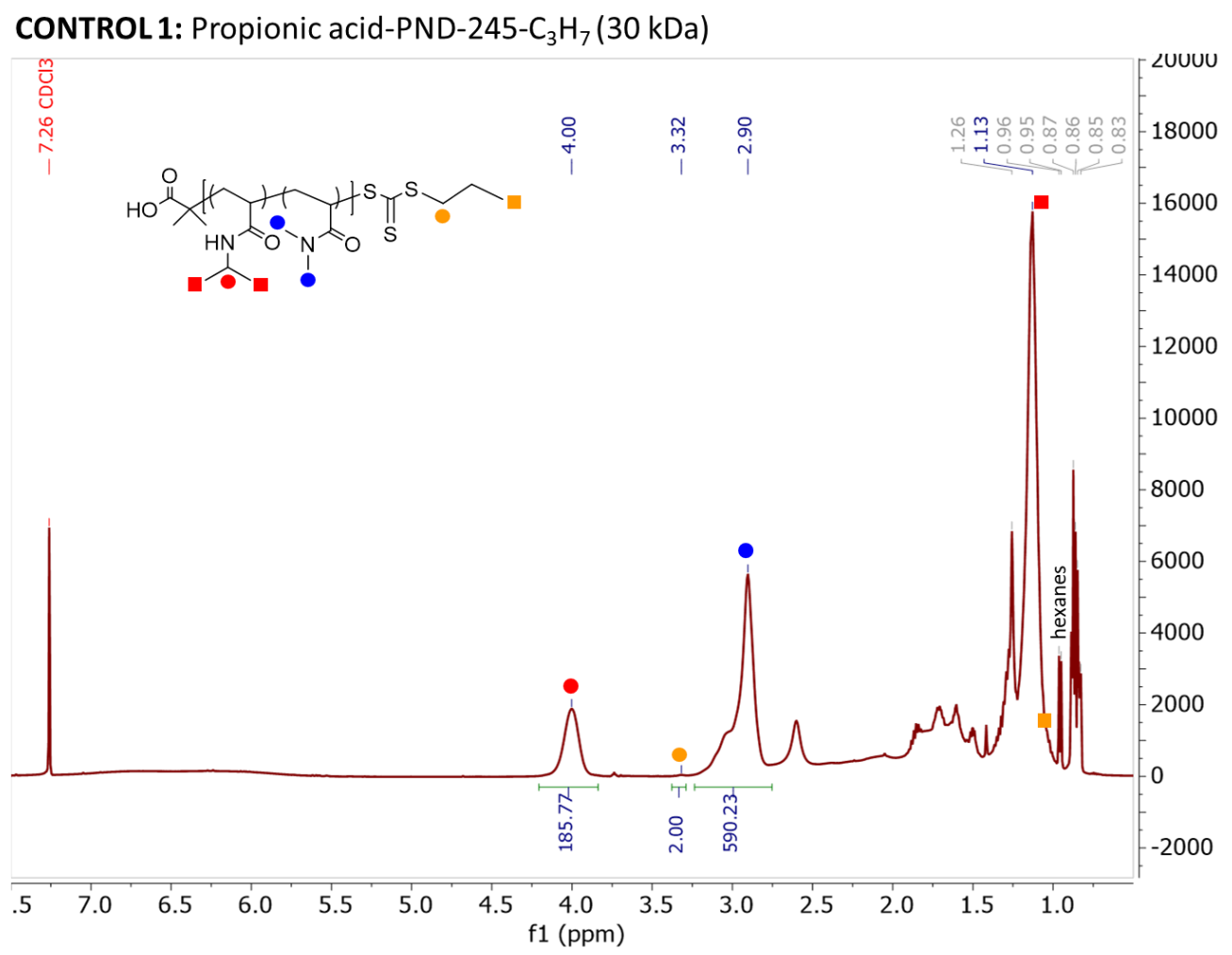

Figure S28. ${ }^{1} \mathrm{H}$ NMR in $\mathrm{CDCl}_{3}$ of propionic acid-245- $\mathrm{C}_{3} \mathrm{H}_{7}(\mathbf{1})$

CONTROL 2: Propionic acid-PND-61- $\mathrm{C}_{3} \mathrm{H}_{7}(7 \mathrm{kDa})$

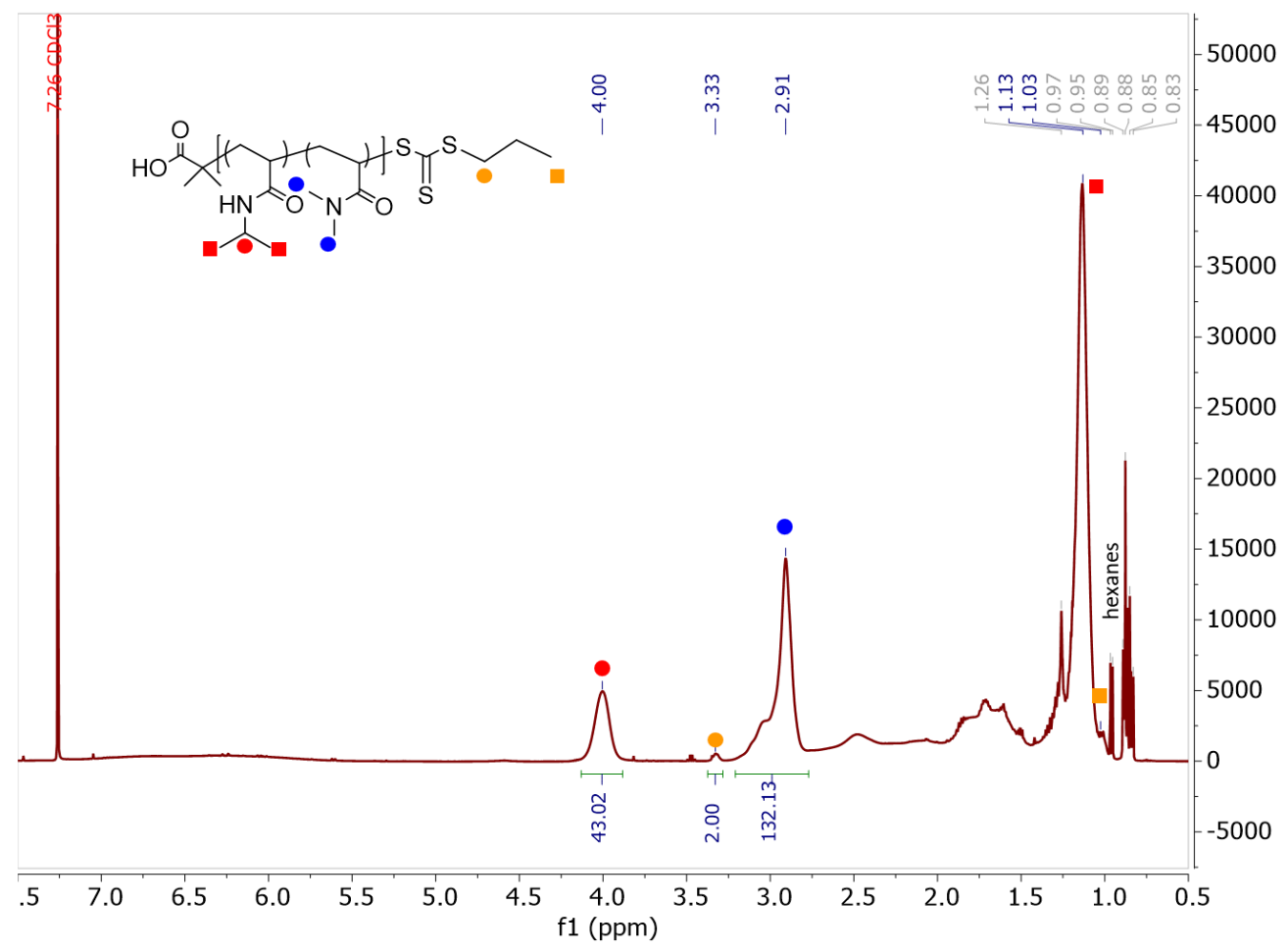

Figure S29. ${ }^{1} \mathrm{H} \mathrm{NMR}$ in $\mathrm{CDCl}_{3}$ of propionic acid-61- $\mathrm{C}_{3} \mathrm{H}_{7}(2)$ 


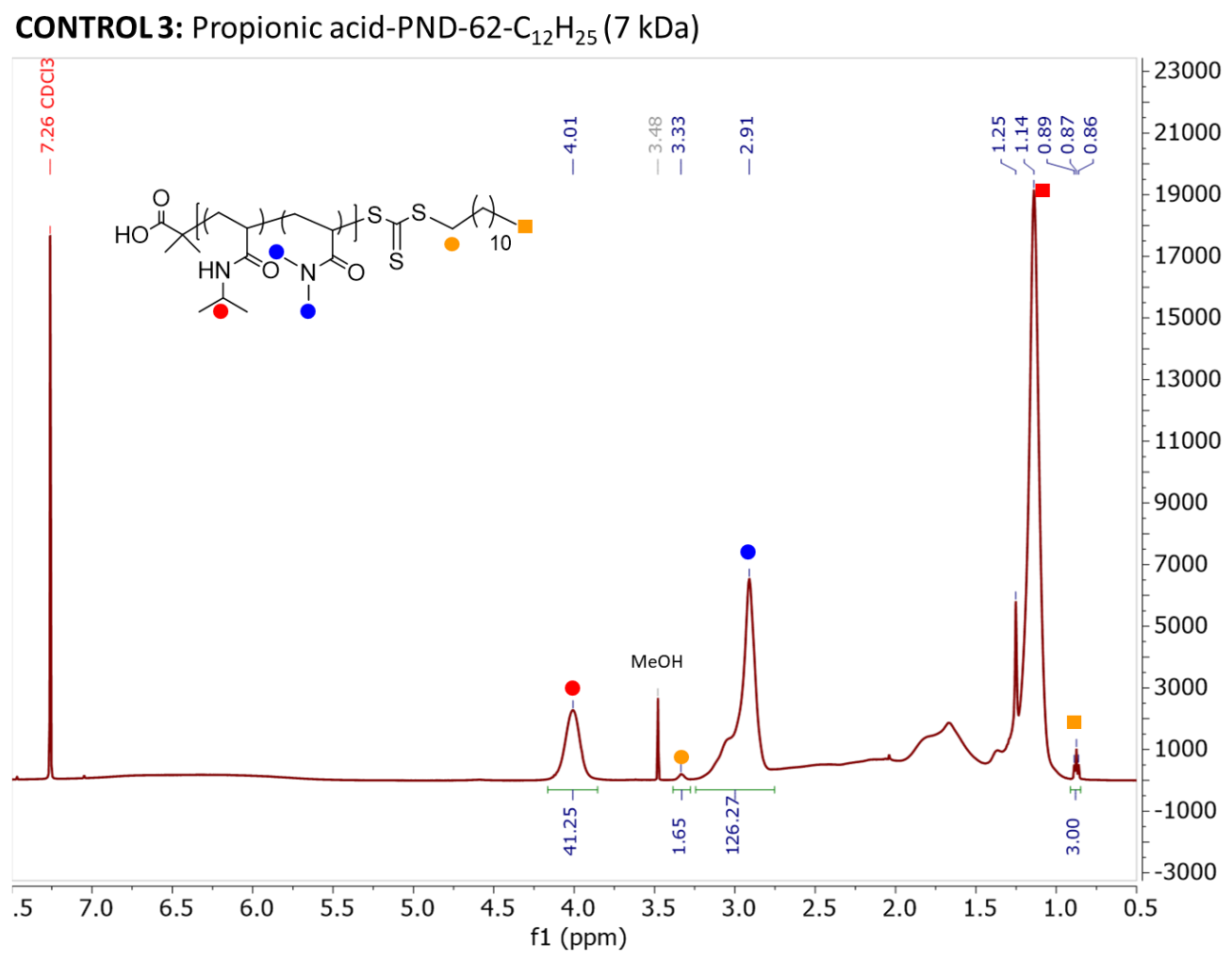

Figure S30. ${ }^{1} \mathrm{H}$ NMR in $\mathrm{CDCl}_{3}$ of propionic acid-62- $\mathrm{C}_{12} \mathrm{H}_{25}(3)$

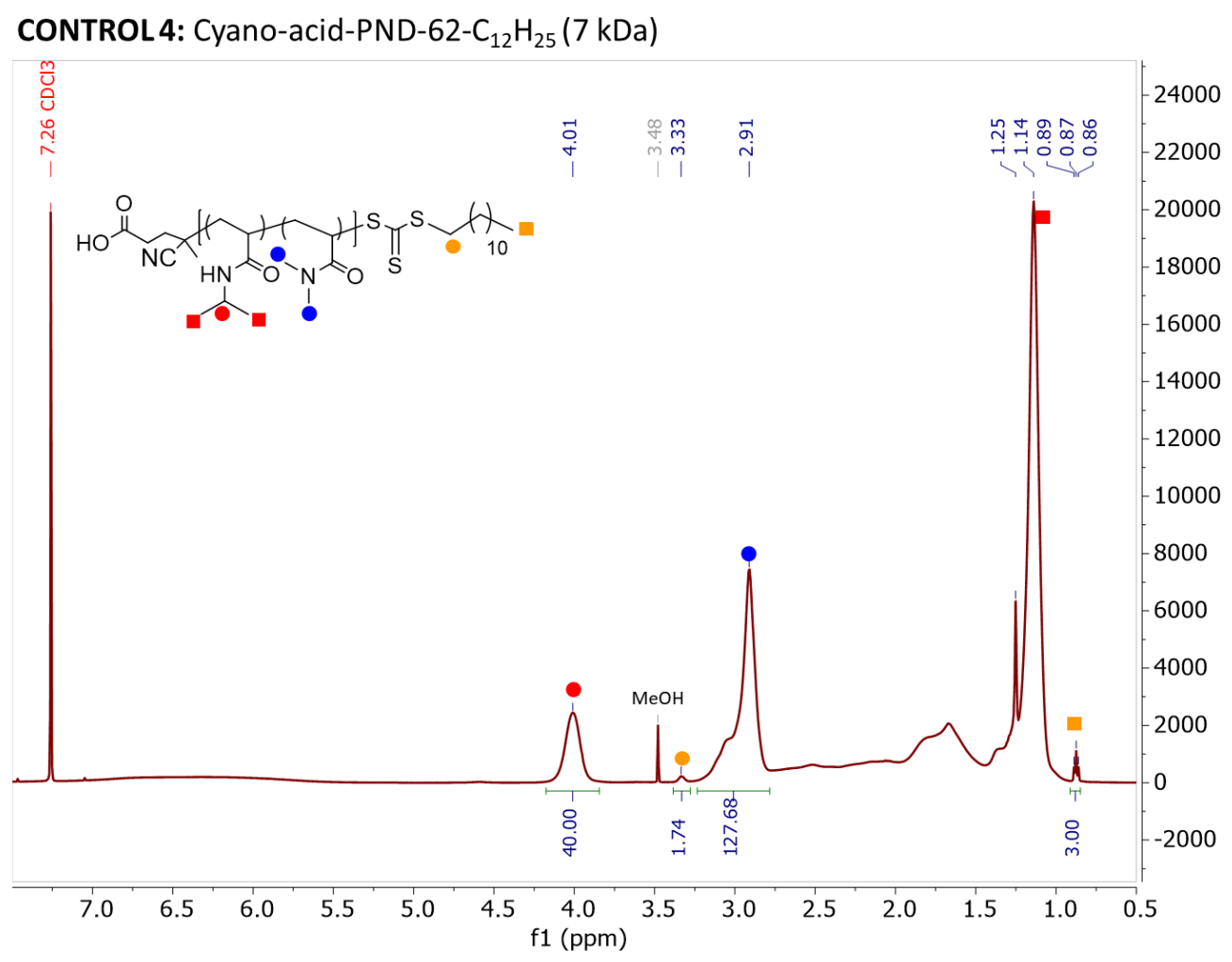

Figure S31. ${ }^{1} \mathrm{H}$ NMR in $\mathrm{CDCl}_{3}$ of cyano-acid-62- $\mathrm{C}_{12} \mathrm{H}_{25}$ (4) 


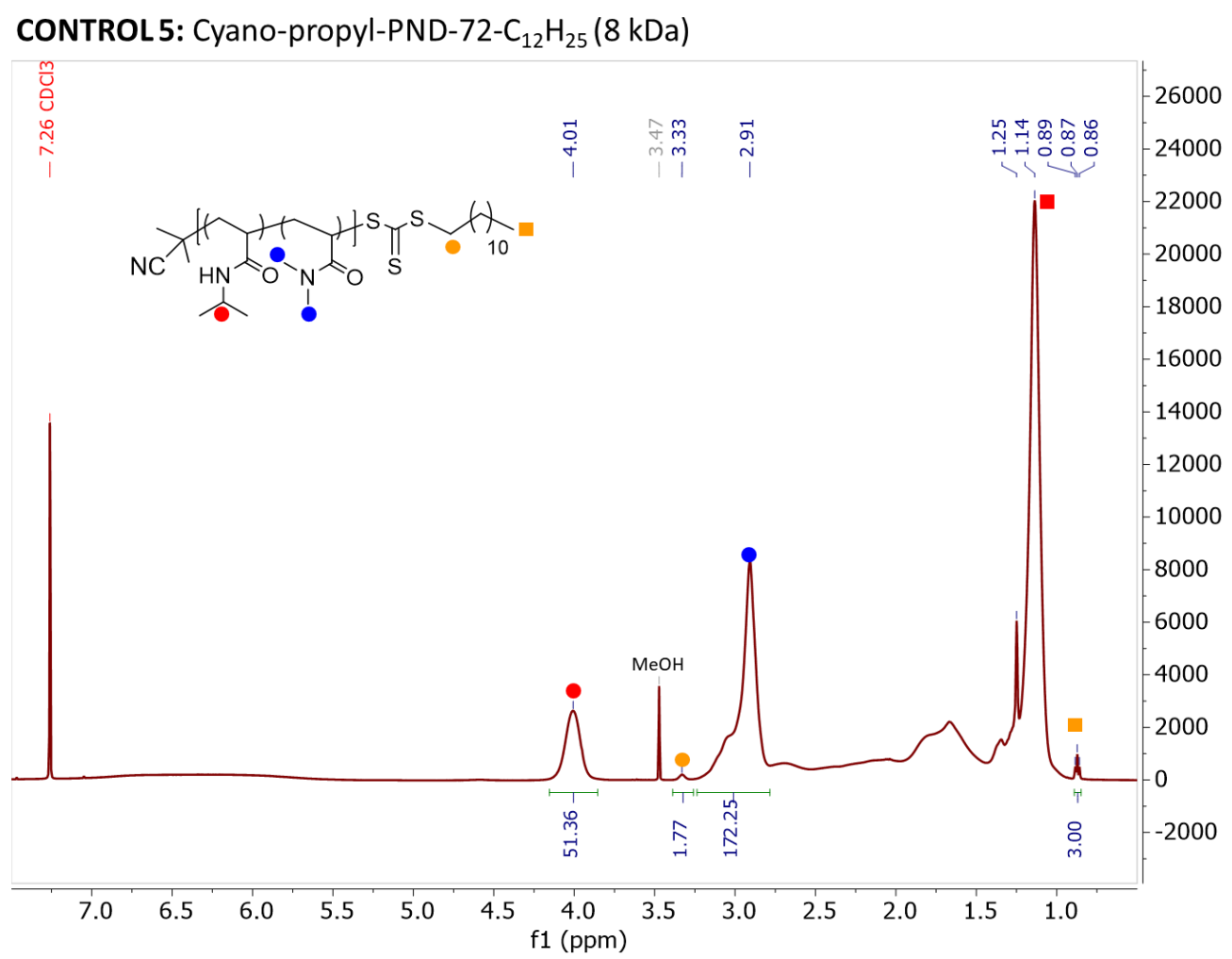

Figure S32. ${ }^{1} \mathrm{H}$ NMR in $\mathrm{CDCl}_{3}$ of cyano-propyl-72- $\mathrm{C}_{12} \mathrm{H}_{25}(\mathbf{5})$
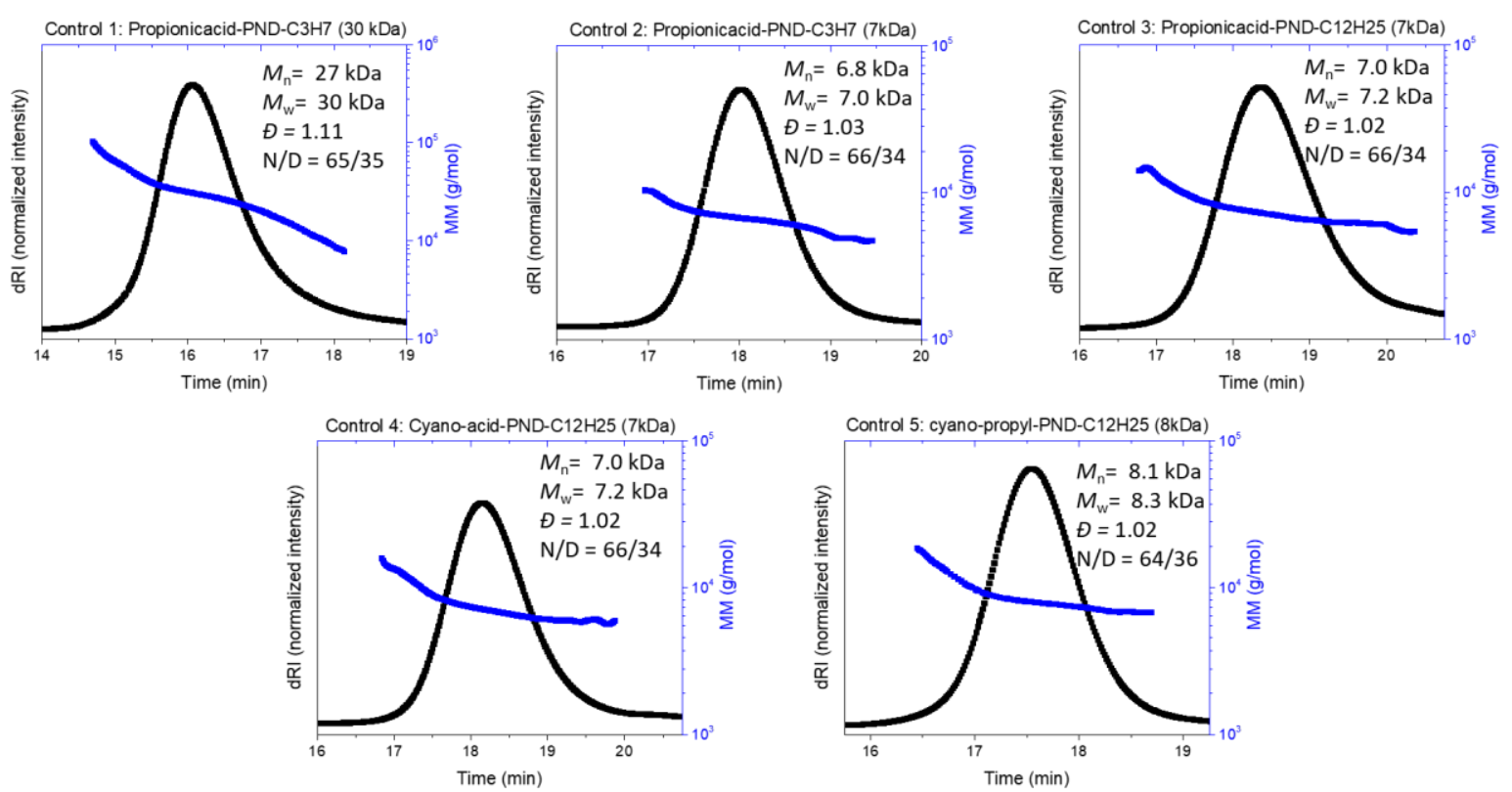

Figure S33. SEC-MALS RI traces (DMF with 0.05M LiBr) with MW overlay 


\section{Solution Characterization:}

\section{Cloud Point Measurements:}

Polymers were dissolved at $9 \mathrm{mg} / \mathrm{mL}$ in PBS pH 6.5 and filtered into glass ampules. The samples were heated at an approximate rate of $0.25 \mathrm{C} / \mathrm{min}$ from room temperature to 50 or $60{ }^{\circ} \mathrm{C}$. The optical transmittance of a $30 \mathrm{~mW} 633 \mathrm{~nm}$ HeNe laser was recorded on a Spex Industries Laser Power Meter 1448 photometer (Metuchen, NJ) upon heating and cooling. The cloud point was defined as when the transmittance dropped below $80 \%$ from the normalized transmittance at room temperature.
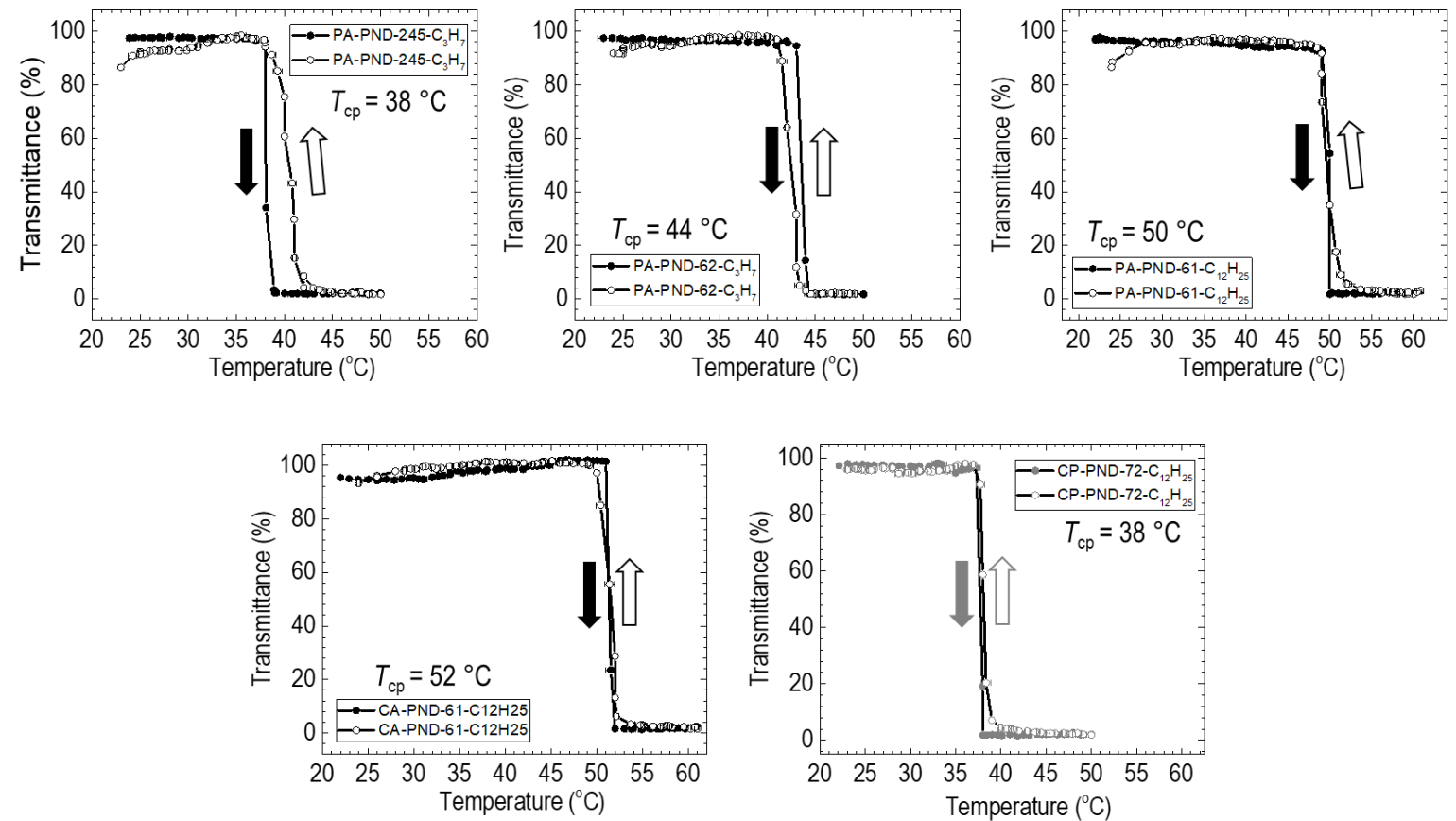

Figure S34. Transmission data upon heating (closed dots) and cooling (open dots) of linear control copolymers $1-5$ in PBS pH 6.5 at $9.0 \mathrm{mg} / \mathrm{mL}$. 

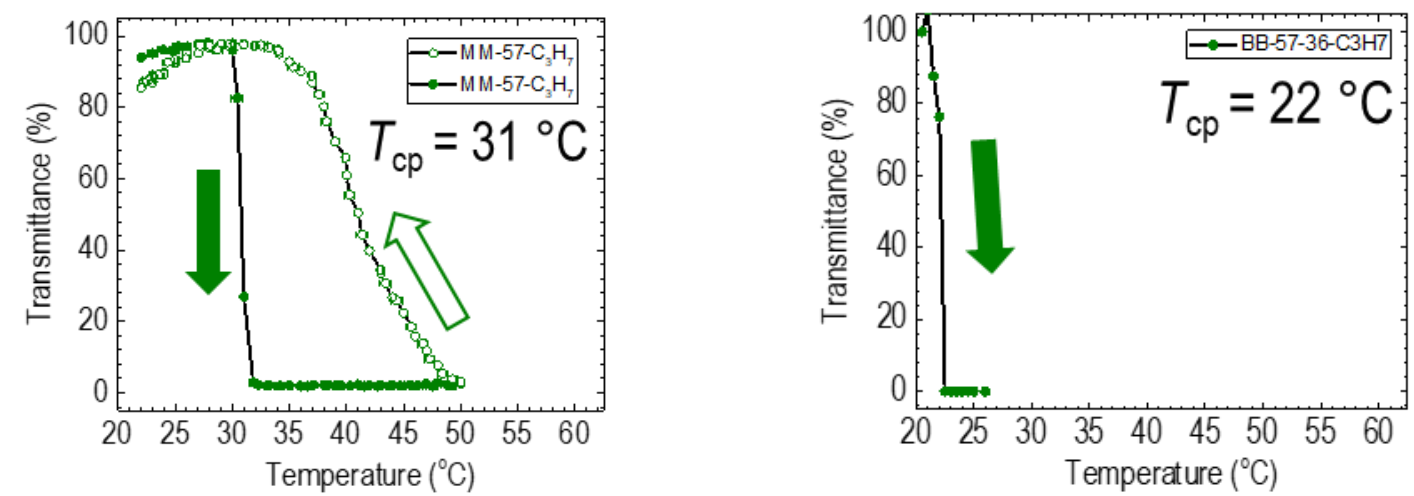

Figure S35. Transmission data upon heating (closed dots) and cooling (open dots) of linear control copolymers 1-5 in PBS pH 6.5 at $9.0 \mathrm{mg} / \mathrm{mL}$.
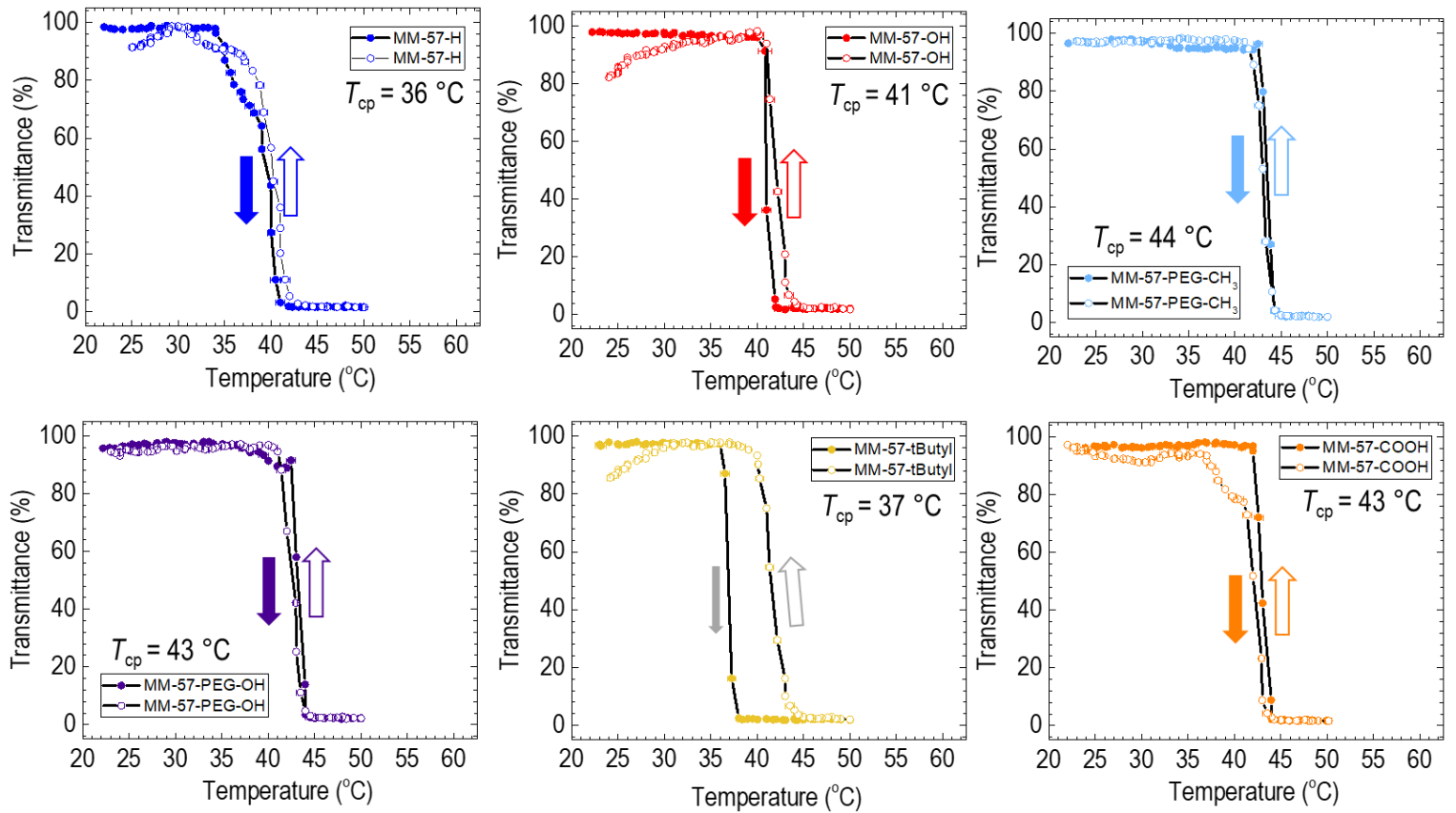

Figure S36. Transmission data upon heating (closed dots) and cooling (open dots) of all end-group modified MM-57-Z in PBS pH 6.5 at $9.0 \mathrm{mg} / \mathrm{mL}$. 

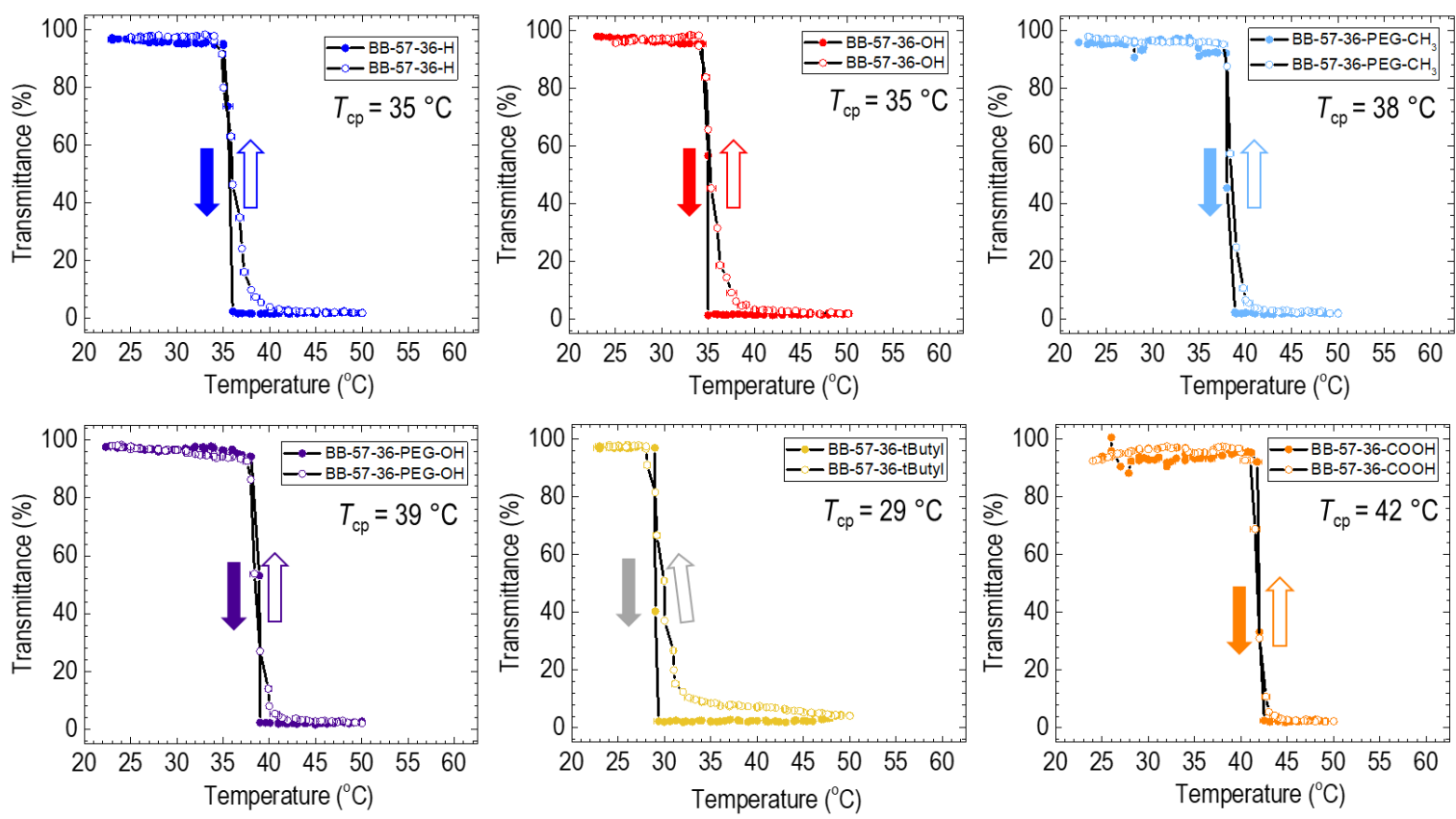

Figure S37. Transmission data upon heating (closed dots) and cooling (open dots) of all end-group modified BB-57-36-Z in PBS pH 6.5 at $9.0 \mathrm{mg} / \mathrm{mL}$ 
Dynamic Light Scattering:

The hydrodynamic radius of each Control, $\mathrm{MM}$, and $\mathrm{BB}$ were measured at $9 \mathrm{mg} / \mathrm{mL}$ in $\mathrm{PBS}(\mathrm{pH}$ 6.5) at 25 and $37^{\circ} \mathrm{C}$ using a high-throughput plate reader DLS (DynaPro Plate Reader DLS, Wyatt Technologies, Santa Barbara, CA). Each $R_{\mathrm{h}}$ distribution was calculated using Regularization (a non-negative least squares fitting algorithm - defined by Wyatt Technology) of the correlation function and the results are summarized in Table S2.

Table S2. Summary of dynamic light scattering results of Control's, MM-57-X, and BB-57-36-X.

\begin{tabular}{|c|c|c|c|c|}
\hline Sample & $\begin{array}{c}\boldsymbol{R}_{\mathbf{h}, \mathbf{2 5}}{ }^{\circ} \mathbf{C} \\
9 \mathrm{mg} / \mathrm{mL} \\
(\mathrm{nm})\end{array}$ & PDI & $\begin{array}{c}\boldsymbol{R}_{\mathbf{h}, \mathbf{3 7}}{ }^{\circ} \mathbf{C} \\
9 \underset{(\mathrm{mg} / \mathrm{mL})}{(\mathrm{nm})}\end{array}$ & PDI \\
\hline 1 Propionic acid-PND-245- $\mathrm{C}_{3} \mathrm{H}_{7}$ & $5.5,34.0$ & $0.29,0.22$ & $5.5,25.1$ & $0.23,0.23$ \\
\hline 2 Propionic acid-PND-61- $\mathrm{C}_{3} \mathrm{H}_{7}$ & 2.5 & 0.18 & 2.2 & 0.12 \\
\hline 3 Propionic acid-PND-62- $\mathrm{C}_{12} \mathrm{H}_{25}$ & 7.4 & 0.16 & 7.5 & 0.12 \\
\hline 4 Cyano-acid-PND-62- $\mathrm{C}_{12} \mathrm{H}_{25}$ & 7.2 & 0.12 & 7.5 & 0.12 \\
\hline 5 Cyano-propyl-PND-245- $\mathrm{C}_{12} \mathrm{H}_{25}$ & 7.9 & 0.04 & 8.7 & 0.11 \\
\hline $\mathrm{MM}-57-\mathrm{C}_{3} \mathrm{H}_{7}$ & 1.6 & 0.11 & turbid & turbid \\
\hline BB-57-36- $\mathrm{C}_{3} \mathrm{H}_{7}$ & $8.8^{*}$ & $0.20 *$ & turbid & turbid \\
\hline MM-57-H & $2.7,11.7$ & $0.29,0.22$ & turbid & turbid \\
\hline BB-57-36-H & 10.5 & 0.25 & turbid & turbid \\
\hline MM-57-OH & 2.6 & 0.31 & $2.4,71$ & $0.18,0.14$ \\
\hline BB-57-36-OH & 10.6 & 0.19 & turbid & turbid \\
\hline MM-57-PEG-CH 3 & 2.5 & 0.17 & $2.5,46$ & $0.16,0.09$ \\
\hline BB-57-36-PEG-CH & 10.5 & 0.15 & 10.8 & 0.19 \\
\hline MM-57-PEG-OH & $2.3,47.6$ & $0.06,0.11$ & $2.8,140$ & $0.33,0.30$ \\
\hline BB-57-36-PEG-OH & 10.5 & 0.32 & 11.0 & 0.29 \\
\hline MM-57-tButyl & 2.2 & 0.22 & $2.4,67$ & $0.19,0.15$ \\
\hline BB-57-36- $t$ Butyl & 10.8 & 0.13 & turbid & turbid \\
\hline MM-57-COOH & $2.4^{\ddagger}$ & 0.34 & $2.4,99.6^{+}$ & - \\
\hline BB-57-36-COOH & 10.0 & 0.20 & 10.8 & 0.20 \\
\hline
\end{tabular}

*measured at $20^{\circ} \mathrm{C},{ }^{\dagger}$ radius distribution calculated using REPES at $90^{\circ}$ 


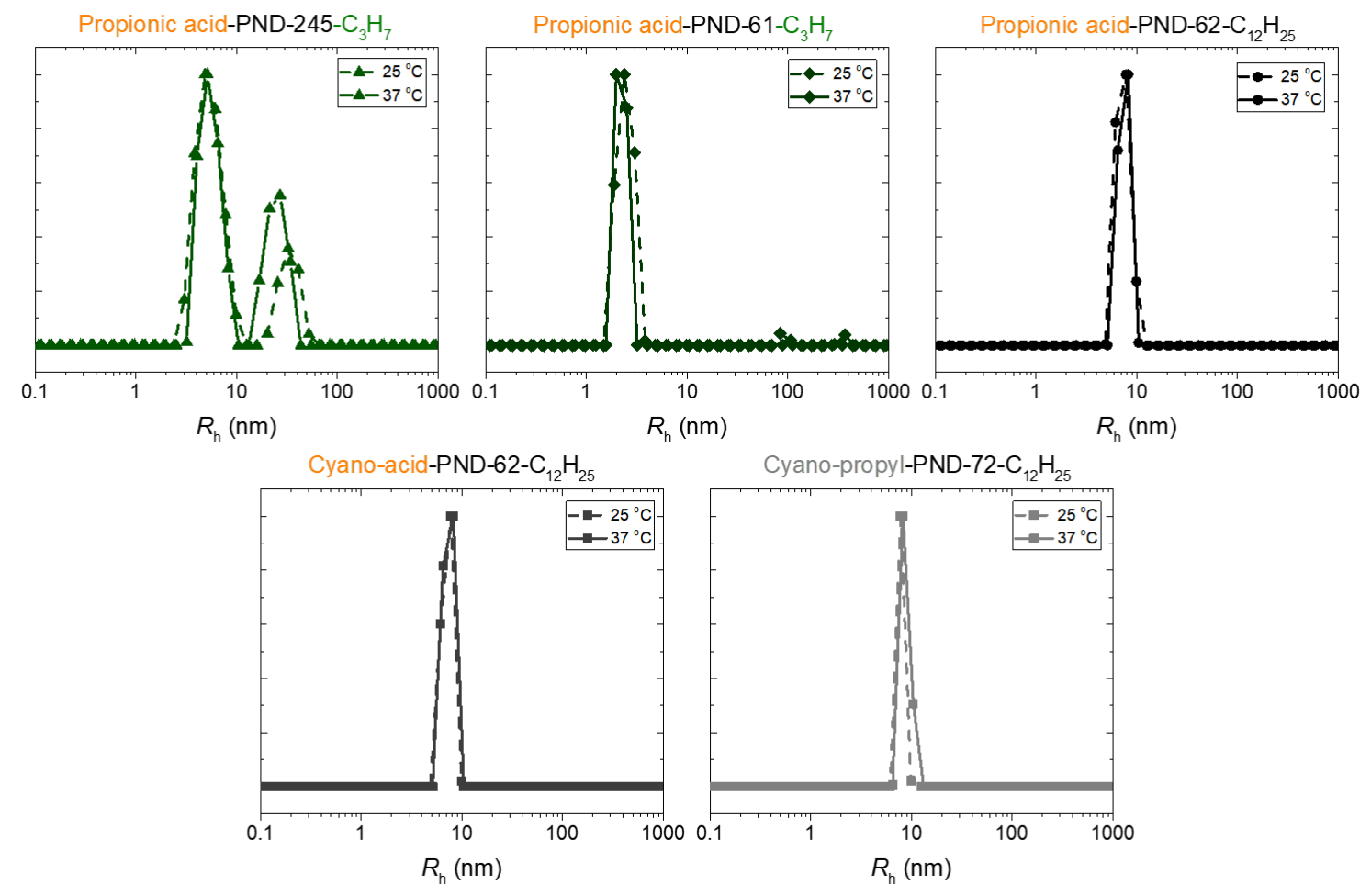

Figure S38. Summary of $R_{\mathrm{h}}$ distributions for Controls 1-5 fit using a regularization fit. Samples are $9 \mathrm{mg} / \mathrm{mL}$ in PBS (pH 6.5) measured at both 25 and $37^{\circ} \mathrm{C}$.
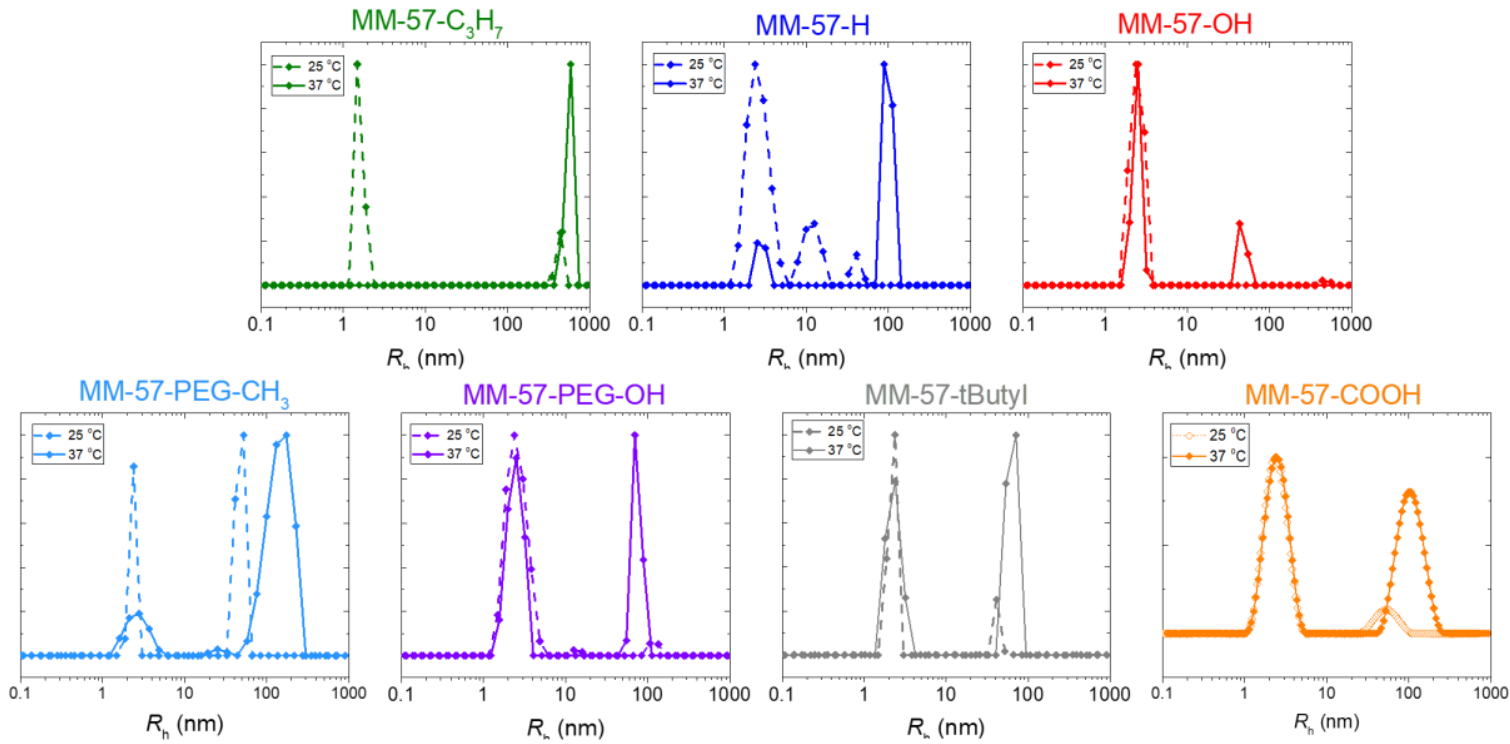

Figure S39. Summary of MM-57-Z $R_{\mathrm{h}}$ distributions fit using a regularization fit. Samples are 9 $\mathrm{mg} / \mathrm{mL}$ in PBS (pH 6.5) measured at both 25 and $37{ }^{\circ} \mathrm{C}$. 

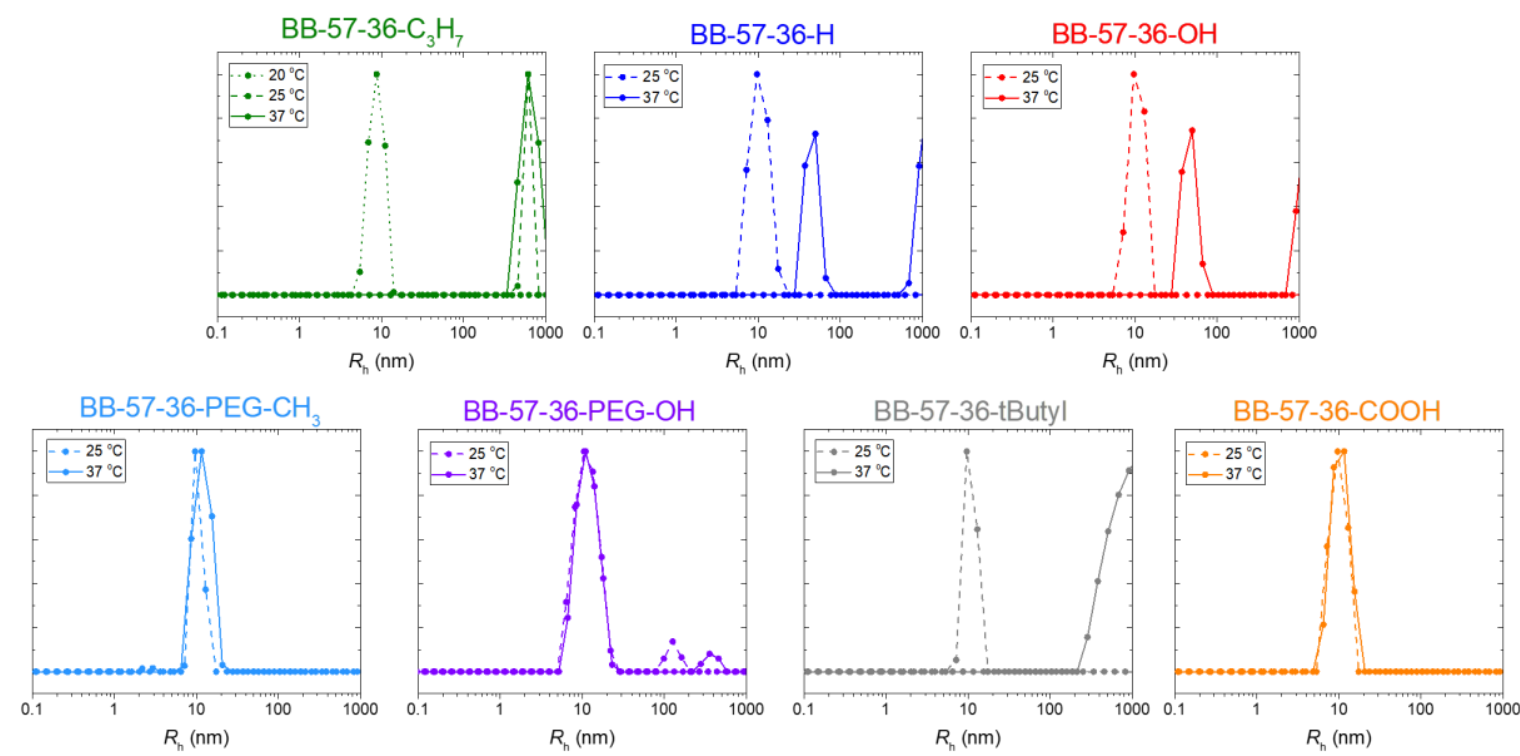

Figure S40. Summary of $R_{\mathrm{h}}$ distributions for BB-57-36-Z fit using a regularization fit. Samples are $9 \mathrm{mg} / \mathrm{mL}$ in PBS (pH 6.5) measured at both 25 and $37^{\circ} \mathrm{C}$. 
Extra Discussion - End-Groups Dictate Solution Properties:

At $25^{\circ} \mathrm{C}$, linear copolymer controls 1 and 2 (Figure S41A) exist as free chains in solution similar to MM-57- $\mathrm{C}_{3} \mathrm{H}_{7}$ (Figure S39). An aggregated population was observed in sample $\mathbf{1}$ and attributed to the fact that the molecular weight of $\mathbf{1}$ was four-fold greater than $\mathbf{2}-\mathbf{5}$. As expected, linear copolymer controls $\mathbf{3}, \mathbf{4}$, and 5 all formed micelles with hydrodynamic radii $R_{\mathrm{h}}=7-8 \mathrm{~nm}$ at both 25 and $37^{\circ} \mathrm{C}$ due to the dodecyl hydrocarbon Z-groups (Figure S41A-B). MM-57-COOH readily dissolved in the aqueous media by visual assessment but DLS revealed a mixture of free chains $R_{\mathrm{h}}=2.3 \mathrm{~nm}$ and an aggregated population with $R_{\mathrm{h}} \approx 60 \mathrm{~nm}$ (Figure $\mathrm{S} 39$ ).

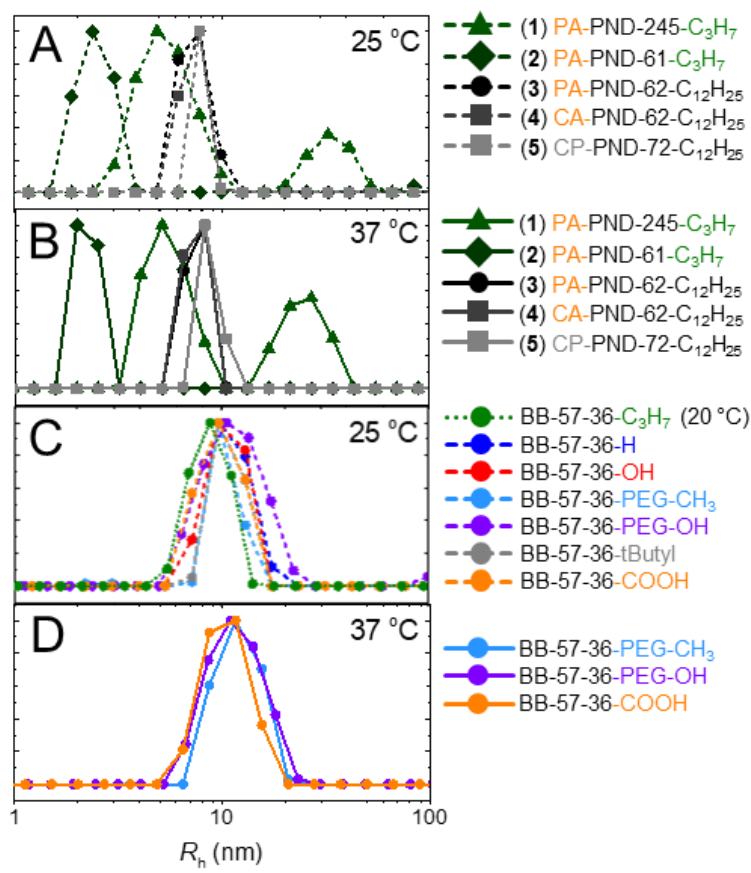

Figure S41. Dynamic light scattering $R_{\mathrm{h}}$ distributions of $9 \mathrm{mg} / \mathrm{mL}$ solutions in PBS $\mathrm{pH} 6.5$ of (A) linear copolymer controls 1 through 5 at $25{ }^{\circ} \mathrm{C}$, (B) linear copolymer controls at $37{ }^{\circ} \mathrm{C}$, (C) endgroup modified BB-57-36-Z at $25^{\circ} \mathrm{C}$, and (D) end-group modified BB-47-36-Z at $37{ }^{\circ} \mathrm{C}$. Note: BB-57-36- $\mathrm{C}_{3} \mathrm{H}_{7}$ was taken at $20{ }^{\circ} \mathrm{C}$ so that the $R_{\mathrm{h}}$ of the sample could be measured below the $T_{\text {cp. }}$ 
Each linear polymer control and bottlebrush polymer are composed of approximately 65 mol \% NIPAm and 35 mol \% DMA. The incorporation of DMA ensures the $T_{\mathrm{cp}}$ of the linear controls remains above body temperature despite end-group functionality or molecular weight. The $T_{\mathrm{cp}}$ of linear control 1 was measured $\left(9 \mathrm{mg} / \mathrm{mL}\right.$ in PBS, pH 6.5) to be $39{ }^{\circ} \mathrm{C} . T_{\mathrm{cp}}$ in NIPAm containing polymers is known to increase as molecular weight decreases. Therefore, from control $1(31 \mathrm{kDa})$ to control $2(7.3 \mathrm{kDa})$, keeping composition and end-groups constant, the $T_{\mathrm{cp}}$ increased by $5{ }^{\circ} \mathrm{C}$, from 39 to $44{ }^{\circ} \mathrm{C}$, respectively. Previous work has revealed that the addition of hydrophobic end-groups decreases the $T_{\mathrm{cp}}$ of linear NIPAm/DMA copolymers. ${ }^{4}$ Therefore, in the case of MM-57- $\mathrm{C}_{3} \mathrm{H}_{7}$, the addition of a ROMP-active exo-imide norbornene R-group moiety in comparison to the propionic acid R-group of control 2, keeping molecular weight, composition, and Z-group the same, resulted in a substantial drop in $T_{\mathrm{cp}}$ of $13{ }^{\circ} \mathrm{C}$, from 44 to $31{ }^{\circ} \mathrm{C}$, respectively (Figure S42). We speculated that the $T_{\mathrm{cp}}$ of the MM could be recovered while keeping ROMPactive R-group by modifying the Z-group to be a carboxylic acid. This hypothesis was confirmed based on the measured value $T_{\mathrm{cp}}=43{ }^{\circ} \mathrm{C}$ for $\mathrm{MM}-57-\mathrm{COOH}$, similar to control 2. The major populations of controls 1-2, MM-57- $\mathrm{C}_{3} \mathrm{H}_{7}$, and $\mathrm{MM}-57-\mathrm{COOH}$ are free chains in solution, as shown above.

Micellization of controls 3-5 in solution, driven by the hydrophobic dodecyl hydrocarbon Z-groups, concentrates the R-groups of the polymers at the surface of each self-assembled micelle. The resulting increase in the micelle surface area-to-volume ratio enhanced the hydrophilic contributions of the carboxylic acid moieties on controls $\mathbf{3}$ and 4 . Therefore, when compared to control $2\left(T_{\mathrm{cp}}=44^{\circ} \mathrm{C}\right)$, the $T_{\mathrm{cp}}$ in PBS (pH 6.5) of controls 3 and 4 increased by 6 and $7{ }^{\circ} \mathrm{C}$ to 50 and $51{ }^{\circ} \mathrm{C}$, respectively. In contrast, for control 5, where the carboxylic acid R-group was removed, $T_{\mathrm{cp}}$ decreased to $38{ }^{\circ} \mathrm{C}$. The difference in $T_{\mathrm{cp}}$ between controls 4 and $\mathbf{5}$ of $13{ }^{\circ} \mathrm{C}$ mimics the suppression in $T_{\mathrm{cp}}$ observed when comparing control 2 and MM-57- $\mathrm{C}_{3} \mathrm{H}_{7}$. Therefore, the presence and or absence of a single carboxylic acid moiety at either terminus of a linear NIPAm containing copolymer can modulate the $T_{\mathrm{cp}}$. 


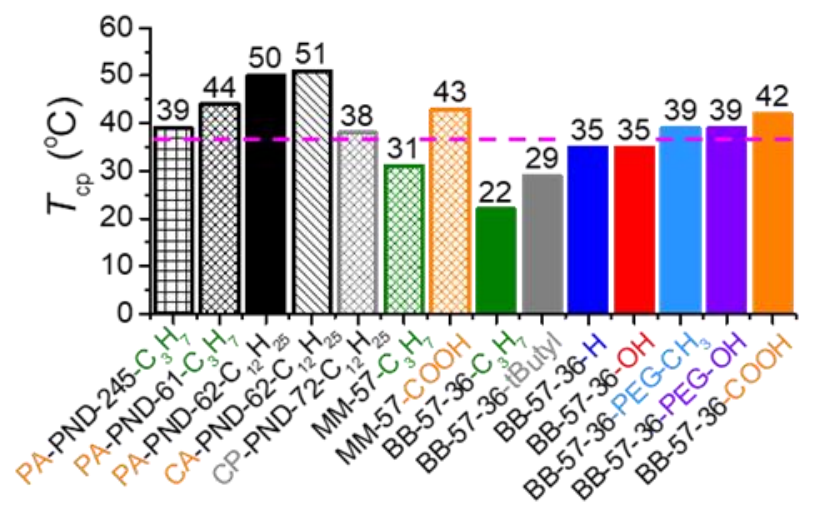

Figure S42. Summary of the $T_{\mathrm{cp}}$ for end-group modified linear polymers, MM, and BB determined by transmittance measurements. The pink, horizontal dotted line indicates $37^{\circ} \mathrm{C}$. 
Multiangle Dynamic Light Scattering:

DLS measurements were performed on an in-house photometer $(30 \mathrm{~mW}$ laser power, avalanche photodiode detector with a $200 \mu \mathrm{m}$ pinhole) over a range of angles $\left(60-120^{\circ}\right)$ with a Brookhaven BI-200SM goniometer and a Brookhaven BI-9000AT correlator at $\lambda=637 \mathrm{~nm}$ at $25{ }^{\circ} \mathrm{C}$. The dispersity of particle size was quantified by the either the second or third cumulant $\mu_{2} / \Gamma^{2}$ with $\Gamma$ being the mean decay rate of first-order scattering autocorrelation. The size distribution was also assessed through the REPES Laplace inversion routine. ${ }^{5}$

Table S3. Summary of solution characterization with multi-angle dynamic light scattering.

\begin{tabular}{lcccc} 
Sample & $\begin{array}{c}\boldsymbol{R}_{\mathbf{h}, 25}{ }^{\circ} \mathbf{C} \\
2^{\text {nd }} \text { cumulant } \\
(\mathrm{nm})\end{array}$ & $\boldsymbol{\mu}_{\mathbf{2}} / \boldsymbol{\Gamma}^{\mathbf{2}}$ & $\begin{array}{c}\boldsymbol{R}_{\mathbf{h}, 25}{ }^{\circ} \mathbf{C} \\
\text { REPES } \\
(\mathbf{n m})\end{array}$ & $\begin{array}{c}\text { Density } \\
(\mathbf{m g} / \mathbf{m L})\end{array}$ \\
\hline 3 PA-PND-62-C ${ }_{12} \mathrm{H}_{25}$ & $7.0^{\dagger}$ & $0.21^{\dagger}$ & 7.4 & $74^{\mathrm{a}}$ \\
\hline BB-57-36-C $\mathrm{C}_{3} \mathrm{H}_{7}$ & $9.5^{*}$ & $0.11^{*}$ & $10.1^{*}$ & $105^{*}$ \\
\hline BB-57-36-H & 9.6 & 0.07 & 9.7 & 101 \\
\hline BB-57-36-OH & 10.0 & 0.09 & 10.7 & 91 \\
\hline BB-57-36-PEG-CH $H_{3}$ & 10.0 & 0.07 & 10.7 & 89 \\
\hline BB-57-36-PEG-OH & 9.7 & 0.13 & 10.0 & 99 \\
\hline BB-57-36-tButyl & 9.6 & 0.07 & 9.8 & 100 \\
\hline BB-57-36-COOH & 9.8 & 0.08 & 10.3 & 96 \\
\hline
\end{tabular}

${ }^{\dagger}$ Third cumulant analysis, ${ }^{*}$ measured at $20^{\circ} \mathrm{C}$, aestimated from literature precident ${ }^{6}$
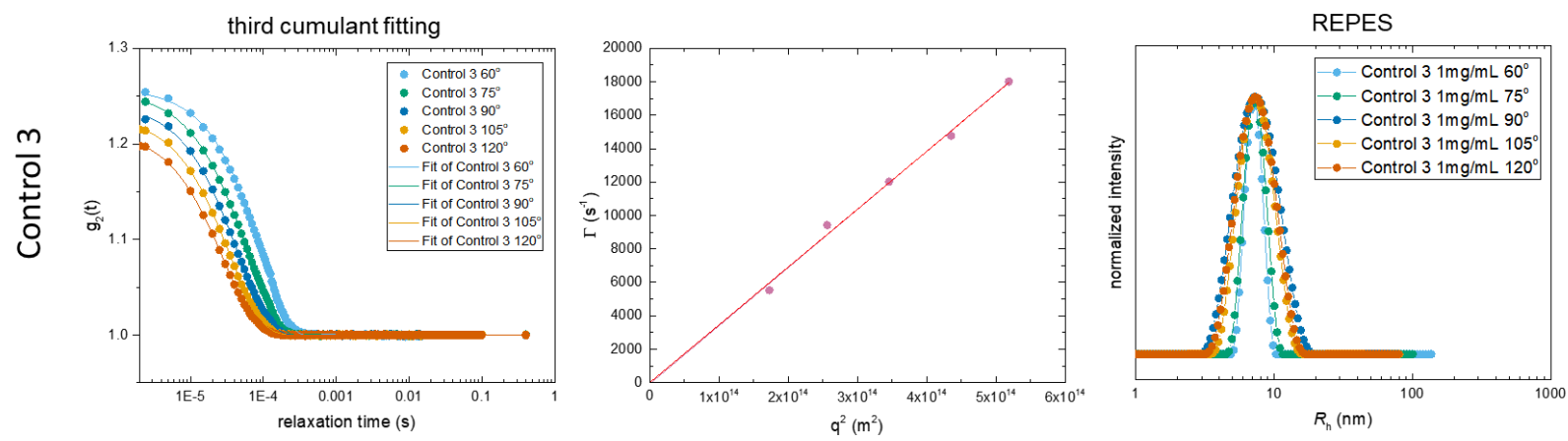

Figure S43. Third cumulant fit for the autocorrelation functions for control 3 measured at 60, 75, 90,105 , and $120^{\circ}$ at $25^{\circ} \mathrm{C}$ at $1 \mathrm{mg} / \mathrm{mL}$ in PBS (pH 6.5). Each fit is shown along with the $\Gamma$ vs. $\mathrm{q}^{2}$ plot and overlay of all REPES distributions over the multiple angles. 

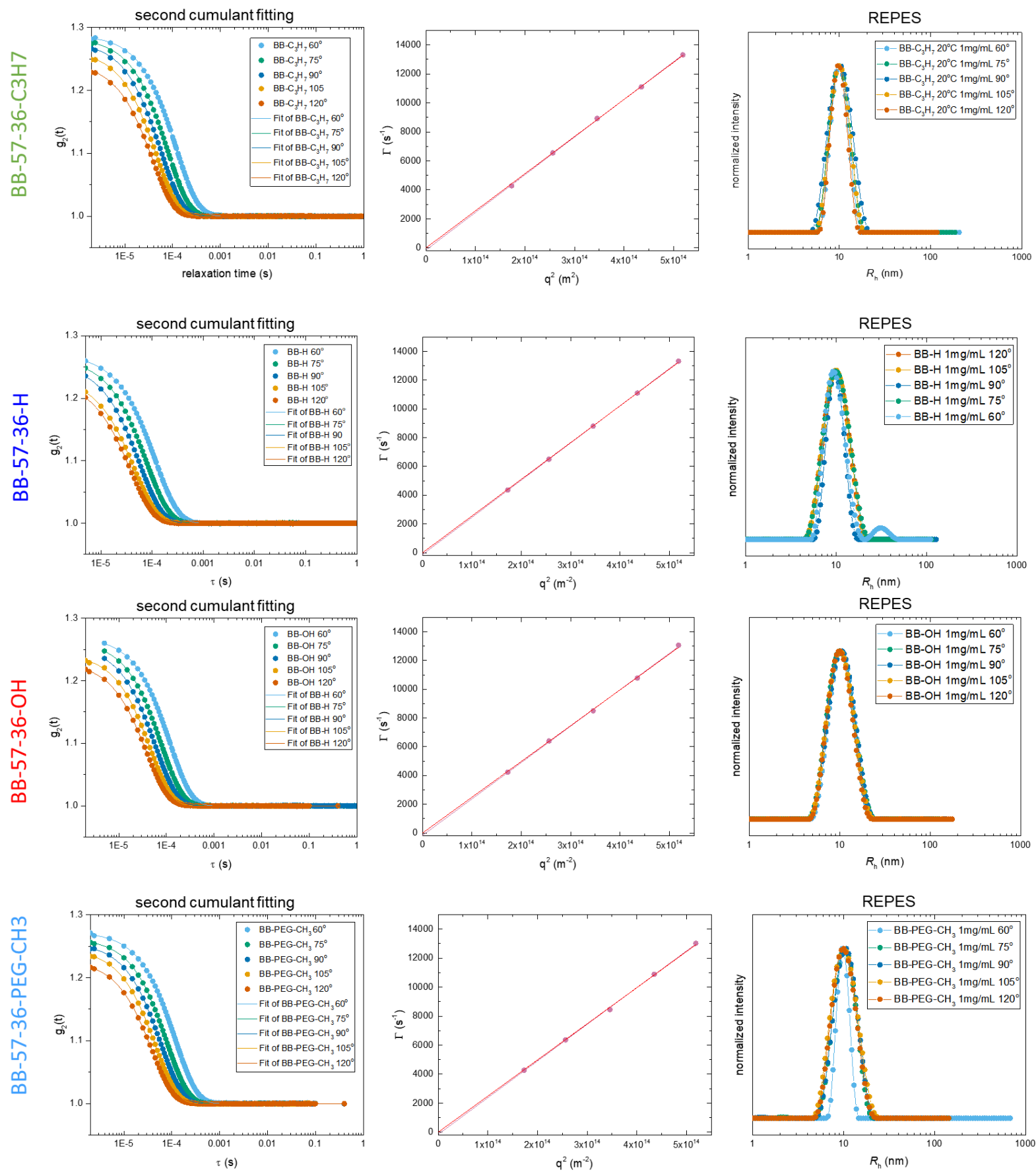

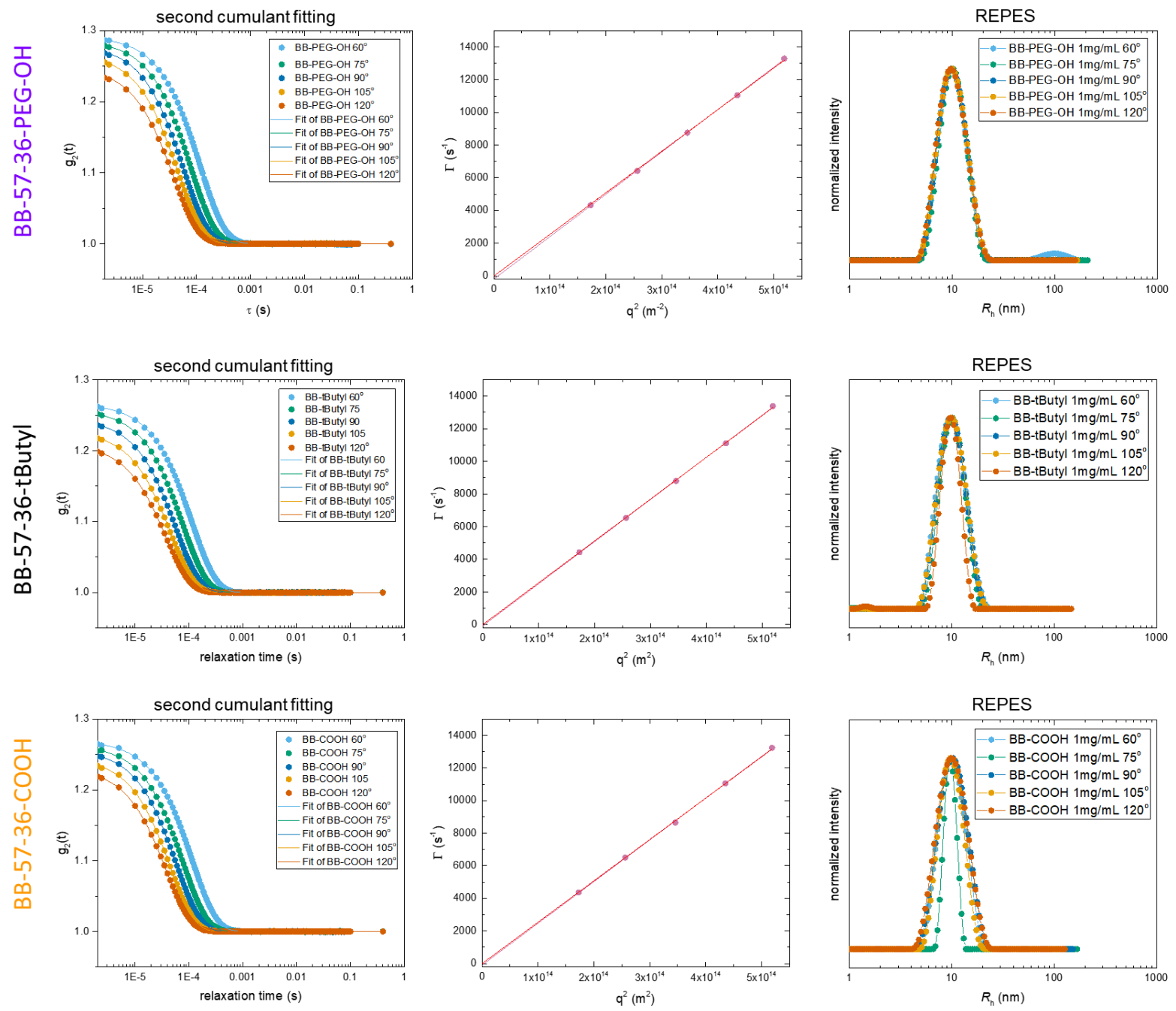

Figure S44. Second cumulant fits for BB-57-36- $\mathrm{C}_{3} \mathrm{H}_{7},-\mathrm{H}$, -OH, -PEG-CH 3 , -PEG-OH, - $t$ Butyl, and $-\mathrm{COOH}$ measured at $60,75,90,105$, and $120^{\circ}$ at $25^{\circ} \mathrm{C}$ at $1 \mathrm{mg} / \mathrm{mL}$ in PBS (pH 6.5). Each fit is shown along with the $\Gamma$ vs. $\mathrm{q}^{2}$ plot and overlay of all REPES distributions over the multiple angles. 
Static Light Scattering (SLS):

Solutions for SLS were prepared by serial dilutions of the polymers in filtered PBS with a pH 6.5. The $d n / d c$ values for each polymer in PBS with a pH 6.5 were measured and are recorded in Table S4. Scattering measurements were collected using the same in-house instrument described in Multiangle Dynamic Light Scattering. Zimm analysis was used to calculate the molar mass $\left(M_{\mathrm{w}}\right)$, second virial coefficient $\left(A_{2}\right)$, and radius of gyration $\left(R_{\mathrm{g}}\right)$.

Table S4: Summary of Zimm Plot Results

\begin{tabular}{lcccccc} 
Sample & $\begin{array}{c}\mathbf{d n} / \mathbf{d c} \\
(\mathrm{mL} / \mathrm{g})\end{array}$ & $\begin{array}{c}\boldsymbol{M}_{\mathbf{w}} \\
(\mathrm{kDa})\end{array}$ & $\boldsymbol{N}_{\mathbf{b b}}$ & $\begin{array}{c}\boldsymbol{A}_{\mathbf{2}} \\
\left(\times 10^{-5} \mathrm{~mol} \mathrm{~cm}^{3} / \mathrm{g}^{2}\right)\end{array}$ & $\begin{array}{c}\boldsymbol{R}_{\mathbf{g}, \mathbf{2 5}}{ }^{\circ} \mathbf{C} \\
(\mathrm{nm})\end{array}$ & $\boldsymbol{R}_{\mathbf{g}} / \boldsymbol{R}_{\mathbf{h}, \mathbf{2 5}}{ }^{\circ} \mathbf{C}$ \\
\hline BB-57-36-PEG-CH & $0.18 \pm 0.01$ & 230 & 34 & 6 & 10.1 & 1.01 \\
\hline BB-57-36-COOH & $0.17 \pm 0.01$ & 252 & 38 & 23 & 9.41 & 0.96 \\
\hline
\end{tabular}
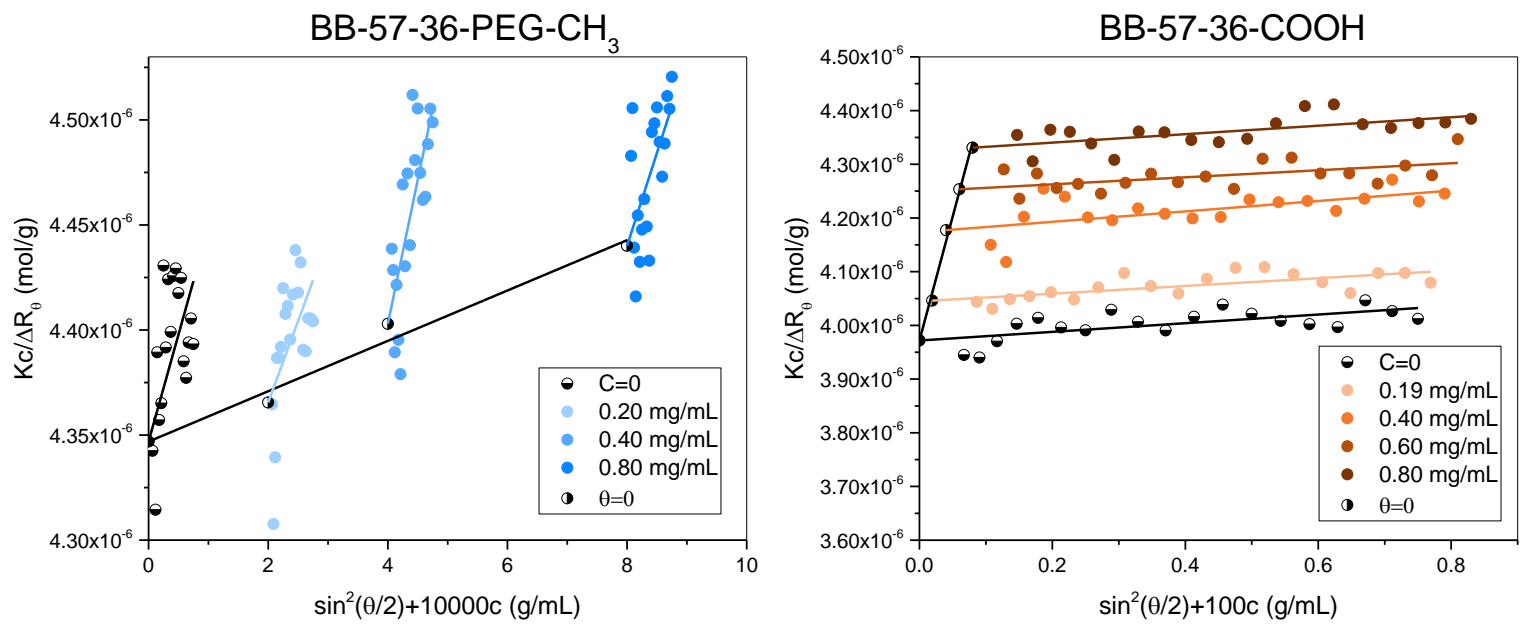

Figure S45: Zimm plots for BB-57-36-PEG-CH 3 (left) and BB-57-36-COOH (right) in PBS buffer $\mathrm{pH} 6.5$. 
Extra Discussion - Shape Factor and Density Calculations:

The shape factor $(\rho)$ for the BB structures was calculated to be 0.96 (Table S4) by dividing the radius of gyration $\left(R_{\mathrm{g}}\right)$ of the bottlebrush (Figure $\left.\mathrm{S} 45\right)$ by the $R_{\mathrm{h}}$. Therefore, our systems were not perfectly spherical $\left(R_{\mathrm{g}} / R_{\mathrm{h}}=0.78\right)$ and did not behave as random coils $\left(R_{\mathrm{g}} / R_{\mathrm{h}}=1.5\right){ }^{7,8}$ These globular molecular structures can be compared to previous work in the drug delivery field with micelles and crosslinked nanogels (that involve noncovalent and loosely crosslinked polymer aggregates, respectively) through the parameter of particle density. ${ }^{6,9-12}$ Under the assumptions that 1) the bottlebrushes are spherical particles and 2) the volume contribution of the norbornene backbone is negligible $\left(R_{\mathrm{h}, \mathrm{NB}} \rightarrow 0\right)$, we can estimate the average density of the bottlebrush unimers $\left(\rho_{\mathrm{BB}}\right)$ using an adaptation of the equation for micelle corona density (equation S1),

$$
\rho_{B B}=\frac{N_{b b} M_{n, S C}}{N_{a v}\left(\frac{4}{3} \pi R_{h, B B}^{3}\right)}
$$

where $N_{\mathrm{bb}}$ is the degree of polymerization of the backbone, $M_{\mathrm{n}, \mathrm{sc}}$ is the molecular weight of the side chain, $N_{\mathrm{av}}$ is Avogadro's number, and using $R_{\mathrm{h}, \mathrm{BB}}$ the second cumulant fit analysis at $90^{\circ}$ shown in Table 1. We estimated the $\rho_{\mathrm{BB}}$ of each end-group modified bottlebrush to be between 89 to $105 \mathrm{mg} / \mathrm{mL}$ (Table 1) replicating the optimal density range exhibited by the previous work on nanogels. ${ }^{9}$

\section{Aspect Ratio Calculation:}

Approximations based on each bond length being the same.

There are 5 bonds per backbone repeat unit. There are two bonds per side chain repeat unit along with the additional 9 bonds that extend the side chain from the backbone and 5 bonds from the propyl trithiocarbonate end-group. We assume that when fully extended, the side chains extend in both directions from the backbone. Therefore, the aspect ratio can be calculated by dividing the length of the fully extended backbone by the width of two side chains extended from either side of the backbone.

\section{Length/Width $\approx(5 * N b b) / 2 *((2 * N s c)+9+5)=180 / 256=0.70$}




\section{Performance Testing:}

Spray Drying:

Each sample with appropriate amount of phenytoin (10 or $25 \mathrm{wt} \%)$ was dissolved in methanol (2 $\mathrm{mg} / \mathrm{mL}$ ). After thorough mixing, the sample was transferred to a $20 \mathrm{~mL}$ syringe, and using a Bend Research Mini Spray Dryer (Bend, OR), the sample was spray dried using the following parameters: solution flow rate $=0.65 \mathrm{~mL} / \mathrm{min}$, inlet temperature $=70{ }^{\circ} \mathrm{C}$, nitrogen flow rate $=12.8$ standard liter per minute (SLPM). The powder was collected on filter paper and dried under vacuum overnight before dissolution tests. The samples were stored in a vacuum desiccator at room temperature.

Wide-Angle X-Ray Scattering:

Polymer amorphous spray dried dispersions were characterized using WAXS from the Advanced Photon Source (APS) at Argonne National Lab on the DND-CAT 5-ID-D beamline. Samples were suspended between two layers of Kapton tape on a silicon washer for sampling. The $\mathrm{x}$-ray beam wavelength at APS was $0.7293 \AA$ and 8.5025 m sample-to-detector distance. The samples were processed by subtracting a blank run of two layers of Kapton tape as a background. 

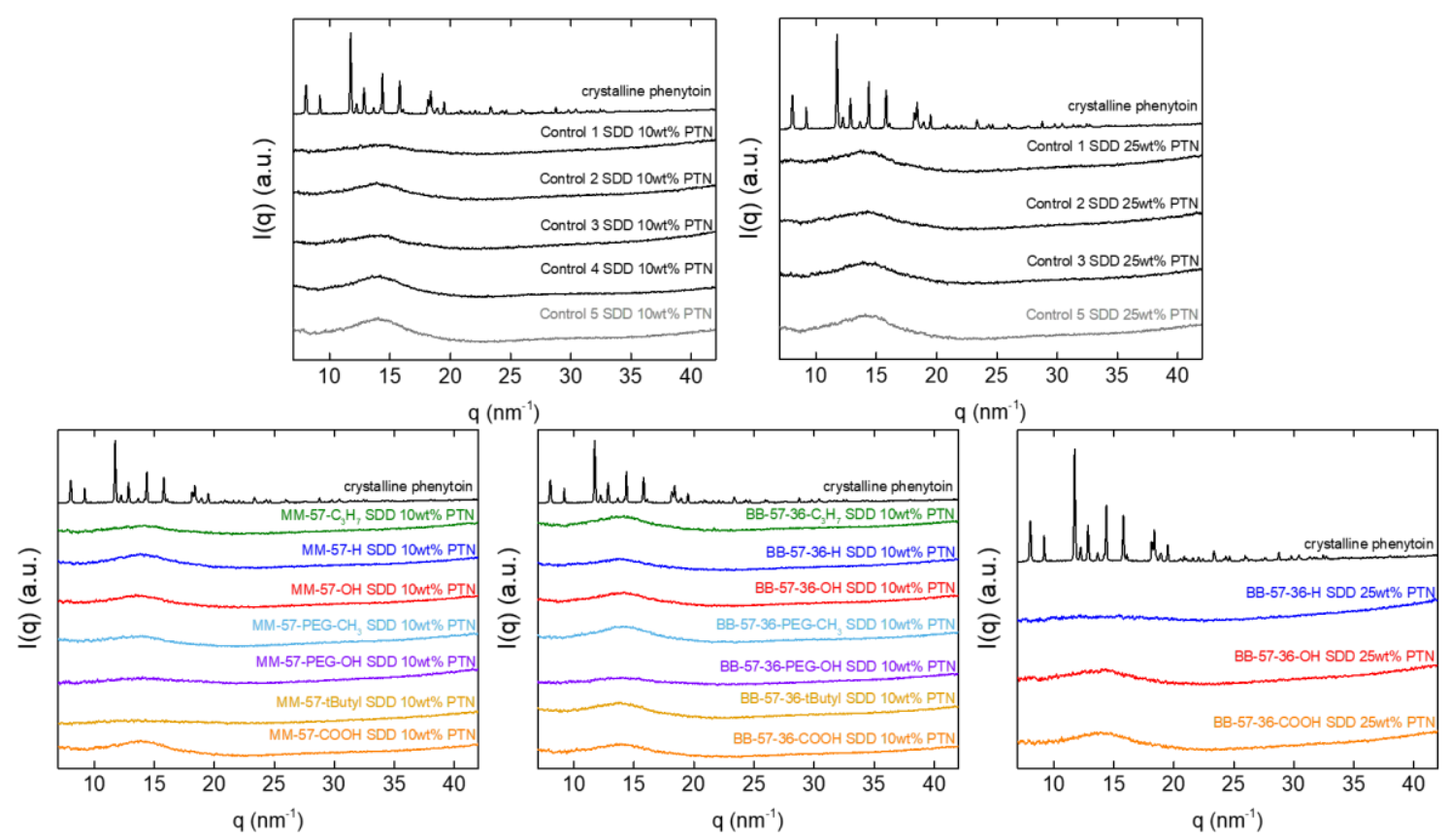

Figure S46: WAXS patters for all PASD's with PTN compared to the crystalline PTN control showing that all PASD's are amorphous. Controls (1) PA-PND-245- $\mathrm{C}_{3} \mathrm{H}_{7}$, (2) PA-PND-61- $\mathrm{C}_{3} \mathrm{H}_{7}$, (3) PA-PND-62- $\mathrm{C}_{3} \mathrm{H}_{7}$, (4) CA-PND-62- $\mathrm{C}_{12} \mathrm{H}_{25}$, and (5) CP-PND-72- $\mathrm{C}_{12} \mathrm{H}_{25}$.

\section{Dissolution:}

Each dissolution experiment was run in triplicate. Each spray dried dispersion was weighed out into $2 \mathrm{~mL}$ centrifuge tubes to which FaSSIF pH 6.5 was added at the desired temperature. The samples were vortexed for 1 minute and placed in a hot plate set at the desired temperature. At 4 minutes, the samples were removed from the hot plate and centrifuged for 1 minute at 13,000 rpm in a pre-heated centrifuge to maintain temperature. After centrifugation, a $50 \mu \mathrm{L}$ aliquot of each supernatant was taken and then the samples were again vortexed for 1 minute before returning to the hot plate. This process was repeated at 4, 10, 20, 40, 90, 180, and 360 minutes. Each aliquot was diluted with $450 \mu \mathrm{L}$ of HPLC grade methanol and filtered through a 0.2 um filter prior to analyzing with reversed-phase HPLC (Agilent 1260 Quaternary Pump, 1260 Standard Autosampler, 1260 Thermostatted Column Compartment, and 1260 Infinity Multiple Wavelength Detector VL) with a reversed-phase EC-C18 column (Poroshell 120, 4.6 x 50 mm, $2.7 \mu \mathrm{m}$ from Agilent, USA) and a mobile phase of 60:40 water:acetonitrile. 

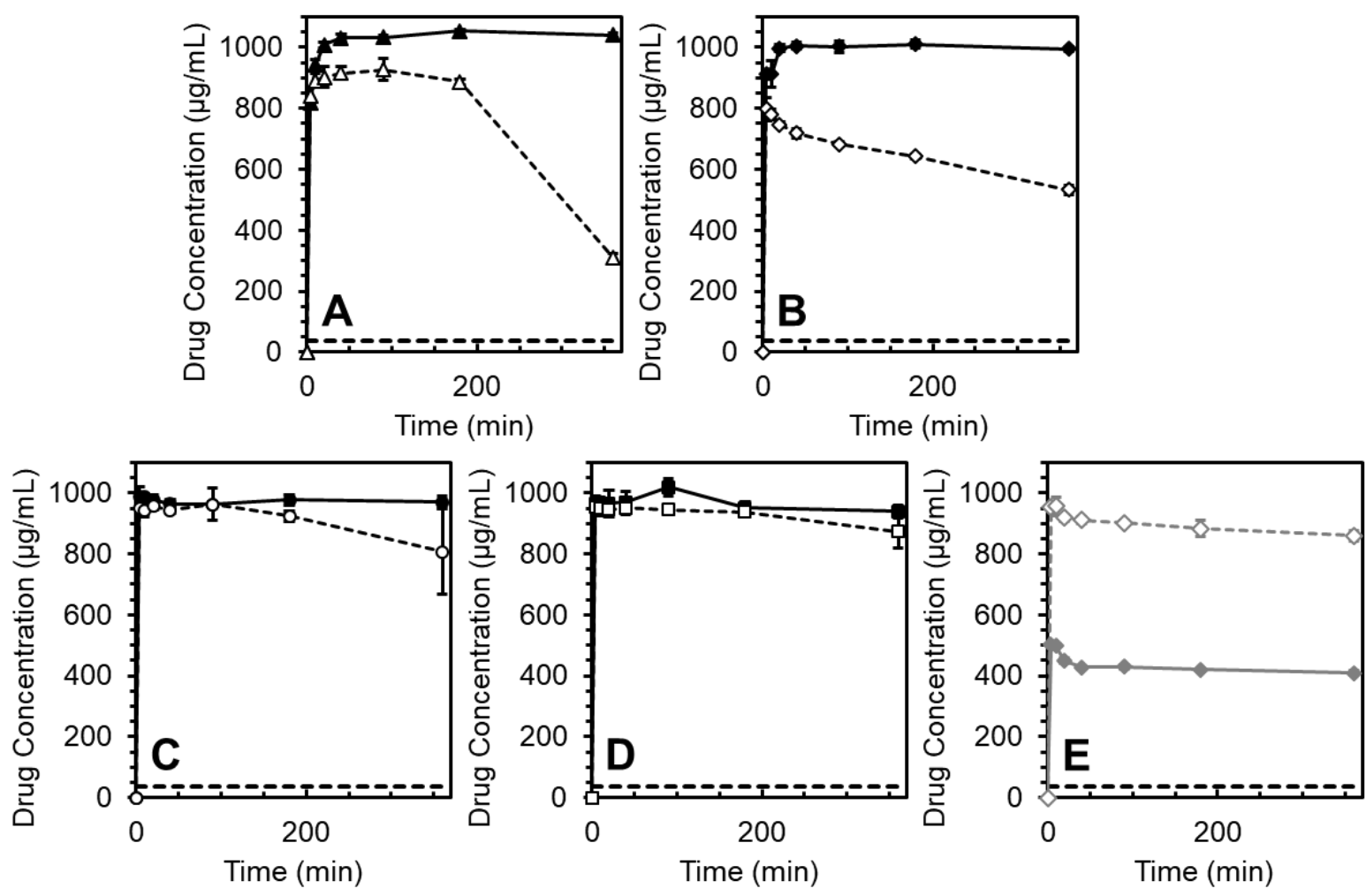

Figure S47. Dissolution performance of linear copolymer controls 1-5 in 0.5 wt \% FaSSIF at 25 (open data points and dashed lines) and $37{ }^{\circ} \mathrm{C}$ (filled data points and solid lines) with 10 wt $\%$ PTN loading. (A) PA-PND-245- $\mathrm{C}_{3} \mathrm{H}_{7}$ (1) and (B) PA-PND-61- $\mathrm{C}_{3} \mathrm{H}_{7}$ (2) exist as free chains, and (C) PA-PND-62- $\mathrm{C}_{12} \mathrm{H}_{25}$ (3), (D) CA-PND-62- $\mathrm{C}_{12} \mathrm{H}_{25}$ (4), and (E) CP-PND-62- $\mathrm{C}_{12} \mathrm{H}_{25}$ (5) forms micelles.
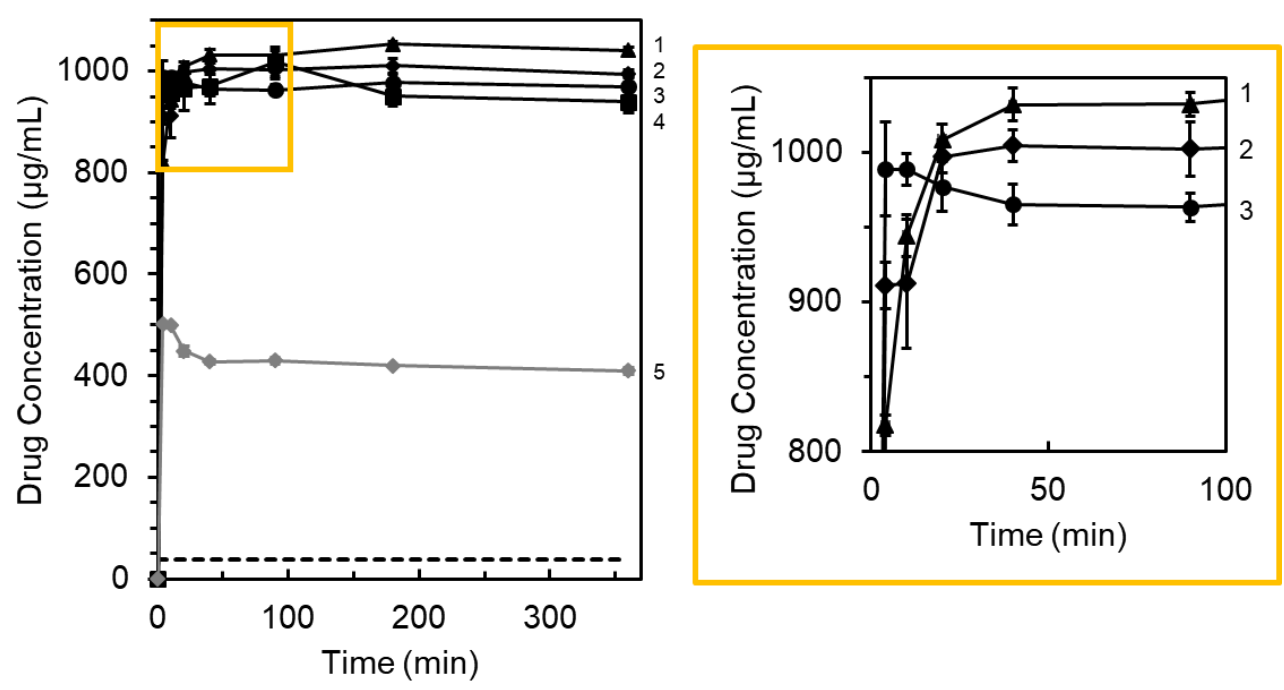

Figure S48. Comparison of the dissolution performance of linear copolymer controls 1-3 in 0.5 wt $\%$ FaSSIF at $37^{\circ} \mathrm{C}$ with 10 wt $\%$ PTN loading. 

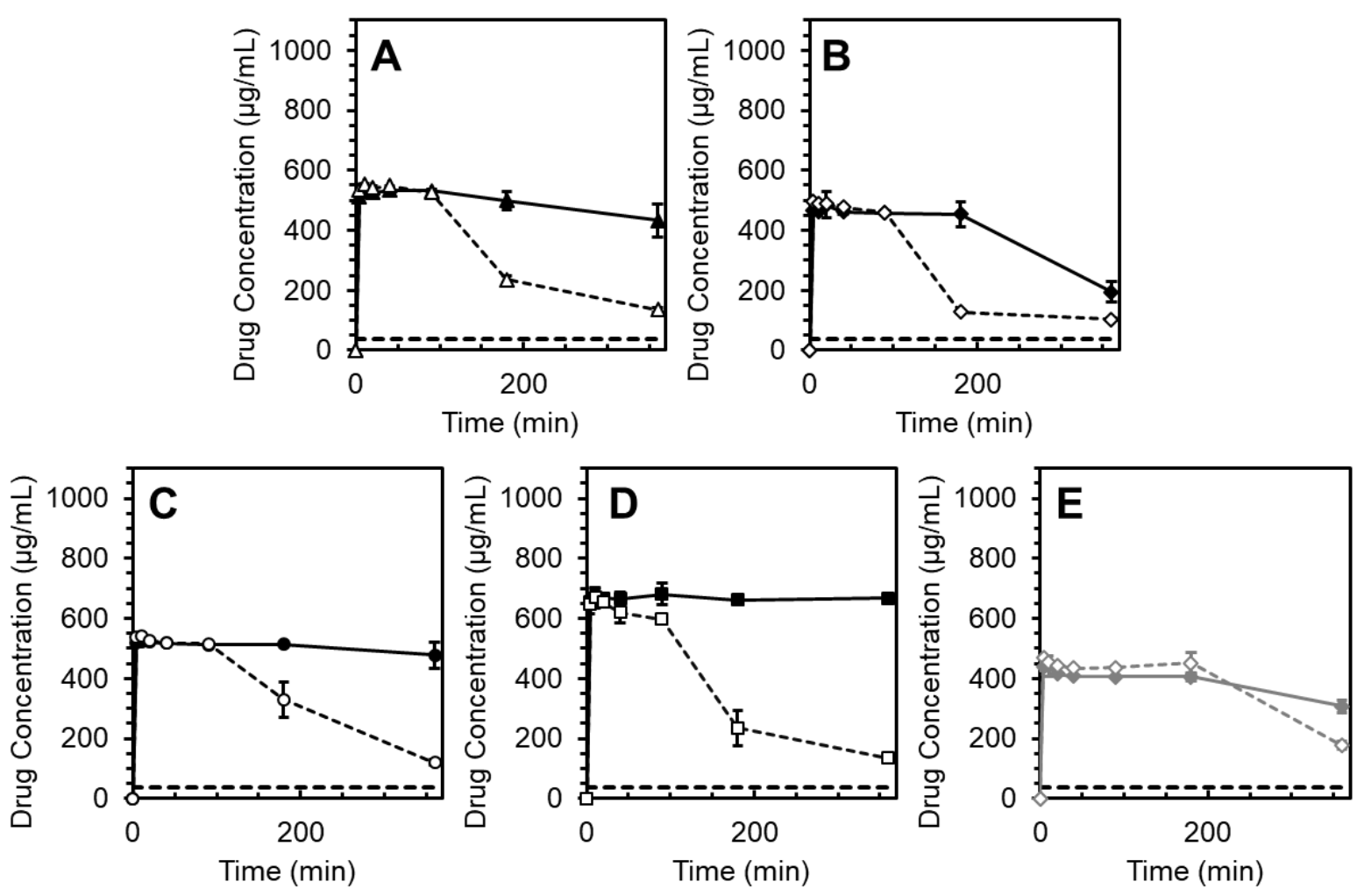

Figure S49. Dissolution performance of linear copolymer controls 1-5 in 0.5 wt $\%$ FaSSIF at 25 and $37{ }^{\circ} \mathrm{C}$ with 25 wt $\%$ PTN loading. (A) PA-PND-245- $\mathrm{C}_{3} \mathrm{H}_{7}$ (1) and (B) PA-PND-61- $\mathrm{C}_{3} \mathrm{H}_{7}$ (2) exist as free chains, and (C) PA-PND-62- $\mathrm{C}_{12} \mathrm{H}_{25}$ (3), (D) CA-PND-62- $\mathrm{C}_{12} \mathrm{H}_{25}$ (4), and (E) CPPND-62- $\mathrm{C}_{12} \mathrm{H}_{25}(\mathbf{5})$ forms micelles. 

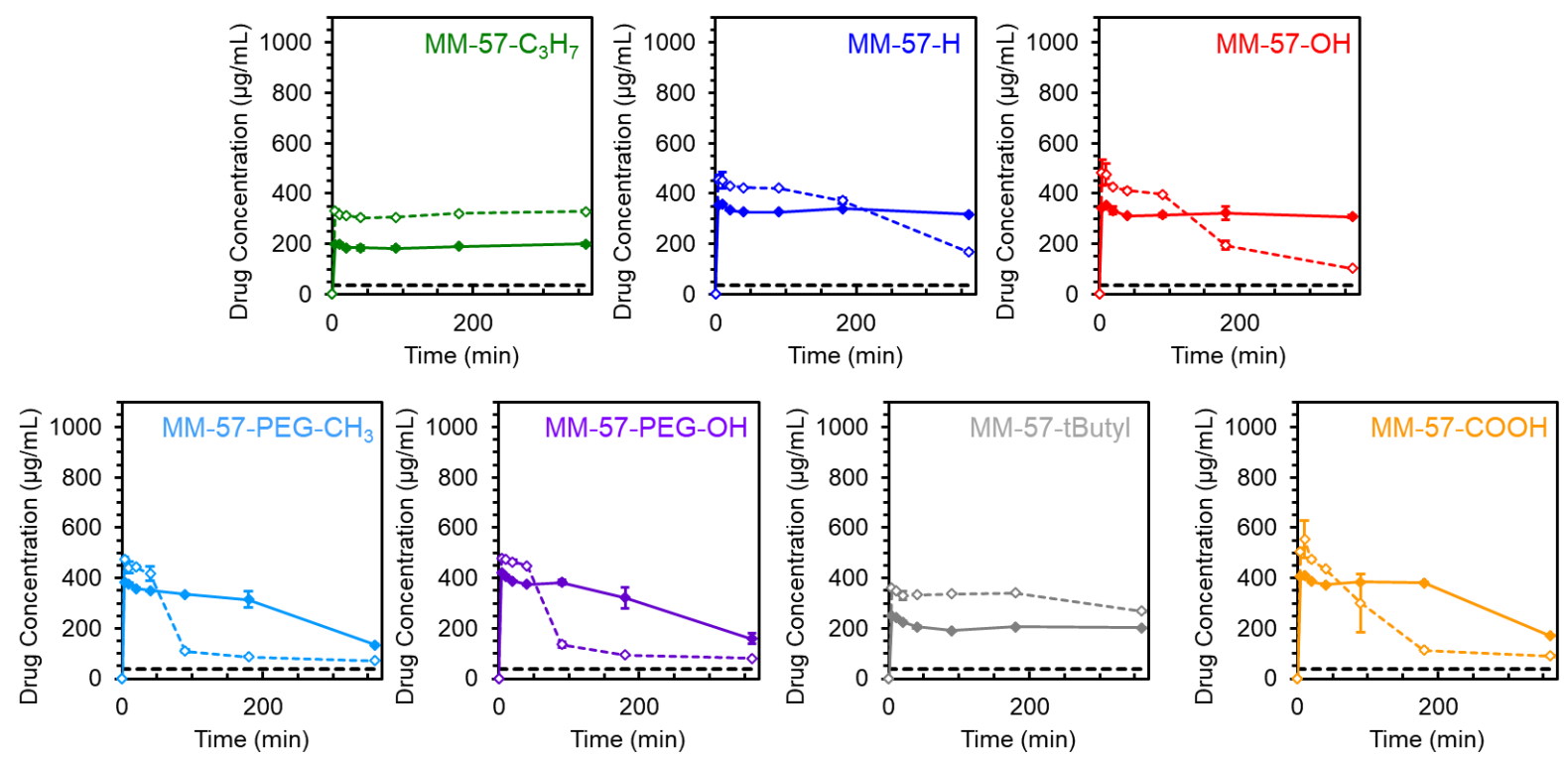

Figure S50. Dissolution performance of MM-57-Z in $0.5 \mathrm{wt} \%$ FaSSIF at 25 (dashed lines) and 37 (solid lines) ${ }^{\circ} \mathrm{C}$ with 10 wt $\%$ PTN loading.

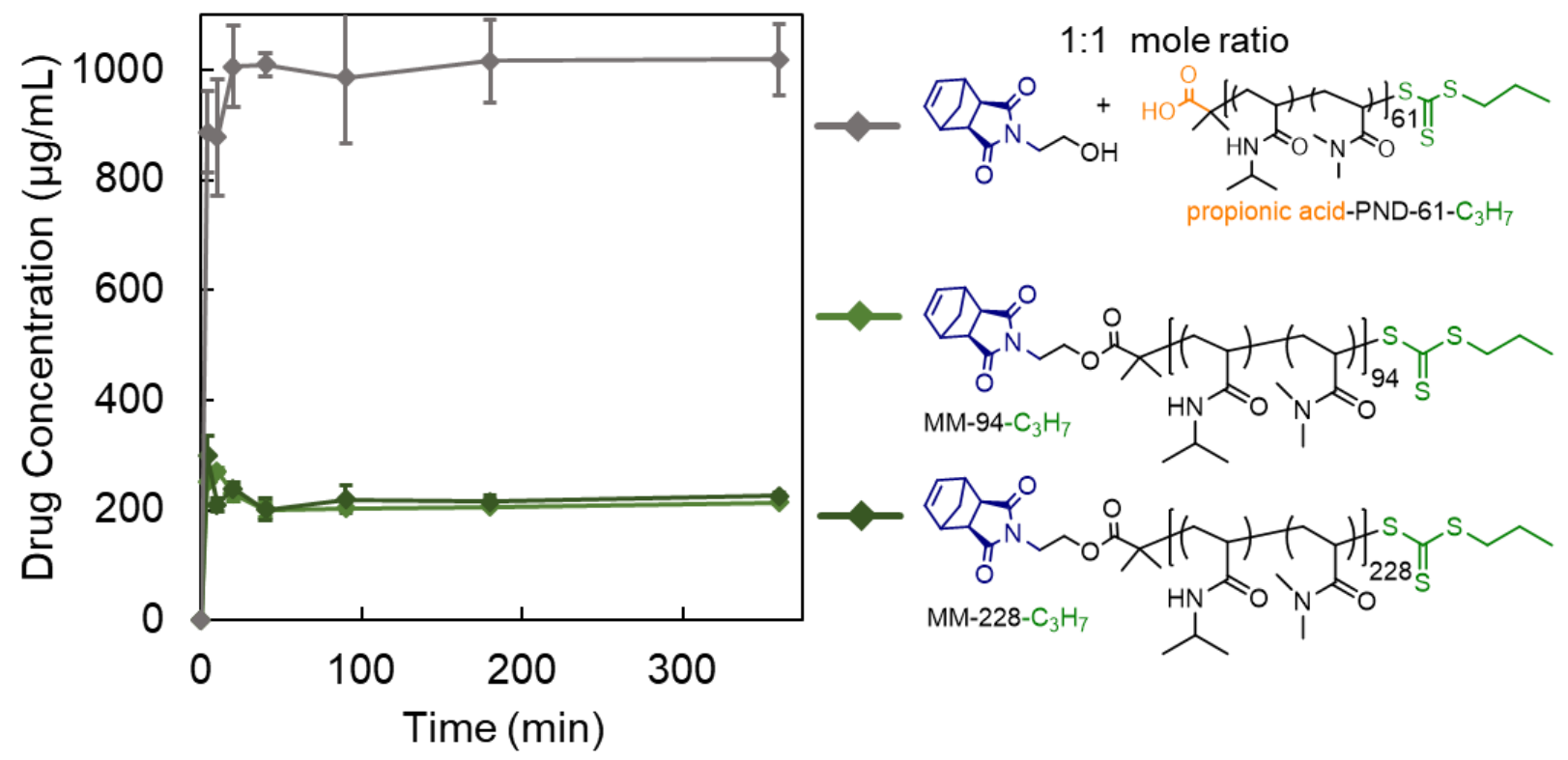

Figure S51. Dissolution performance of propionic acid-PND-61- $\mathrm{C}_{3} \mathrm{H}_{7}$ doped with exo-norbornene imide alcohol (grey diamonds), MM-94- $\mathrm{C}_{3} \mathrm{H}_{7}$ (green diamonds), and MM-228- $\mathrm{C}_{3} \mathrm{H}_{7}$ (dark green diamonds) in 0.5 wt $\%$ FaSSIF at $37^{\circ} \mathrm{C}$ with 10 wt \% PTN loading. 


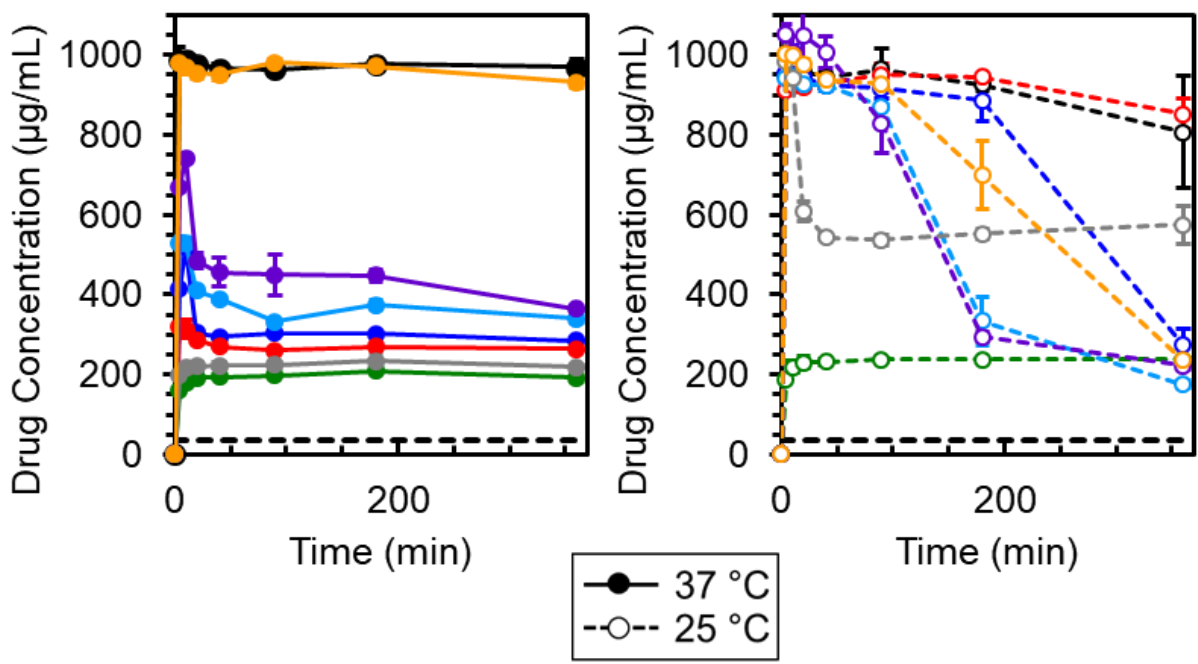

Figure S52. Overlay of BB-57-36-Z and control 3 dissolution performance in $0.5 \mathrm{wt} \% \mathrm{FaSSIF}$ at 25 and $37{ }^{\circ} \mathrm{C}$ with 10 wt \% PTN loading.

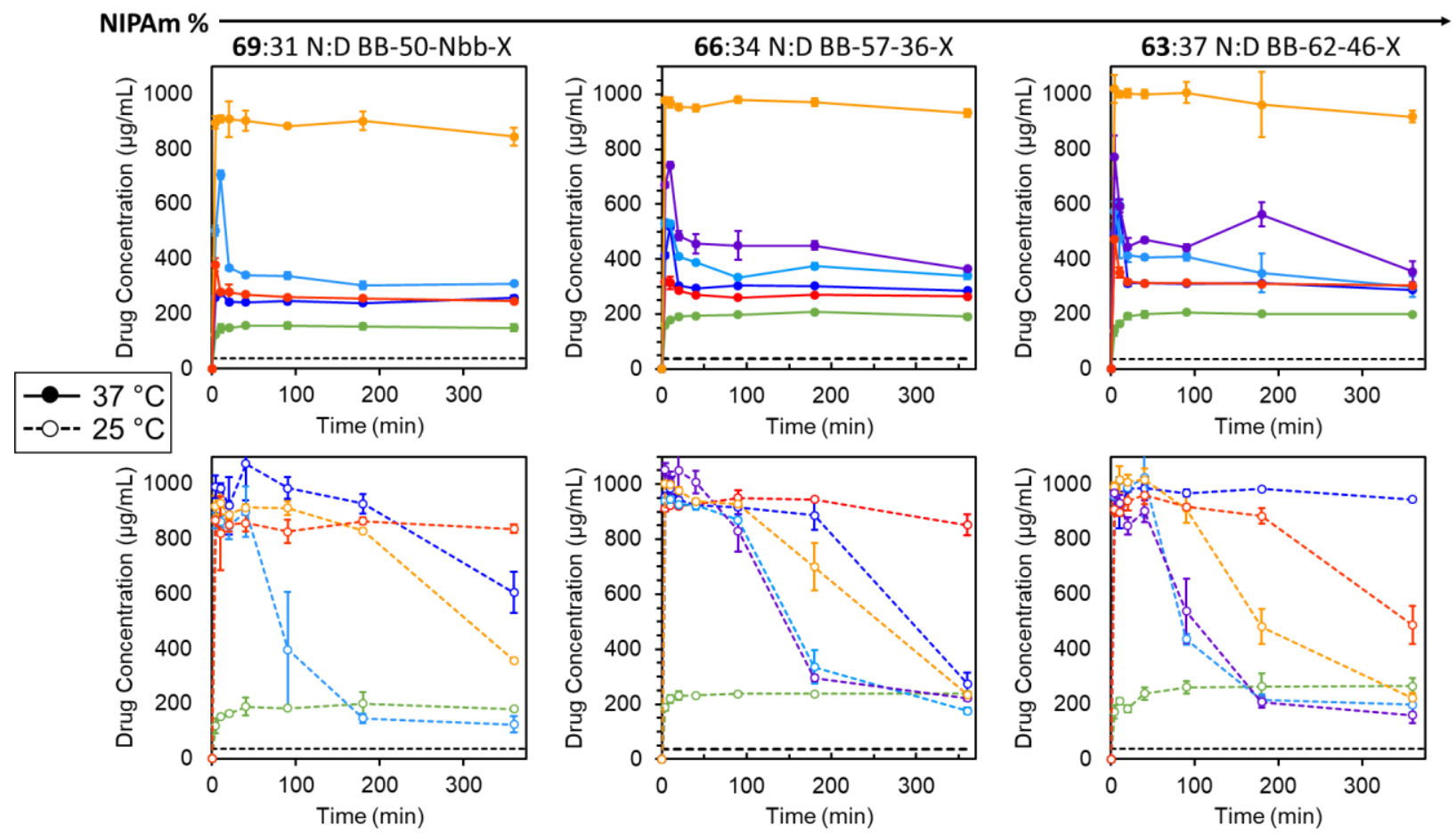

Figure S53. The influence of NIPAm \% incorporation in statistical copolymer side chains on the dissolution performance of BB-57-36-Z in $0.5 \mathrm{wt} \%$ FaSSIF at 25 and $37{ }^{\circ} \mathrm{C}$ with $10 \mathrm{wt} \% \mathrm{PTN}$ loading. 

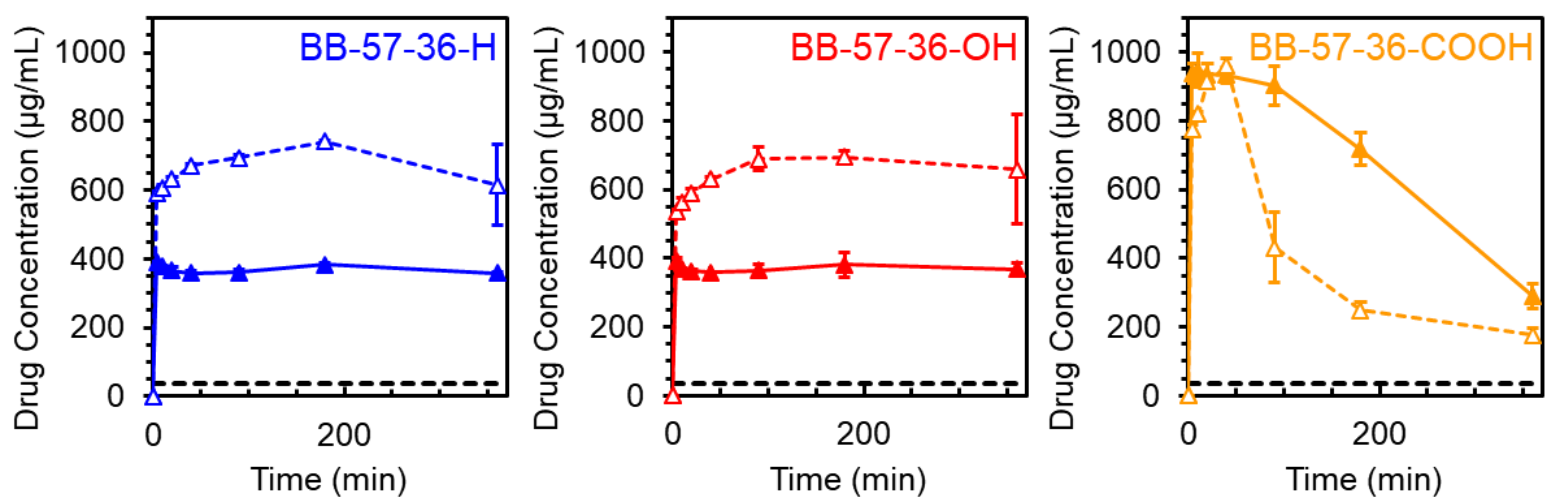

Figure S54. Dissolution performance of BB-57-36-H, -OH, and -COOH in $0.5 \mathrm{wt} \%$ FaSSIF at 25 ${ }^{\circ} \mathrm{C}$ (dotted lines) and $37{ }^{\circ} \mathrm{C}$ (solid lines) with 25 wt \% PTN loading.

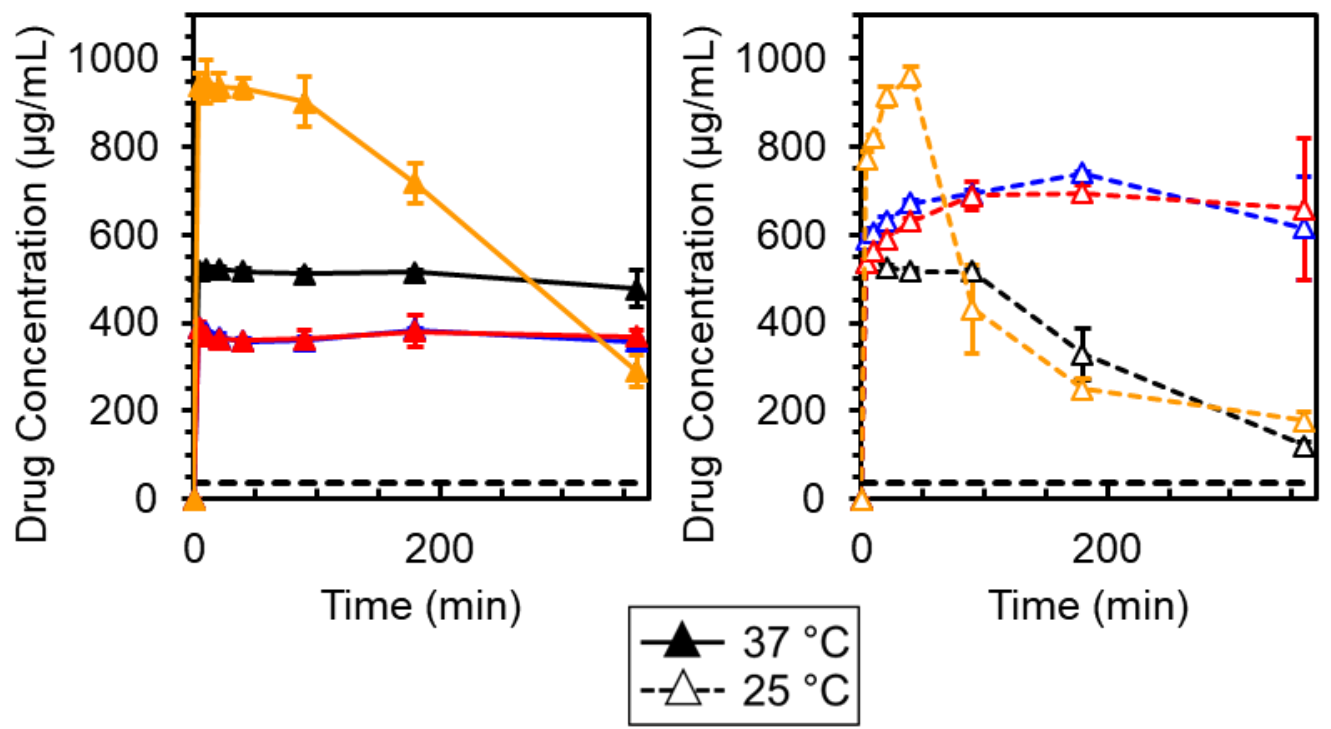

Figure S55. Overlay of BB-57-36-Z dissolution performance in $0.5 \mathrm{wt} \% \mathrm{FaSSIF}$ at $25^{\circ} \mathrm{C}$ (dotted lines, right plot) and $37^{\circ} \mathrm{C}$ (solid lines, left plot) with $25 \mathrm{wt} \%$ PTN loading. BB-57-36-H (blue), BB-57-36-OH (red), BB-57-36-COOH (orange), Control 3 (PA-PND-62- $\mathrm{C}_{12} \mathrm{H}_{25}$, black). 


\section{Extra Discussion - Drug Dissolution Performance.}

By first comparing the performance of the five linear copolymer controls, we observed a striking correlation with performance between the presence and absence of carboxylic acid groups independent of molecular weight or length of the hydrocarbon Z-group (see Figures S47-49 for a comparison of all linear copolymer dissolution behavior). Linear control $\mathbf{2}$ can fully solubilize $1000 \mu \mathrm{g} / \mathrm{mL}$ of PTN at $37{ }^{\circ} \mathrm{C}$ for 6 hours, which closely models the average time for gastric emptying (Figure S56). Comparatively, control 5, despite having a $T_{\mathrm{cp}}$ above $37{ }^{\circ} \mathrm{C}$, failed to solubilize more than $500 \mu \mathrm{g} / \mathrm{mL}$ of drug (Figure S56) at $37^{\circ} \mathrm{C}$. This highlights the importance the carboxylic acid functional groups play on solubility and keeping the PASD suspended in solution despite the hydrophobic contributions from the thermoresponsive collapse of NIPAm rich regions of the copolymer. This thermoresponse creates a hydrophobic reservoir for PTN in which polymer-

drug interactions are favored over drug-drug interactions resulting in crystallization prevention. ${ }^{13}$ Interestingly, the linear controls $\mathbf{3}$ and $\mathbf{4}$, with a dodecyl Z-group and carboxylic acid containing R-group, reached $1000 \mu \mathrm{g} / \mathrm{mL}$ concentrations within 4 minutes. In contrast, controls 1 and 2 with propyl Z-groups, had a short induction period of 10-20 minutes before reaching $1000 \mu \mathrm{g} / \mathrm{mL}$ in solution (see Figure S47-S48). We attribute the increased rate of dissolution to the greater surface area to volume ratio of the micelle forming linear controls $(\mathbf{3}-\mathbf{5})$ vs. the free chains $(\mathbf{1}-\mathbf{2})$. The carboxylic acid groups decorating the exterior of the micelle promote rapid dispersion of the amorphous PTN. 


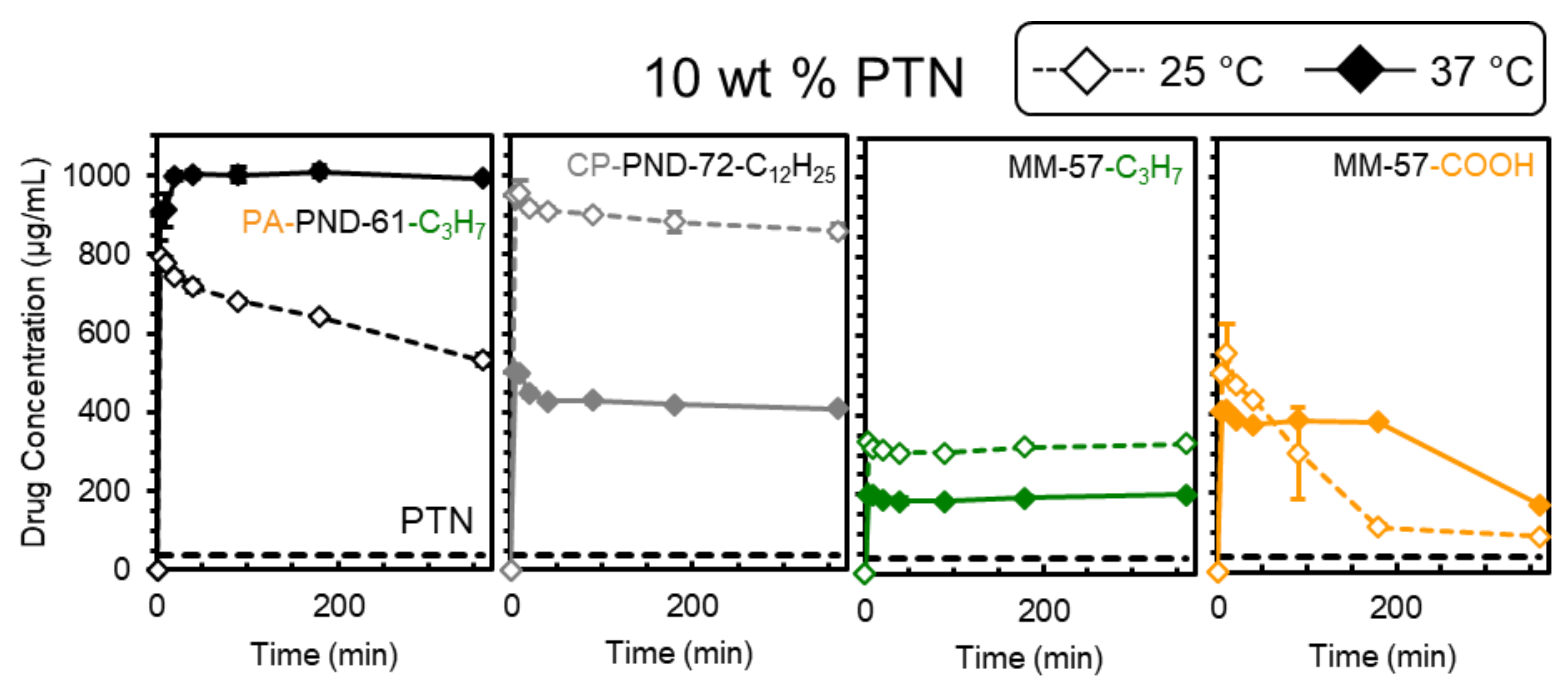

Figure S56. Dissolution results for the linear controls, PA-PND-61- $\mathrm{C}_{3} \mathrm{H}_{7}$ (2) and CP-PND-72$\mathrm{C}_{12} \mathrm{H}_{25}(\mathbf{5})$, and macromonomer (MM-57- $\mathrm{C}_{3} \mathrm{H}_{7}$ and $-\mathrm{COOH}$ ) samples at $10 \mathrm{wt} \%$ drug loading with phenytoin in $0.5 \mathrm{wt} \% \mathrm{SIF}$ at $25^{\circ} \mathrm{C}$ (dotted lines, open data points) and $37{ }^{\circ} \mathrm{C}$ (solid lines, filled data points). Crystalline solubility of PTN in FaSSIF is represented by the black dotted line at 37 $\mu \mathrm{g} / \mathrm{mL}$ in each graph.

When the dissolution efficacy of linear copolymers $\mathbf{1}-\mathbf{5}$ were tested at $25{ }^{\circ} \mathrm{C}$ (Figure S47), it was observed that all three micelle-forming controls solubilized $1000 \mu \mathrm{g} / \mathrm{mL}$ of PTN for 6 hours, even CP-PND-72- $\mathrm{C}_{12} \mathrm{H}_{25}$ (5) (Figure S47 and S56, dotted lines). The dodecyl hydrocarbon chains drive micellization increasing the proximity of NIPAm repeat units between polymer chains, similar to the bottlebrush architectures, promoting intermolecular interactions between the isopropyl groups of the NIPAm monomers. Such associations are called "n-clusters" and create a hydrophobic environment for the PTN molecules without the temperature-driven poly(NIPAm) hydrophilic-to-hydrophobic transition. ${ }^{14}$ In contrast, both linear copolymers with propyl Z-groups (1 and 2), which existed as free chains in solution, initially solubilized the drug at $25^{\circ} \mathrm{C}$. Over the 6 hours, the PTN concentration was observed to decrease as a result of crystallization caused by lack of temperature-driven NIPAm hydrophobic collapse at room temperature and the lack of "nclusters" creating a hydrophobic environment for the hydrophobic small molecule without the dodecyl end-groups to drive chain associations, the PTN crystalized over time (Figure S47 and S56). This highlights the importance of polymer chain proximity in creating a hydrophobic 
environment for the drug independent of the thermoresponsive hydrophobic collapse from NIPAm.

Control 2 and MM-57- $\mathrm{C}_{3} \mathrm{H}_{7}$ are chemically identical aside from the exo-imide norbornene conjugated to the carboxylic acid R-group to form the ROMP-active MM derivative. However, end-group modification to make MM-57-COOH restored the lack of carboxylic acid moiety and the $T_{\text {cp }}$ was increased to above $37{ }^{\circ} \mathrm{C}$. Dissolution profiles for MM-57- $\mathrm{C}_{3} \mathrm{H}_{7}$ and MM-57-COOH are shown in Figure S56, and at both 37 and $25^{\circ} \mathrm{C}$, neither MM sample was able to solubilize 1000 $\mu \mathrm{g} / \mathrm{mL}$ of PTN. This result makes sense for $\mathrm{MM}-57-\mathrm{C}_{3} \mathrm{H}_{7}$ because the $T_{\mathrm{cp}}$ was not above $37{ }^{\circ} \mathrm{C}$. However, it was expected that the re-introduction of a carboxylic acid Z-group, which salvaged the $T_{\mathrm{cp}}$ and mimicked the linear controls, would fully solubilize the drug. This further demonstrates the importance of end-group functionality for excipient efficacy. The inability to solubilize more than $500 \mu \mathrm{g} / \mathrm{mL}$ of PTN at $10 \mathrm{wt} \%$ drug loading was consistent across all the MM samples as shown in Figure S50. It was hypothesized that the exo-imide norbornene group on the MMs was acting as a nucleation site for PTN crystallization. As a control, exo-imide norbornene alcohol was doped into a dissolution experiment with control 2, but no change in the dissolution performance was observed (Figure S51). The molecular weight of the MMs was also increased to minimize the contributions of the end-groups and the dissolution performance did not improve for the MMs at $37^{\circ} \mathrm{C}$ in $0.5 \mathrm{wt} \% \mathrm{FaSSIF}$ (Figure S51). Therefore, the presence of the exo-imide norbornene was not acting as a crystallization nucleation site when not conjugated to the polymer, but it was still hindering dissolution performance of high molecular weight MMs. We wanted to understand if the drug in the PASDs with MM excipients remained amorphous during the dissolution experiment and was limited by the hydrophobicity of the exo-imide norbornene functionalized polymers or if the PTN was crystallizing causing the poor dissolution performance.

Polarized light microscopy was used to investigate if there was crystalline drug present at any point during the dissolution of the PASDs in 0.5 wt \% FaSSIF. Sample aliquots were taken after vortexing and dispensed onto a glass slide. This workflow allowed us to sample all species 
in the dissolution media, soluble and insoluble, to gain a holistic understanding of the amorphous or crystalline state of PTN during the dissolution experiment. We observed that the MM- $57-\mathrm{C}_{3} \mathrm{H}_{7}$ PASD never dissolved in the solution and interestingly, no drug crystallization was observed at 4 or 360 minutes in solution or in the pellet of precipitate that was collected after centrifugation (Figure S61-62). Therefore, the drug concentration observed during the dissolution test in Figure S56 was the maximum concentration that could be achieved by the PASD at 37 and $25^{\circ} \mathrm{C}$. For the MM-57-COOH PASD, we found that at $37^{\circ} \mathrm{C}$ the sample also formed micron-sized insoluble amorphous particles at early time points, but the addition of a carboxylic acid Z-group increased the basal solubility of the PASD. Only after 180 minutes did rapid crystallization of drug occur represented by the precipitous loss of drug concentration (Figures S56 and S63). The same phenomenon was observed at $25{ }^{\circ} \mathrm{C}$, but the rapid onset of PTN crystallization occurred at 10 minutes (Figure S64). We hypothesized that the exo-norbornene R-group was contributing to the hydrophobicity of the PASD preventing full dissolution in all MM PASDs, but the addition of an increasingly hydrophilic Z-group increases the hydrophilicity of the PASD resulting in dissociation of drug and polymer in solution with time leading to eventual drug crystallization.

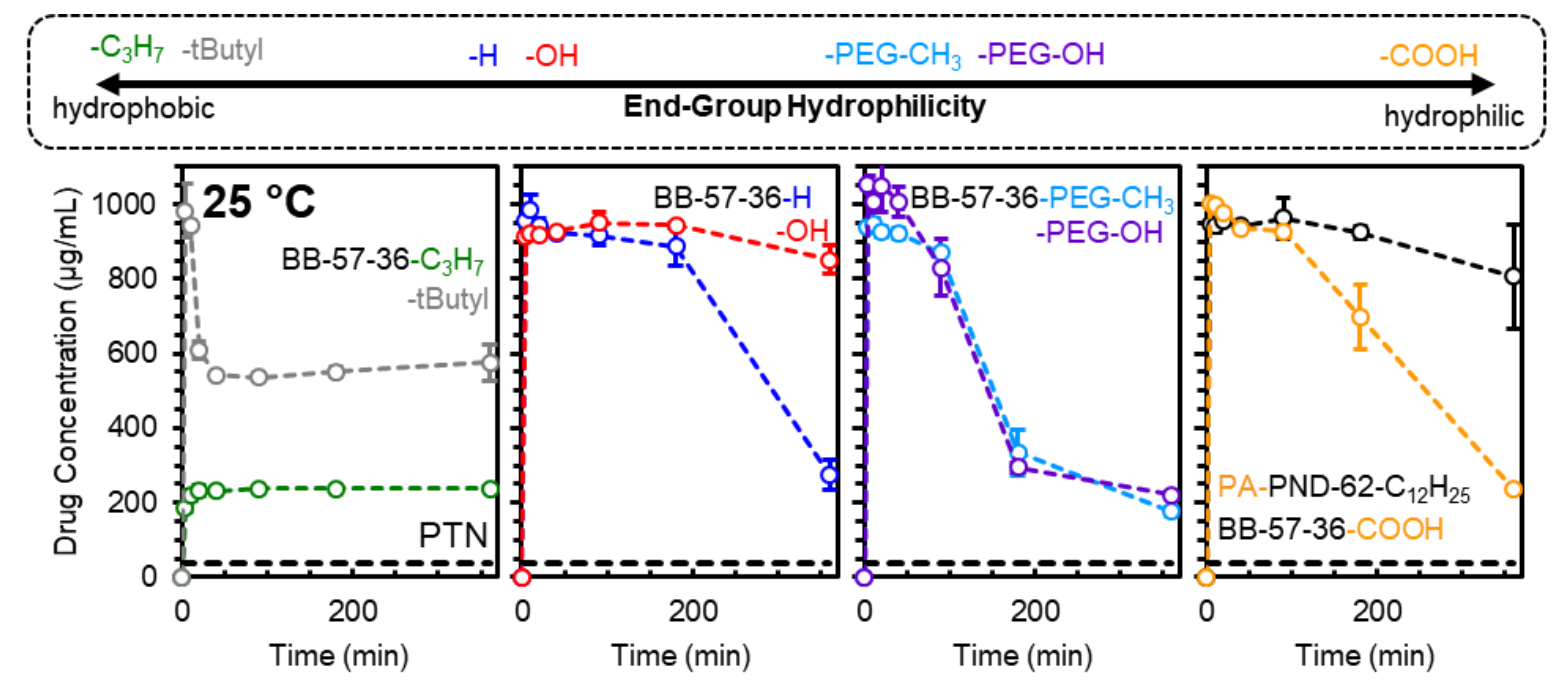

Figure S57. Dissolution results for the end-group modified bottlebrush polymers (BB-57-36-Z) and linear control 3 (PA-PND-62- $\mathrm{C}_{12} \mathrm{H}_{25}$ ) with $10 \mathrm{wt} \% \mathrm{PTN}$ in FaSSIF pH 6.5 at $25^{\circ} \mathrm{C}$ (dotted lines) arranged in order of most hydrophobic to hydrophilic end-group moiety. 
As discussed in the main text, both the control 3 and BB-57-36-COOH were able to fully solubilize $1000 \mu \mathrm{g} / \mathrm{mL}$ of PTN at $10 \mathrm{wt} \%$ drug loading and $37^{\circ} \mathrm{C}$. We compared the solubilization mechanisms of both polymers during dissolution using DLS to investigate the size of solubilized drug/polymer nanoparticles. The measurements were conducted in PBS without added FaSSIF to simplify the analysis and assignment of size distributions. At $10 \mathrm{wt} \% \mathrm{PTN}$ loading and $37{ }^{\circ} \mathrm{C}$, the $R_{\mathrm{h}}$ of both samples increased to $10 \mathrm{~nm}$ for the drug-loaded nanoparticles compared to the drugfree micelles and bottlebrushes with $R_{\mathrm{h}}$ equal to 7.5 and $9.4 \mathrm{~nm}$, respectively, in PBS alone (Figures S58-59). This data suggests that the polymer architectures swell slightly when loaded with drug and through non-covalent interactions successfully retain the drug as well-defined, uniform hydrophobic reservoirs maintaining polymer-drug associations and enhancing dissolution performance.

At room temperature for the end-group modified bottlebrush polymers, it was observed that the trend in dissolution performance almost inverts. Interestingly, the bottlebrush samples with less hydrophilic groups (e.g., BB-57-36-OH) fully solubilize $1000 \mu \mathrm{g} / \mathrm{mL}$ of PTN for 6 hours (Figure S57). Reminiscent of the arguments made with control 5 at $25^{\circ} \mathrm{C}$ based on Figure S56, the density of polymer chains within a $20 \mathrm{~nm}$ globular particle may result in a hydrophobic environment within the particle due to polymer chain proximity, driving $\mathrm{n}$-clustering, polymerdrug non-covalent interactions, and delayed crystallization. The PEGylated and carboxylated samples on the other hand, have high $\mathrm{A} 2$ values at $25^{\circ} \mathrm{C}$ meaning the polymer side chains are more extended allowing PBS and FaSSIF to penetrate the dense particle resulting in drug-polymer dissociation and rapid crystallization of PTN after 90 minutes. This was confirmed by polarized light microscopy experiments with BB-57-36-COOH at $25^{\circ} \mathrm{C}$ and 10 wt \% PTN loading where crystalline PTN was observed in solution after 90 minutes (Figure S70). By polarized light microscopy, the BB-57-36- $\mathrm{C}_{3} \mathrm{H}_{7}$ sample was observed to face the same solubility challenge as the MM-57- $\mathrm{C}_{3} \mathrm{H}_{7}$, where the polymer acted as a hydrophobic sink for the amorphous hydrophobic drug pulling the drug out of solution (Figures S65-66). The drug concentration observed 
throughout BB-57-36- $\mathrm{C}_{3} \mathrm{H}_{7}$ dissolution was the solubility limit of the PASD in FaSSIF. Therefore, end-group functionality drives bottlebrush solution and thermoresponsive properties, which ultimately dictate the excipient solution structure and efficacy. When the end-group functionality was optimized, the bottlebrush excipients acted as hydrophobic reservoirs for the non-covalently bound drug in FaSSIF to rapidly solubilize and inhibit crystallization of the small molecule therapeutics.

\section{Dynamic Light Scattering Dissolution:}

All measurements were taken on an in-house photometer $(30 \mathrm{~mW}$ laser power, avalanche photodiode detector with a $200 \mu \mathrm{m}$ pinhole) over a range of angles (60-120 $)$ with a Brookhaven BI- 200SM goniometer and a Brookhaven BI-9000AT correlator at $\lambda=637 \mathrm{~nm}$ at $37{ }^{\circ} \mathrm{C}$. Dissolution experiments were performed in PBS ( $\mathrm{pH}$ 6.5) alone without FaSSIF to mimic the dissolution environment during the DLS measurements. The dissolution data collected at 10 and 25 wt \% PTN loading at $37 \mathrm{C}$ in PBS only are shown to the right of the DLS distributions in Figures S58 and S59. A DLS measurement was collected of each polymer at 9 and $4 \mathrm{mg} / \mathrm{mL}$ at 37 $\mathrm{C}$ as a polymer only control. Dissolution vials were vortexed and incubated at $37{ }^{\circ} \mathrm{C}$ following the dissolution procedure described above. After centrifugation, a $250 \mu \mathrm{L}$ aliquot was taken of the supernatant and filtered through a $0.45 \mu \mathrm{m}$ filter (to remove dust) into a DLS tube before being placed into a Brookhaven Instrument which had been preheated to $37^{\circ} \mathrm{C}$. The DLS measurement was taken for $30 \mathrm{sec}$ to 5 minutes depending on baseline stability. For the more dynamic samples, shorter acquisition times were observed. Each correlation function collected was fit with a REPES Laplace inversion to acquire the intensity vs. $R_{\mathrm{h}}$ plots. 

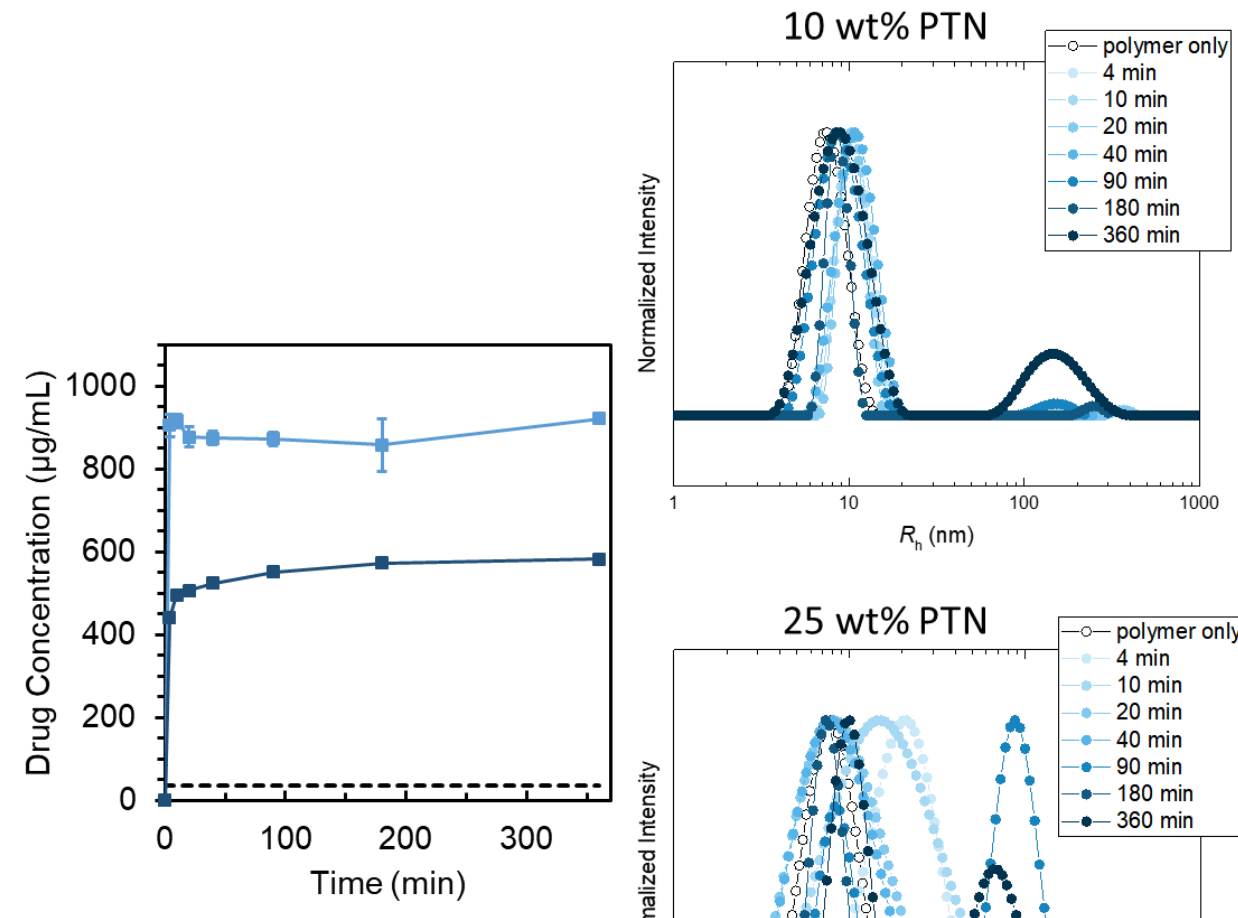

\begin{tabular}{|c|c|}
\hline $\begin{array}{c}\text { Time } \\
\text { (min) }\end{array}$ & $\begin{array}{c}\text { Rh } \\
(\mathbf{n m})\end{array}$ \\
\hline 0 & 7.5 \\
\hline 4 & 10.3 \\
\hline 10 & 10.3 \\
\hline 20 & 10.2 \\
\hline 40 & 10.8 \\
\hline 90 & 8.8 \\
\hline 180 & 8.3 \\
\hline 360 & 9.0 \\
\hline
\end{tabular}

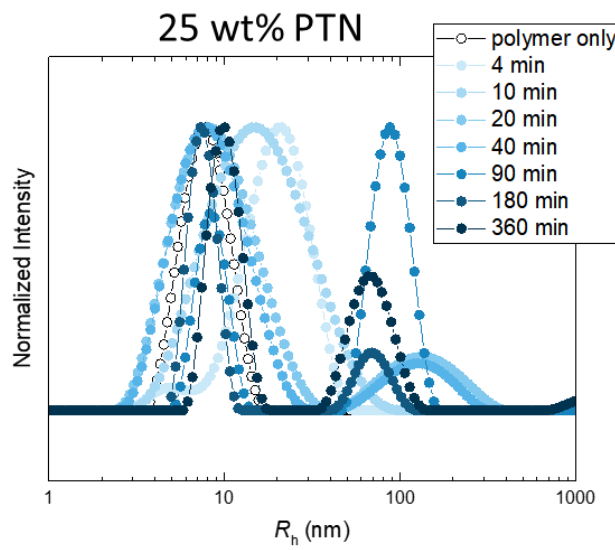

\begin{tabular}{|c|c|}
\hline $\begin{array}{c}\text { Time } \\
\text { (min) }\end{array}$ & $\begin{array}{c}\mathbf{R h} \\
\mathbf{( n m )}\end{array}$ \\
\hline 0 & 7.8 \\
\hline 4 & 21.2 \\
\hline 10 & 15.1 \\
\hline 20 & 8.1 \\
\hline 40 & 8.0 \\
\hline 90 & 8.2 \\
\hline 180 & 7.3 \\
\hline 360 & 10.0 \\
\hline
\end{tabular}

Figure S58. Dissolution performance of Control 3 at $10 \mathrm{wt} \%$ (light blue) and $25 \mathrm{wt} \%$ (dark blue) PTN loading and DLS analysis of the supernatant at $37^{\circ} \mathrm{C}$ in PBS to investigate the mechanism of drug solubilization and nanoparticle formation with drug. 

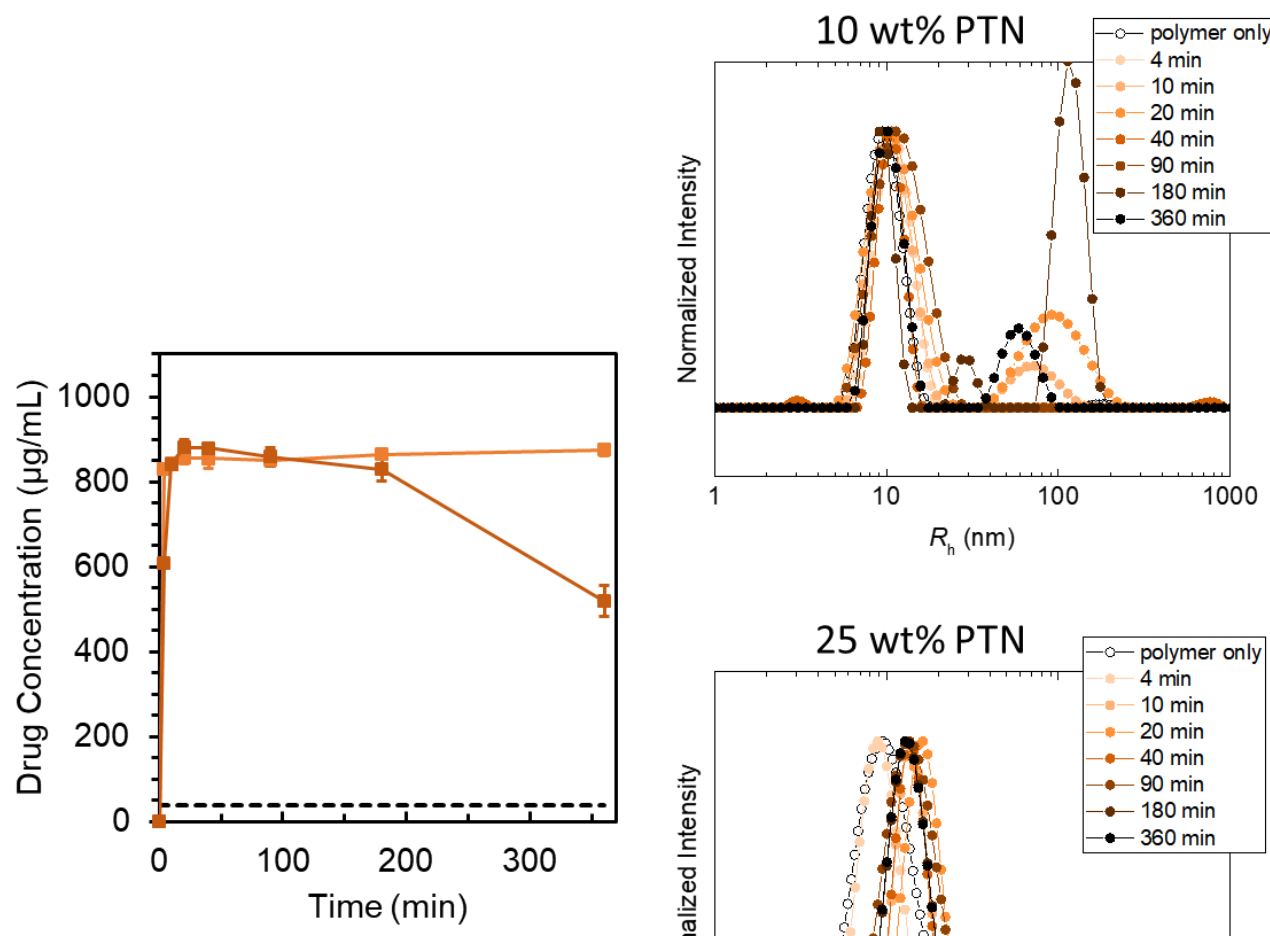

\begin{tabular}{|c|c|}
\hline $\begin{array}{c}\text { Time } \\
(\mathbf{m i n})\end{array}$ & $\begin{array}{c}\mathbf{R h} \\
(\mathbf{n m})\end{array}$ \\
\hline 0 & 9.4 \\
\hline 4 & 10.8 \\
\hline 10 & 10.1 \\
\hline 20 & 10.1 \\
\hline 40 & 10.7 \\
\hline 90 & 10.1 \\
\hline 180 & 9.1 \\
\hline 360 & 10.1 \\
\hline
\end{tabular}

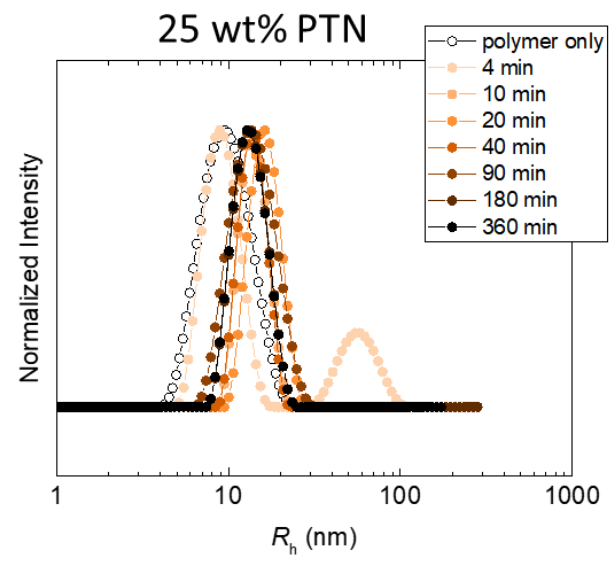

\begin{tabular}{|c|c|}
\hline $\begin{array}{c}\text { Time } \\
(\mathbf{m i n})\end{array}$ & $\begin{array}{c}\text { Rh } \\
(\mathbf{n m})\end{array}$ \\
\hline 0 & 9.4 \\
\hline 4 & 8.9 \\
\hline 10 & 13.6 \\
\hline 20 & 16.3 \\
\hline 40 & 13.6 \\
\hline 90 & 13.6 \\
\hline 180 & 12.8 \\
\hline 360 & 12.8 \\
\hline
\end{tabular}

Figure S59. Dissolution performance of BB-57-36-COOH at $10 \mathrm{wt} \%$ (light orange) and $25 \mathrm{wt} \%$ (dark orange) PTN loading and DLS analysis of the supernatant at $37^{\circ} \mathrm{C}$ in PBS to investigate the mechanism of drug solubilization and nanoparticle formation with drug. 

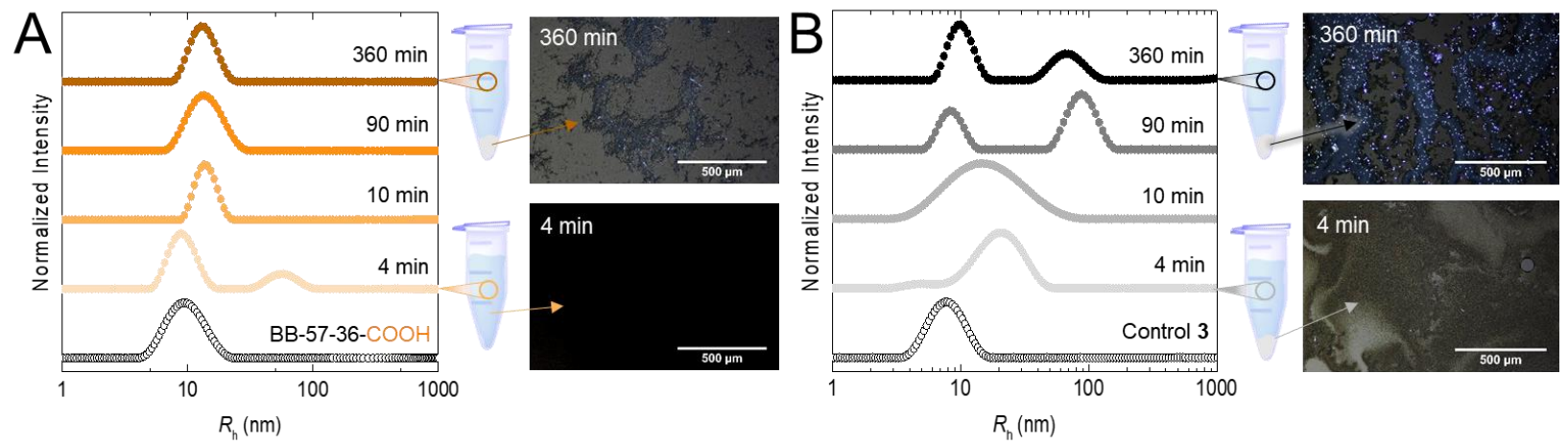

Figure S60. Dynamic light scattering measurements during dissolution in PBS pH 6.5 at $37{ }^{\circ} \mathrm{C}$ and 25 wt \% PTN. (A) BB-57-36-COOH at $9 \mathrm{mg} / \mathrm{mL}$ without drug (open circles) at 4, 10, 90, and 360 minutes during dissolution. At 4-10 min, no precipitate was observed in the sample vial as shown in the cartoon and the PLM image (bottom right), but there was a pellet of crystallized drug after centrifugation during 90-360 min as shown in the PLM image (top right). (B) $9 \mathrm{mg} / \mathrm{mL}$ of PA-PND-62- $\mathrm{C}_{12} \mathrm{H}_{25}$ (3) without drug (open circles) at 4, 10, 90, and 360 minutes during dissolution. All samples were observed to have a precipitate in the bottom of vial after centrifugation. At $4 \mathrm{~min}$, the precipitate is amorphous as shown in the PLM image (bottom right), but by 360 min the precipitated pellet was crystalline as shown by the birefringence in the PLM image (top right).

\section{Polarized Light Microscopy:}

Images were collected under normal dissolution conditions. However, each sample aliquot was taken after $30 \mathrm{sec}$ of vortexing instead of centrifugation to gain a wholistic understanding about the presence of crystalline or amorphous precipitates in the dissolution vial. At each timepoint, after vortexing, a $20 \mu \mathrm{L}$ aliquot was taken and deposited on a precleaned glass slide (3" x 1", Thermo Scientific) the droplet was dispersed with a glass cover slip (24 x $40 \mathrm{~mm}^{2}$, Fisher). The samples were imaged with a Canon SL 1 digital camera mounted on a Nikon Optiphoto polarized microscope at 10X magnification. Each image, bright field or polarized was taken within 3 minutes of sampling. The images of the pellet were taken at the respective timepoints after 1 minute of centrifugation $(13,000 \mathrm{rpm})$ after removing all of the supernatant and transferring the remaining pellet onto a glass slide. Image analysis was performed using ImageJ (Nation Institutes of Health, MD, USA). 

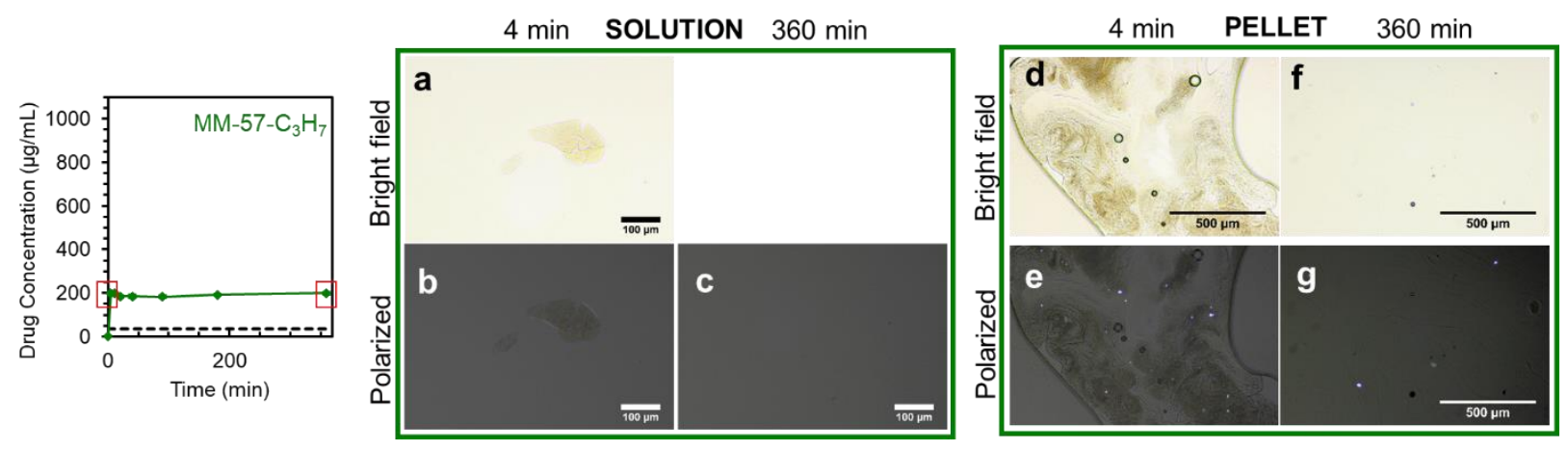

Figure S61. Polarized and bright field light microscopy images of MM-57- $\mathrm{C}_{3} \mathrm{H}_{7}$ during dissolution with $10 \mathrm{wt} \% \mathrm{PTN}$ at $37{ }^{\circ} \mathrm{C}$ at 4 minutes and 360 minutes. The following images show: (a) bright field image of the solution at 4 minutes, (b) the polarized image at 4 minutes showing no crystallinity in the suspended particles, (c) polarized image of the solution at 360 min showing no particles and no crystallinity in the solution, (d) the pellet after centrifugation at 4 minutes in the bright field and confirmed to have little to no crystallinity by the (e) polarized image, (f) the bright field image of the pellet formed after centrifugation at 360 minutes, $(\mathrm{g})$ crystallization on par with the 4 minute pellet is shown in the polarized image.
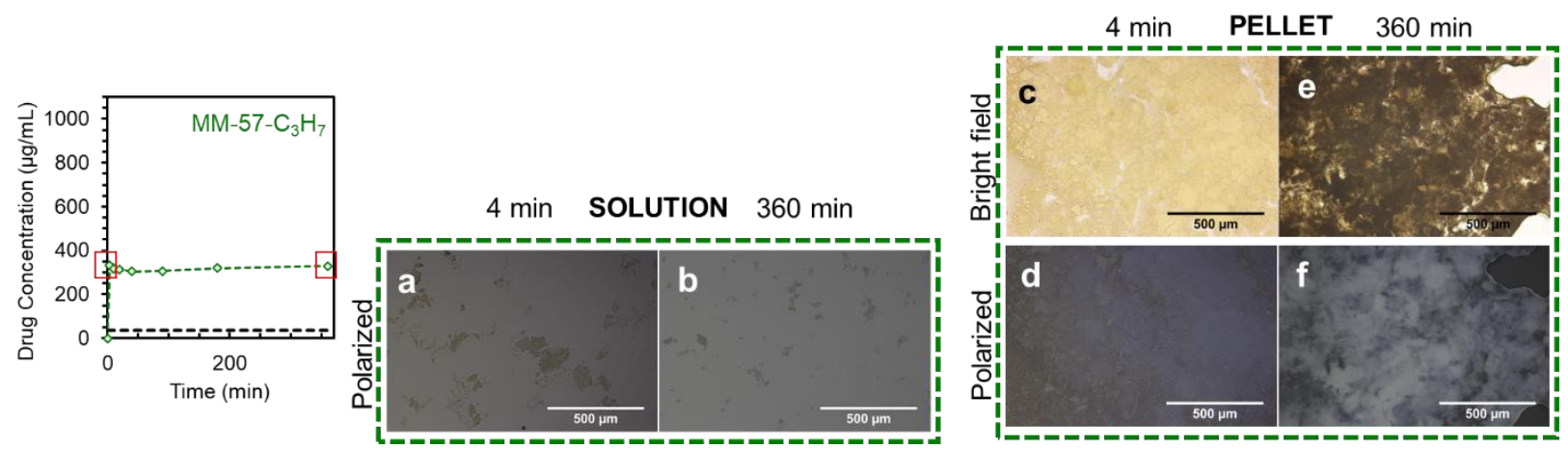

Figure S62. Polarized and bright field light microscopy images of $\mathrm{MM}-57-\mathrm{C}_{3} \mathrm{H}_{7}$ during dissolution with $10 \mathrm{wt} \%$ at $25^{\circ} \mathrm{C}$ at 4 minutes and 360 minutes. The following images show: (a) polarized image of the solution at 4 minutes and (b) the polarized image of the solution at 360 minutes. Both (a) and (b) show suspended amorphous particles in solution. (c) The bright field image of the pellet formed at 4 minutes and (d) the polarized image showing no evidence of crystallization as the scattering is not directional. (e) The bright field image of the pellet formed at 360 minutes and (f) the polarized image showing no crystallization. 

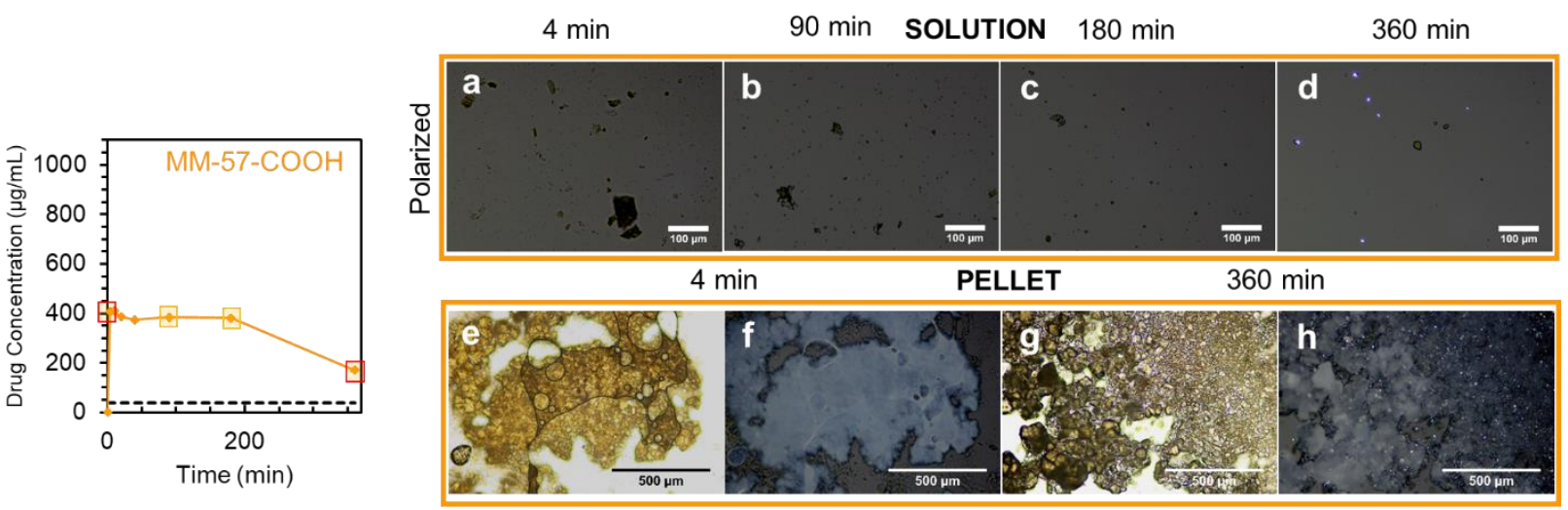

Figure S63. The polarized and bright field light microscopy images of MM-57-COOH at $37{ }^{\circ} \mathrm{C}$ during dissolution with $10 \mathrm{wt} \%$ at 4, 90, 180, and 360 minutes. The polarized light microscopy images at (a) $4 \mathrm{~min}$, (b) $90 \mathrm{~min}$, (c) $180 \mathrm{~min}$, and (d) $360 \mathrm{~min}$ show 10-100 micron sized amorphous particles that decrease in size overtime before crystallization occurs at $360 \mathrm{~min}$. The (e) bright field and (f) polarized images of the pellet at 4 minutes confirms that the suspended particles when centrifuged down are amorphous, and at $360 \mathrm{~min}$, the (g) bright field and (h) polarized images show that the centrifuged are partially crystalline as seen in the solution.
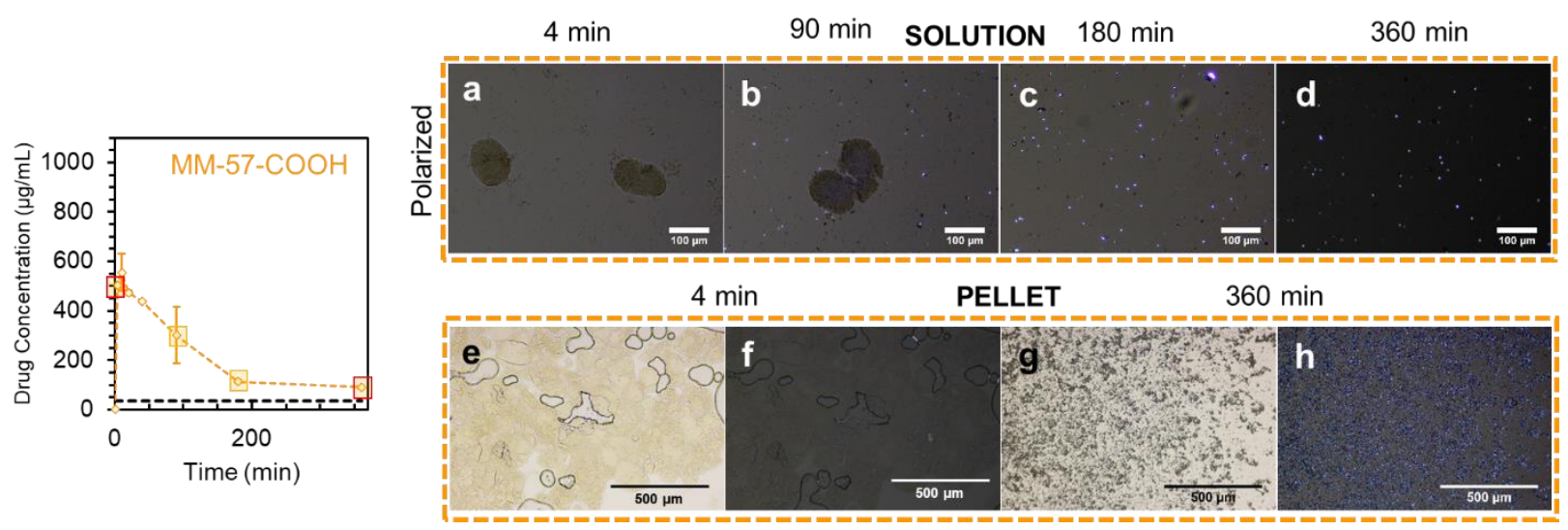

Figure S64. The polarized and bright field light microscopy images of MM-57-COOH at $25{ }^{\circ} \mathrm{C}$ during dissolution with $10 \mathrm{wt} \% \mathrm{PTN}$ at 4, 90, 180, and 360 minutes. The polarized light microscopy images at (a) $4 \mathrm{~min}$, (b) $90 \mathrm{~min}$, (c) $180 \mathrm{~min}$, and (d) $360 \mathrm{~min}$ show 100 micron sized amorphous particles that persist over time but crystallization onset is 90 minutes. The (e) bright field and (f) polarized images of the pellet at 4 minutes confirms that the suspended particles when centrifuged down are amorphous, and at $360 \mathrm{~min}$, the (g) bright field and (h) polarized images show that the centrifuged particles are highly crystalline as seen in the solution. 

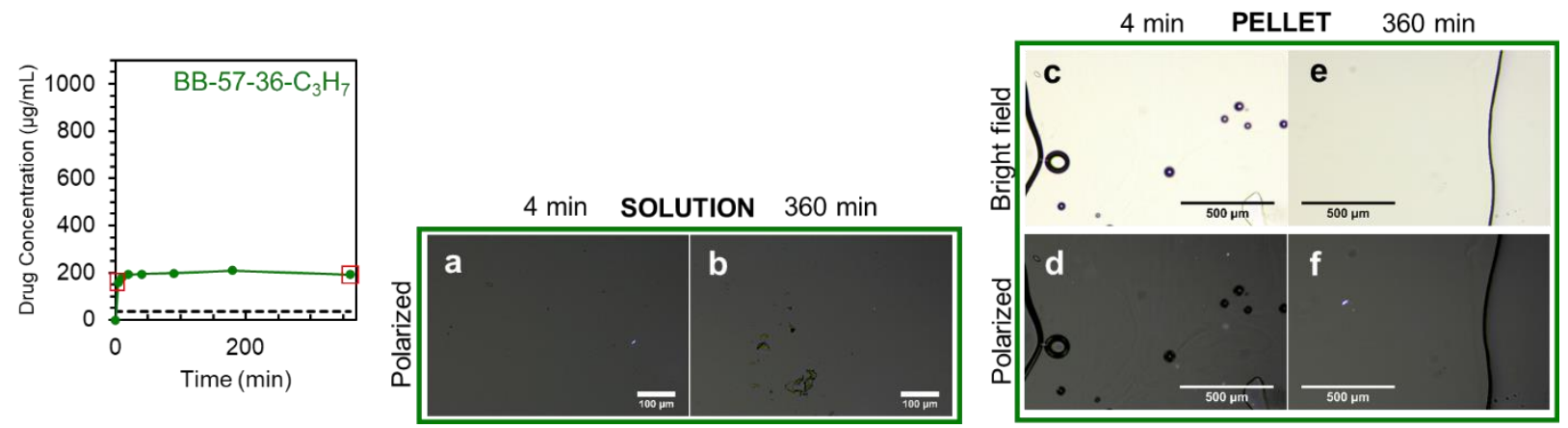

Figure S65. Polarized and bright field light microscopy images of BB-57-26- $\mathrm{C}_{3} \mathrm{H}_{7}$ during dissolution with $10 \mathrm{wt} \%$ PTN at $37^{\circ} \mathrm{C}$. Polarized light microscopy images of the solution at (a) 4 min and (b) 360 min show micron sized amorphous particles in solution with small amounts of crystalline phenytoin present. For the pellet, the (c) bright field and (d) polarized images show a mainly amorphous precipitate with a few crystallites at 4 minutes and the (e) bright field and (f) polarized images at 360 minutes show the sample is relatively unchanged.
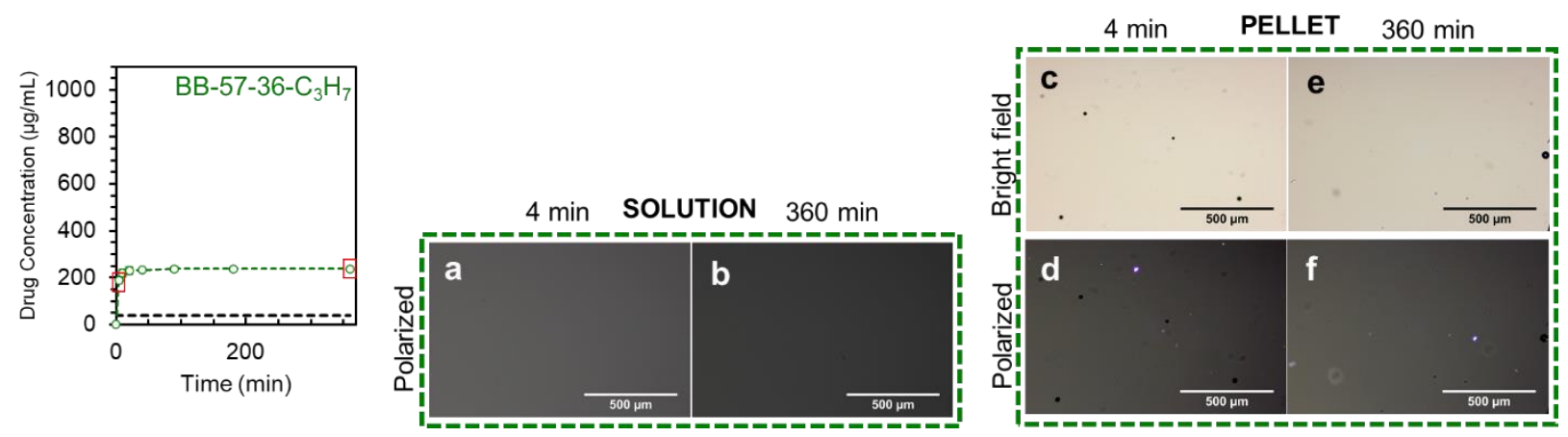

Figure S66. Polarized and bright field light microscopy images of BB-57-26- $\mathrm{C}_{3} \mathrm{H}_{7}$ during dissolution with $10 \mathrm{wt} \%$ PTN at $25^{\circ} \mathrm{C}$. Polarized light microscopy images of the solution at (a) 4 min and (b) 360 min show few to none crystalline or amorphous particles in solution. For the pellet, the (c) bright field and (d) polarized images show a mainly amorphous precipitate with a few crystallites at 4 minutes and the (e) bright field and (f) polarized images at 360 minutes show the the sample is relatively unchanged. 

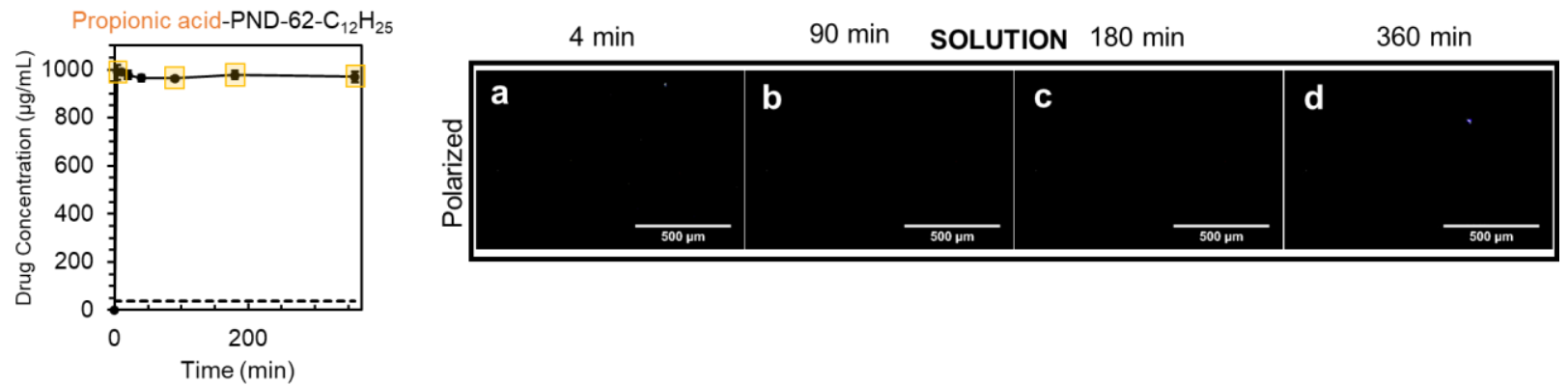

Figure S67. Polarized light microscopy images for the solution of PA-PND-62- $\mathrm{C}_{12} \mathrm{H}_{25}$ during dissolution at $37^{\circ} \mathrm{C}$ with $10 \mathrm{wt} \%$ PTN loading at (a) 4, (b) 90, (c) 180, and (d) 360 minutes. No particles are visible in the solution and only a very small amount of crystallization is observable at 360 minutes.
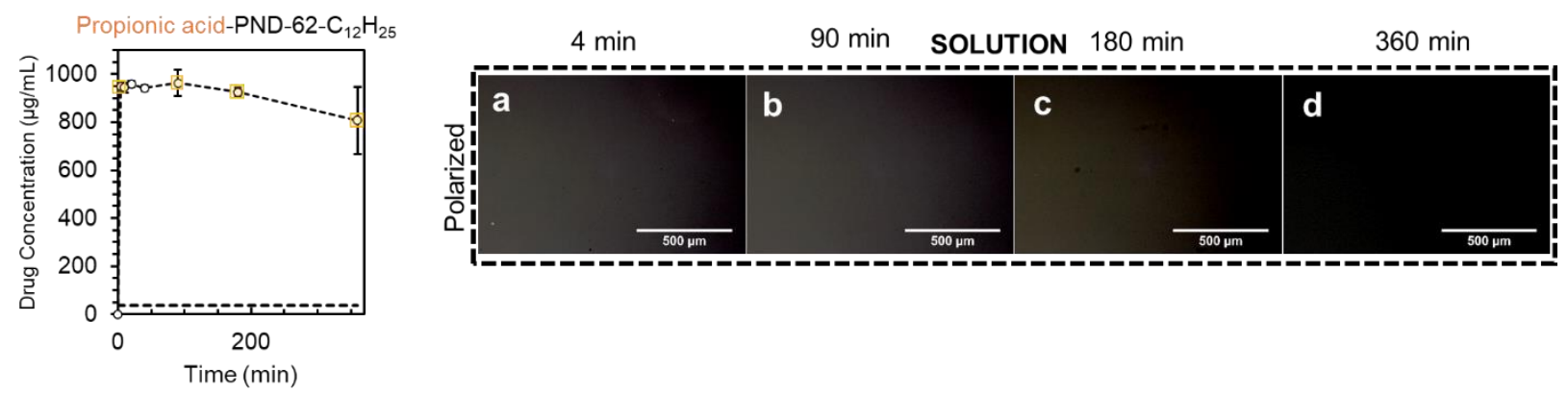

Figure S68. Polarized light microscopy images for the solution of PA-PND-62- $\mathrm{C}_{12} \mathrm{H}_{25}$ during dissolution at $25{ }^{\circ} \mathrm{C}$ with $10 \mathrm{wt} \%$ PTN loading at (a) 4, (b) 90, (c) 180, and (d) 360 minutes. Few amorphous micron-sized particles are visible in the solution over the total 360 minutes.
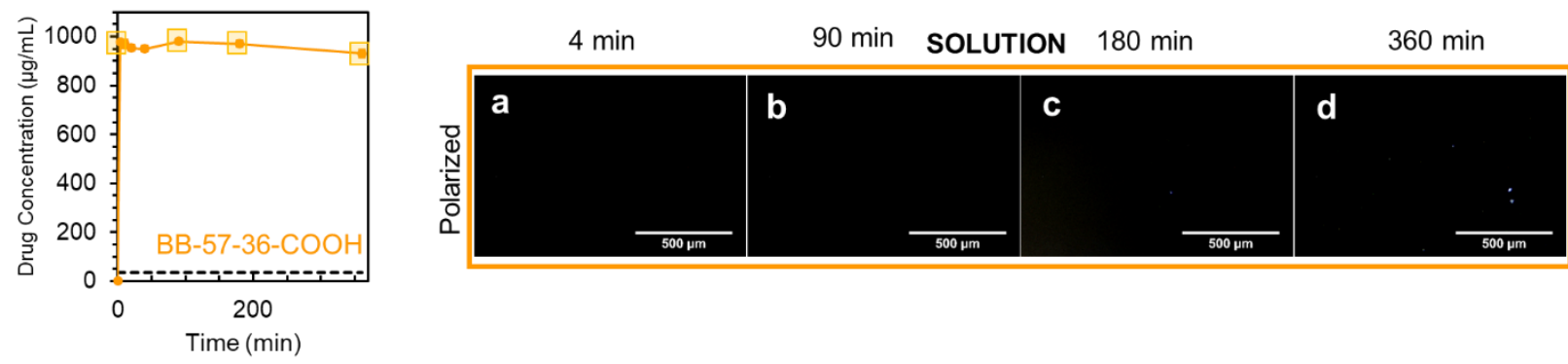

Figure S69. Polarized light microscopy images for the solution of BB-57-36-COOH during dissolution at $37{ }^{\circ} \mathrm{C}$ with $10 \mathrm{wt} \%$ PTN loading at (a) 4, (b) 90, (c) 180, and (d) 360 minutes. No particles are visible in the solution and only a very small amount of crystallization is observable at 360 minutes. 


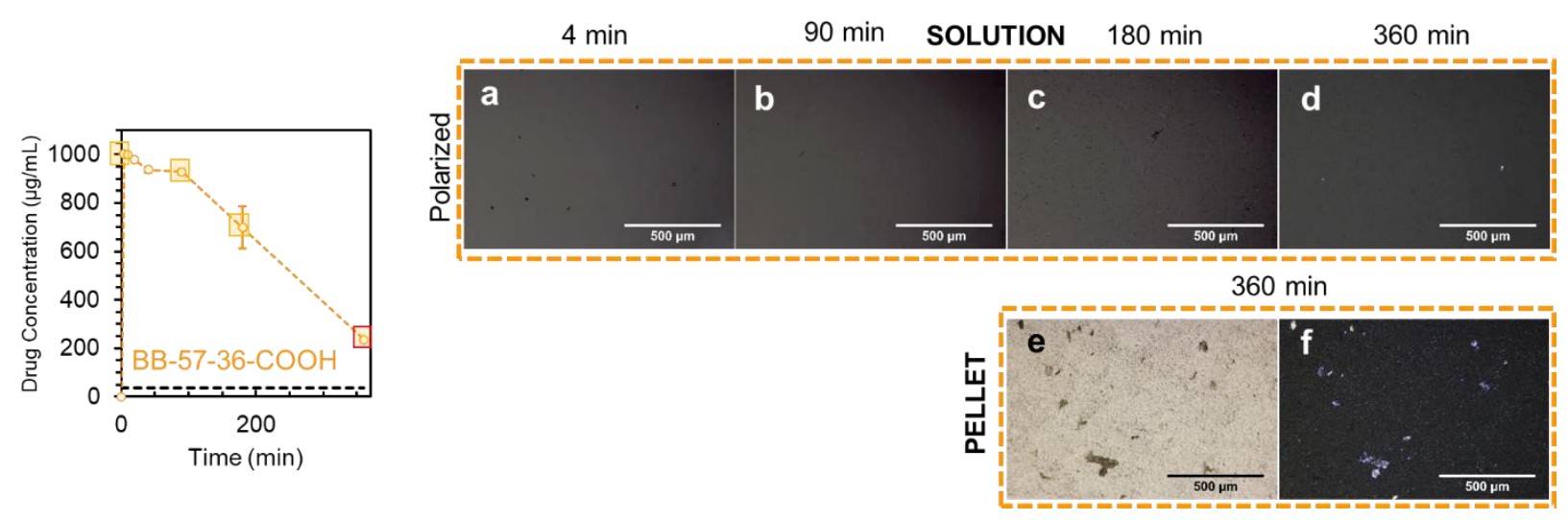

Figure S70. Polarized and bright field light microscopy images for the solution of BB-57-36$\mathrm{COOH}$ during dissolution at $25^{\circ} \mathrm{C}$ with $10 \mathrm{wt} \% \mathrm{PTN}$ loading at (a) 4, (b) 90, (c) 180, and (d) 360 minutes. Visible amorphous particles are present at 4 minutes until 90 minutes when crystallization onset begins. The (e) bright field and (f) polarized images of the pellet at 360 minutes are indicative of significant crystallization of PTN as shown by the precipitous drop in drug concentration shown in the dissolution plot on the left.

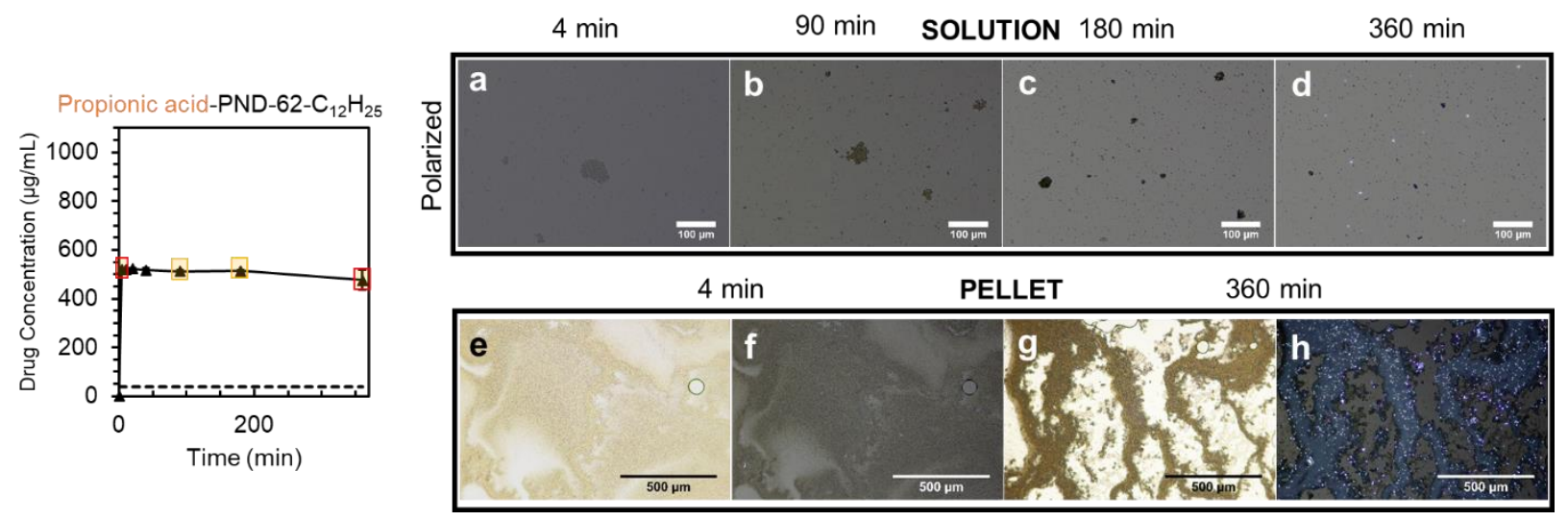

Figure S71. Polarized and bright field light microscopy images during the dissolution of PA-PND$62-\mathrm{C}_{12} \mathrm{H}_{25}$ at $37{ }^{\circ} \mathrm{C}$ with $25 \mathrm{wt} \%$ PTN at 4, 90, 180, and 360 minutes. The polarized images of the solution at (a) 4, (b) 90, (c) 180, and (d) 360 minutes show 10-80 $\mu \mathrm{m}$ sized amorphous particles that slowly decrease in size over time and crystalline particles are visible at $360 \mathrm{~min}$. (e) Bright field and (f) polarized light images of the pellet after centrifugation at 4 minutes showing that the precipitate is amorphous. (g) Bright field and (h) polarized light images after 360 minutes showing that the sample has partially crystallized over the course of 6 hours. 

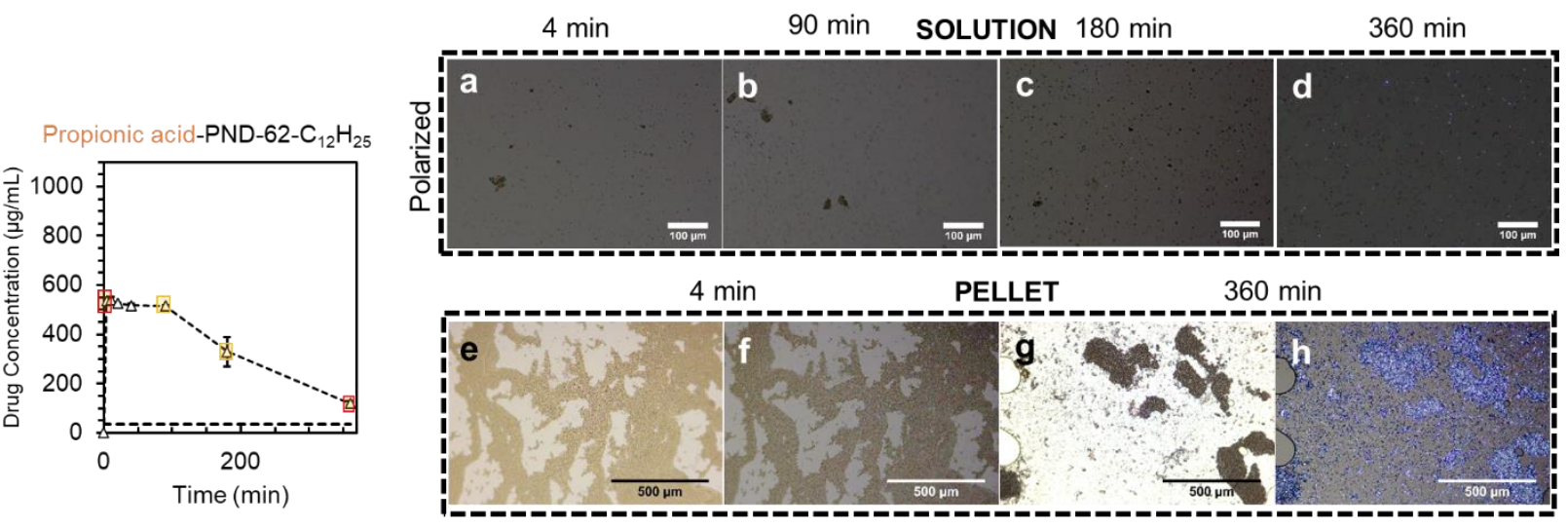

Figure S72. Polarized and bright field light microscopy images during the dissolution of PA-PND$62-\mathrm{C}_{12} \mathrm{H}_{25}$ at $25{ }^{\circ} \mathrm{C}$ with $25 \mathrm{wt} \%$ PTN at 4, 90, 180, and 360 minutes. The polarized images of the solution at (a) 4, (b) 90, (c) 180, and (d) 360 minutes show 10-80 $\mu \mathrm{m}$ sized amorphous particles that slowly decrease in size over time and crystalline particles are visible at $360 \mathrm{~min}$. (e) Bright field and (f) polarized light images of the pellet after centrifugation at 4 minutes showing that the precipitate is amorphous. (g) Bright field and (h) polarized light images after 360 minutes showing that the sample has partially crystallized over the course of 6 hours.

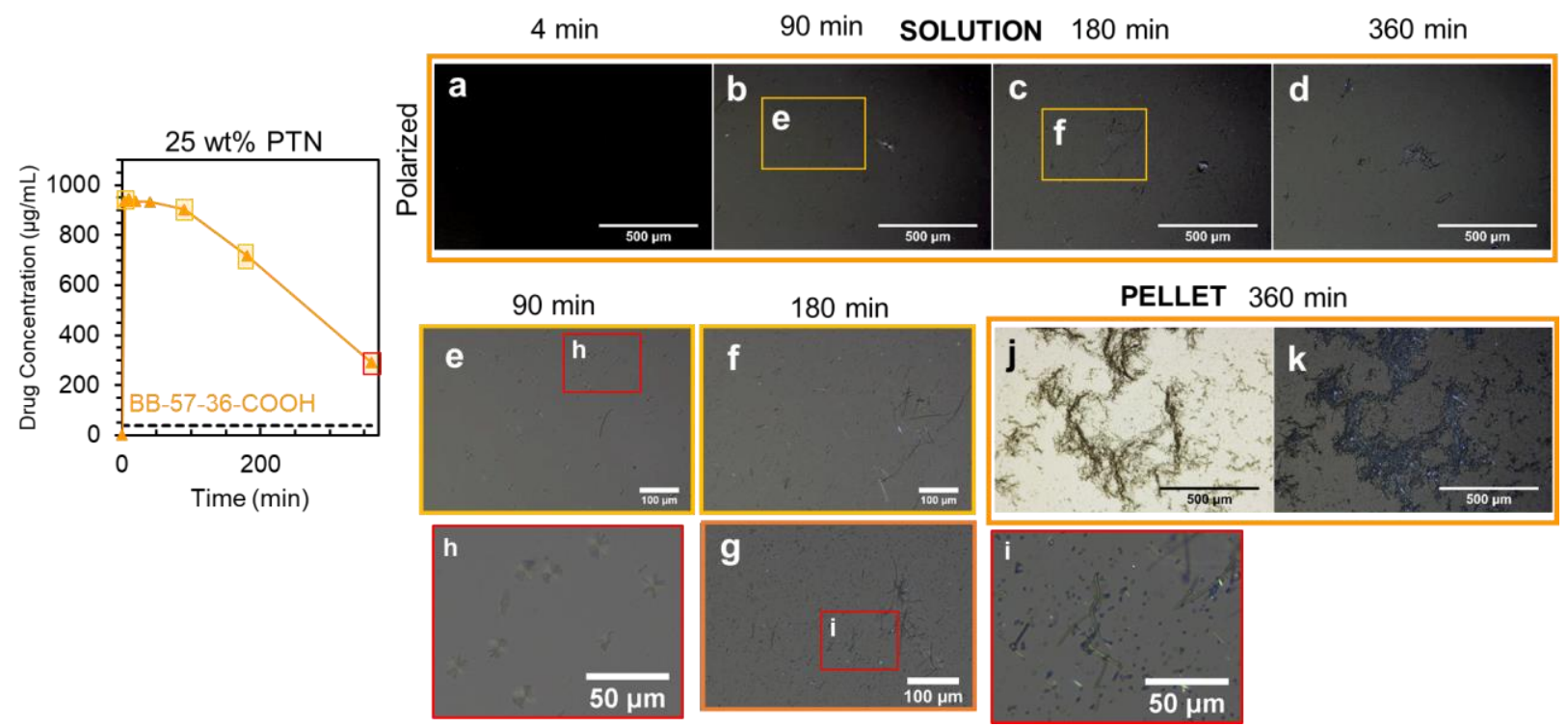

Figure S73. Polarized and bright field light microscopy images during the dissolution of BB-57$36-\mathrm{COOH}$ at $37{ }^{\circ} \mathrm{C}$ with $25 \mathrm{wt} \% \mathrm{PTN}$ at 4, 90, 180, and 360 minutes. The polarized images of the solution at (a) 4, (b) 90, (c) 180, and (d) 360 minutes show that the ASD completely dissolves initially, but by $90 \mathrm{~min}, 10 \mu \mathrm{m}$ spherulite-like crystalline particles form that transition into rod-like crystals (shown in inset (e, h) and (f, g, and i)) over the course of 6 hours. (j) Bright field and (k) polarized light images of the pellet after centrifugation at 360 minutes showing that the precipitate that formed during the dissolution is crystalline. 


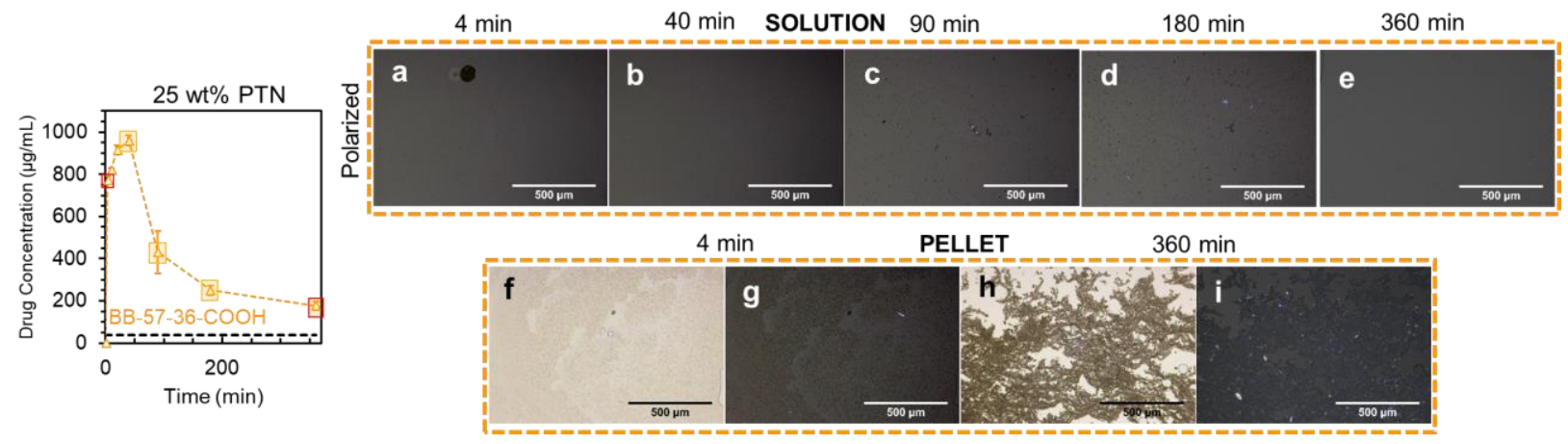

Figure S74. Polarized and bright field light microscopy images during the dissolution of BB-57$36-\mathrm{COOH}$ at $25{ }^{\circ} \mathrm{C}$ with $25 \mathrm{wt} \% \mathrm{PTN}$ at $4,90,180$, and 360 minutes. The polarized images of the solution at (a) 4, (b) 40, (c) 90, (d) 180, and (e) 360 minutes show that it takes 40 minutes for the ASD to completely dissolve before rapid crystallization occurs by 90 minutes leading to very few suspended particles present in solution after 6 hours. (f) Bright field and (g) polarized light images of the pellet after centrifugation at 4 minutes showing that the precipitate that formed during initially is amorphous. (h) Bright field and (i) polarized light images showing the complete precipitation of the drug into rod-like crystals after 6 hours. 


\section{References:}

(1) Lin, T.-P.; Chang, A. B.; Chen, H.-Y.; Liberman-Martin, A. L.; Bates, C. M.; Voegtle, M. J.; Bauer, C. A.; Grubbs, R. H. Control of Grafting Density and Distribution in Graft Polymers by Living Ring-Opening Metathesis Copolymerization. J. Am. Chem. Soc. 2017, 139, 3896-3903 DOI: 10.1021/jacs.7b00791.

(2) Li, X.; Prukop, S. L.; Biswal, S. L.; Verduzco, R. Surface Properties of Bottlebrush Polymer Thin Films. Macromolecules 2012, 45, 7118-7127 DOI: 10.1021/ma301046n.

(3) Ting, J. M.; Tale, S.; Purchel, A. A.; Jones, S. D.; Widanapathirana, L.; Tolstyka, Z. P.; Guo, L.; Guillaudeu, S. J.; Bates, F. S.; Reineke, T. M. High-Throughput Excipient Discovery Enables Oral Delivery of Poorly Soluble Pharmaceuticals. ACS Cent. Sci. 2016, 2 (10), 748-755 DOI: 10.1021/acscentsci.6b00268.

(4) Ohnsorg, M. L.; Ting, J. M.; Jones, S. D.; Jung, S.; Bates, F. S.; Reineke, T. M. Tuning PNIPAm Self-Assembly and Thermoresponse: Roles of Hydrophobic End-Groups and Hydrophilic Comonomer. Polym. Chem. 2019, 10, 3469-3479 DOI: 10.1039/C9PY00180H.

(5) Jakeš, J. Regularized Positive Exponential Sum (REPES) Program - A Way of Inverting Laplace Transform Data Obtained by Dynamic Light Scattering. Collect. Czechoslov. Chem. Commun. 1995, 60, 1781-1797 DOI: 10.1135/cccc19951781.

(6) Li, Z.; Lenk, T. I.; Yao, L. J.; Bates, F. S.; Lodge, T. P. Maintaining Hydrophobic Drug Supersaturation in a Micelle Corona Reservoir. Macromolecules 2018, 51 (2), 540-551 DOI: 10.1021/acs.macromol.7b02297.

(7) Stockmayer, W. H.; Schmidt, M. Effects of Polydispersity, Branching and Chain Stiffness on Quasielastic Light Scattering. Pure Appl. Chem. 1982, 54 (2), 407-414.

(8) Wu, C.; Zhou, S. Thermodynamically Stable Globule State of a Single Poly(NIsopropylacrylamide) Chain in Water. Macromolecules 1995, 28 (15), 5388-5390 DOI: 10.1021/ma00119a036.

(9) Li, Z.; Van Zee, N. J.; Bates, F. S.; Lodge, T. P. Polymer Nanogels as Reservoirs to Inhibit Hydrophobic Drug Crystallization. ACS Nano 2019, 13, 1232-1243 DOI: 10.1021/acsnano.8b06393.

(10) Johnson, L. M.; Li, Z.; LaBelle, A. J.; Bates, F. S.; Lodge, T. P.; Hillmyer, M. A. Impact of Polymer Excipient Molar Mass and End Groups on Hydrophobic Drug Solubility Enhancement. Macromolecules 2017, 50, 1102-1112 DOI: 10.1021/acs.macromol.6b02474.

(11) Li, Z.; Johnson, L. M.; Ricarte, R. G.; Yao, L. J.; Hillmyer, M. A.; Bates, F. S.; Lodge, T. P. Enhanced Performance of Blended Polymer Excipients in Delivering a Hydrophobic Drug through the Synergistic Action of Micelles and HPMCAS. Langmuir 2017, 33, 28372848 DOI: 10.1021/acs.langmuir.7b00325.

(12) Dalsin, M. C.; Tale, S.; Reineke, T. M. Solution-State Polymer Assemblies Influence BCS Class II Drug Dissolution and Supersaturation Maintenance. Biomacromolecules 2014, 15 , 500-511 DOI: 10.1021/bm401431t.

(13) Ricarte, R. G.; Van Zee, N. J.; Li, Z.; Johnson, L. M.; Lodge, T. P.; Hillmyer, M. A. Recent Advances in Understanding the Micro- and Nanoscale Phenomena of Amorphous Solid Dispersions. Mol. Pharm. 2019, 16, 4089-4103 DOI: 
10.1021/acs.molpharmaceut.9b00601.

(14) de Gennes, P. G. A Second Type of Phase Separation in Polymer Solutions. C. R. Adad. Sci., Ser. II Mec., Phys., Chim., Sci. Terre Univers 1991, 313 (10), 1117-1122. 